Keywords: CSSX, cesium, solvent extraction

Retention: Permanent

\title{
V5 and V10 Contactor Testing with the Next Generation (CSSX) Solvent for the Savannah River Site Integrated Salt Disposition Process
}

M. L. Restivo, T. B. Peters, R. A. Pierce, F. F. Fondeur, T. J. Steeper, M. R. Williams, B. J. Giddings, B. A. Hickman, S. D. Fink

January 2012 
SRNL-STI-2011-00695

Revision 0

\section{DISCLAIMER}

This work was prepared under an agreement with and funded by the U.S. Government. Neither the U.S. Government or its employees, nor any of its contractors, subcontractors or their employees, makes any express or implied:

1. warranty or assumes any legal liability for the accuracy, completeness, or for the use or results of such use of any information, product, or process disclosed; or

2. representation that such use or results of such use would not infringe privately owned rights; or

3. endorsement or recommendation of any specifically identified commercial product, process, or service.

Any views and opinions of authors expressed in this work do not necessarily state or reflect those of the United States Government, or its contractors, or subcontractors.

\section{Printed in the United States of America \\ Prepared for U.S. Department of Energy}


SRNL-STI-2011-00695

Revision 0

\section{REVIEWS AND APPROVALS}

\section{AUTHORS:}

M. L. Restivo, Engineering Development Laboratory

Date

T. B. Peters, Separations and Actinide Science Programs

Date

F. F. Fondeur, Separations and Actinide Science Programs

Date

T. J. Steeper, Engineering Development Laboratory

Date

M. R. Williams, Engineering Development Laboratory

Date

R. A. Pierce, Separations and Actinide Science Programs

Date

TECHNICAL REVIEW:

M. C. Thompson, Technical Review, Separations and Actinide Science Programs Date

M. G. Geeting, Technical Review, MCU Process Engineering

Date APPROVAL:

B. J. Giddings, Manager

Date

Engineering Development Laboratory

S. D. Fink, Manager

Date

Separations and Actinide Science Programs

S.L. Marra, Manager

Date

Environmental \& Chemical Process Technology Research Programs

A. Samadi-Dezfouli, Manager

Date

MCU Life Extension/NGS 


\section{PREFACE OR ACKNOWLEDGEMENTS}

The team would like to thank the following people for their efforts in completing this research: Vernon Bush for his expertise in setting up the Data Acquisition System and support of the experiments, Michael Armstrong for his expertise in building the Test Rig and his continuous efforts to improve functionality, Andrew Foreman and Chris Rose for their support of the experiments. We would also like to thank David Missimer and Ronnie Rutherford for their support in analyzing in an expedited manner the droplet size distribution samples.

Mark Geeting (Savannah River Remediation) was extremely helpful in defining the test conditions, assessing the equipment configuration, and providing references and consultation on work from earlier studies in 2004-2005. Bruce Moyer, Joe Birdwell and Ralph Leonard helped in the definition of the test scope. Joe and Ralph also helped assessed readiness of the equipment prior to operation.

We dedicate this work to the memory of Ralph Leonard: a friend, a gentleman, a scholar, and an exceptional individual. 


\section{EXECUTIVE SUMMARY}

A solvent extraction system for removal of cesium (Cs) from alkaline solutions was developed utilizing a novel solvent invented at the Oak Ridge National Laboratory (ORNL). This solvent consists of a calix[4]arene-crown-6 extractant dissolved in an inert hydrocarbon matrix. A Modifier is added to the solvent to enhance the extraction power of the calixarene and to prevent the formation of a third phase. An additional additive, called a suppressor, is used to improve stripping performance. The process that deploys this solvent system is known as Caustic Side Solvent Extraction (CSSX). The solvent system has been deployed at the Savannah River Site (SRS) in the Modular CSSX Unit (MCU) since 2008.

Subsequent development efforts by ORNL identified an improved solvent system that can raise the expected decontamination factor (DF) in MCU from $\sim 200$ to more than 40,000. The improved DF is attributed to an improved distribution ratio for cesium $[\mathrm{D}(\mathrm{Cs})]$ in extraction from $\sim 15$ to $\sim 60$, an increased solubility of the calixarene in the solvent from $0.007 \mathrm{M}$ to $>0.050 \mathrm{M}$, and use of boric acid $\left(\mathrm{H}_{3} \mathrm{BO}_{3}\right)$ stripping that also yields improved $\mathrm{D}(\mathrm{Cs})$ values. Additionally, the changes incorporated into the Next Generation CSSX Solvent (NGS) are intended to reduce solvent entrainment by virtue of more favorable physical properties.

The MCU and Salt Waste Processing Facility (SWPF) facilities are actively pursuing the changeover from the current CSSX solvent to the NGS solvent. To support this integration of the NGS into the MCU and SWPF facilities, the Savannah River Remediation (SRR)/ARP/MCU Life Extension Project requested that the Savannah River National Laboratory (SRNL) perform testing of the new solvent for the removal of Cs from the liquid salt waste stream. Additionally, SRNL was tasked with characterizing both strip (20-in long, 10 micron pore size) and extraction (40-in long, 20 micron pore size) coalescers.

SRNL designed a pilot-scale experimental program to test the full size strip (V5) and extraction (V10) centrifugal contactors and the associated strip and extraction effluent coalescers to determine the hydraulic and mass transfer characteristics with the NGS. The test program evaluated the amount of organic carryover and the droplet size of the carryover phases using several analytical methods. Provisions were also made to enable an evaluation of coalescer performance.

Stage efficiency and mass distribution ratios were determined using Cs mass transfer measurements. Using 20 millimolar $(\mathrm{mM})$ extractant (instead of $50 \mathrm{mM}$ ), the nominal $\mathrm{D}(\mathrm{Cs})$ measured was 16.0-17.5. The data indicate that equilibrium is achieved rapidly and maintained throughout sampling. The data showed good stage efficiency for extraction (Tests 1A-1D), ranging from $98.2 \%$ for Test $1 \mathrm{~A}$ to $90.5 \%$ for Test $1 \mathrm{D}$. No statistically-significant differences were noted for operations at $12 \mathrm{gpm}$ aqueous flow when compared with either $4 \mathrm{gpm}$ or $8 \mathrm{gpm}$ of aqueous flow. The stage efficiencies equal or exceed those previously measured using the baseline CSSX solvent system.

The nominal target for scrub Cs distribution values are $\sim 1.0-2.5$. The first scrub test yielded an average scrub value of 1.21 and the second scrub test produced an average value of 0.78 . Both values are considered acceptable. Stage efficiency was not calculated for the scrub tests.

For stripping behavior, six tests were completed in a manner to represent the first strip stage. For three tests at the baseline flow ratios (O:A of 3.75:1) but at different total flow rates, the $\mathrm{D}(\mathrm{Cs})$ values were all similar at $\sim 0.052$. Similar behavior was observed for two tests performed at an O:A ratio of $7: 1$ instead of 3.75:1. The data for the baseline strip tests exhibited acceptable stage 
efficiency, ranging from $82.0 \%$ for low flow to $89-90 \%$ for medium and high flow. The difference in efficiency may be attributable to the low volume in the contactor housing at lower flow rates.

The concentrations of Isopar $\mathrm{L}^{\circledR}$ and Modifier were measured using semi-volatile organic analysis (SVOA) and Fourier Transform Infrared (FTIR) Spectroscopy. However, due to issues associated with sample point configuration, the two methods cannot be correlated by this data. SVOA measurements provided a measure of Isopar $\mathrm{L}^{\circledR}$ and Modifier carryover for both stripping and extraction. For low-flow conditions in stripping, Isopar $\mathrm{L}^{\mathbb{B}}$ concentration measured $\sim 300-500 \mathrm{mg} / \mathrm{L}$. For moderate-flow conditions, Isopar L ${ }^{\circledR}$ was $\sim 1800-1900 \mathrm{mg} / \mathrm{L}$. For high-flow conditions, Isopar $\mathrm{L}^{\circledR}$ was $\sim 1350-1750 \mathrm{mg} / \mathrm{L}$ for one test and $\sim 700-800 \mathrm{mg} / \mathrm{L}$ for a second test. In extraction, the quantity of Isopar $\mathrm{L}^{\circledR}$ was $\sim 160 \mathrm{mg} / \mathrm{L}$ at low flow, $\sim 250-350 \mathrm{mg} / \mathrm{L}$ at moderate flow, and $\sim 220-390 \mathrm{mg} / \mathrm{L}$ at high flow. For the above Isopar $\mathrm{L}^{\circledR}$ concentrations, Modifier was also present at the nominal Isopar-to-Modifier ratio of 3.65. When the current test data compared to previous V5 and V10 contactors tests with BOB CalixC6 solvent, the measured Isopar $\mathrm{L}^{\circledR}$ carry over values are of the same order of magnitude for extraction, but not for stripping. Carry over for stripping operations were comparable in some cases, but in other cases it was appreciably (e.g., 2-3X) higher.

Droplet-size data obtained by MicroTrac ${ }^{\text {TM }}$ S3400 analyzer consistently show that the particle sizes measured post-coalescer exceed those measured pre-coalescer. Although the data contains a significant amount of scatter, particle-size increases are between 25 and $180 \%$. The increase in droplet size appears to be greater, in general, for stripping tests than for the extraction tests. This behavior may be attributable to the smaller coalescer pore sizes used for the stripping tests. For the extraction tests, there were modest droplet-size increases ranging from 5-25\%. For stripping and extraction tests, the size of the droplets exiting the coalescer was comparable even though stripping employed a 10-micron coalescer and extraction a 20-micron coalescer.

The only method available for measuring the effect of the decanter on solvent concentration in the aqueous stream was FTIR. No effort was made in these tests to replicate the MCU decanter design and operation. Within method uncertainty, there was no change in Isopar $L^{\circledR}$ or Modifier concentrations due to the operation of the decanter. However, this result may reflect limitations imposed by the configuration of the sample ports. 


\section{TABLE OF CONTENTS}

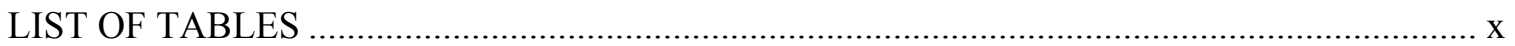

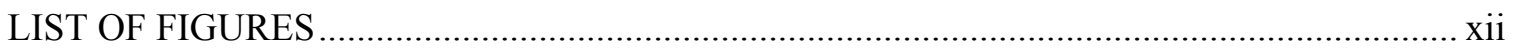

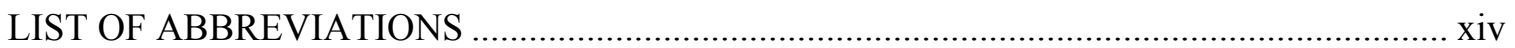

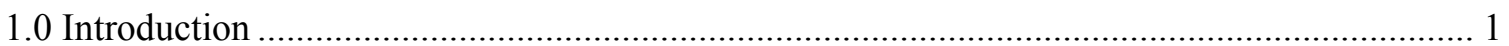

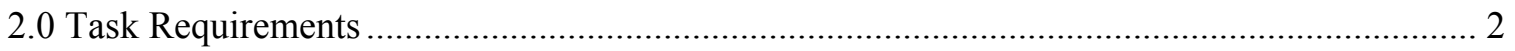

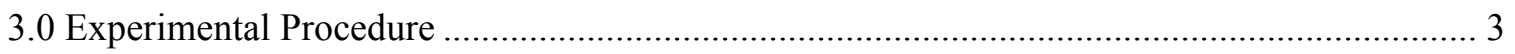

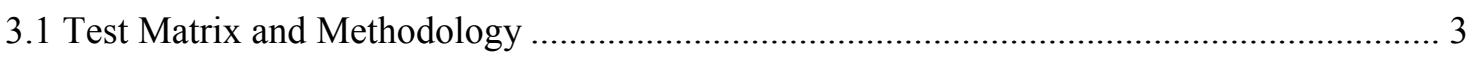

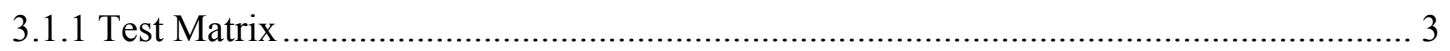

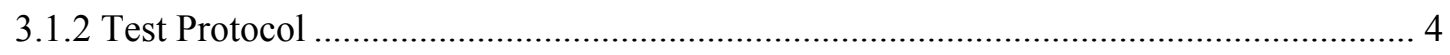

3.2 Experimental Design/Test Apparatus/Configuration....................................................... 5

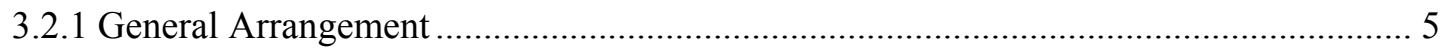

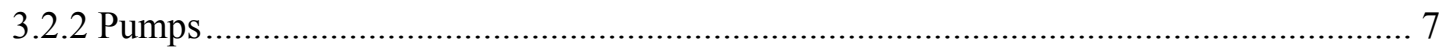

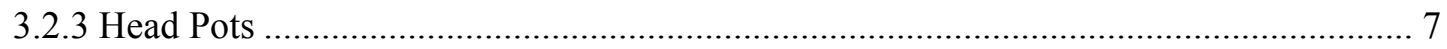

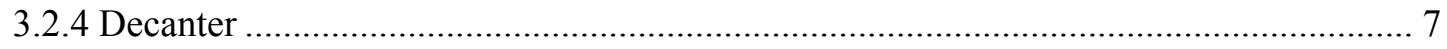

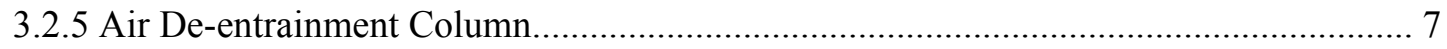

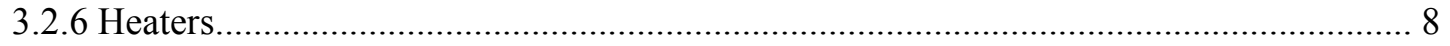

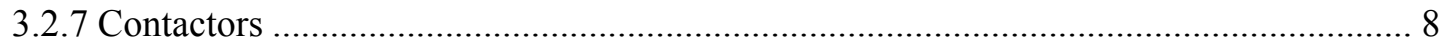

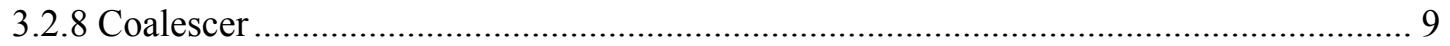

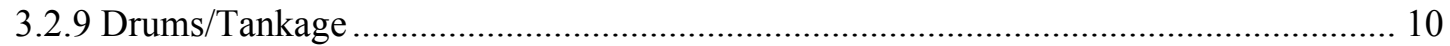

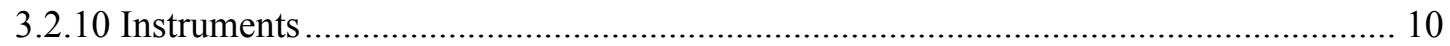

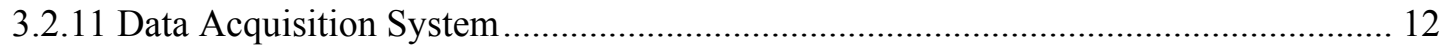

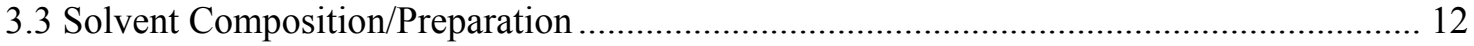

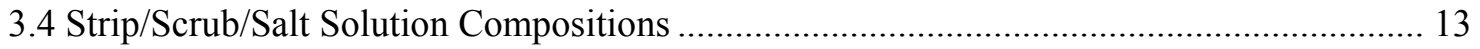

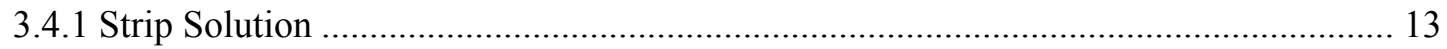

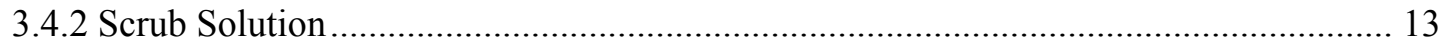

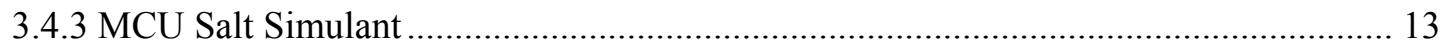

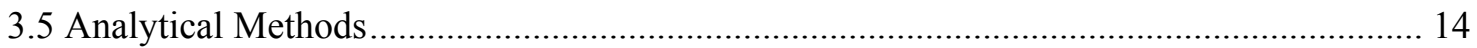

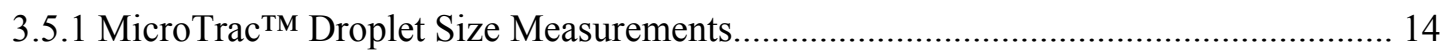

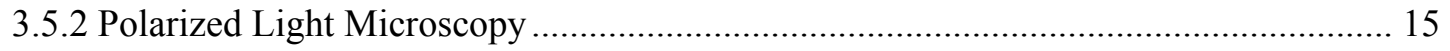

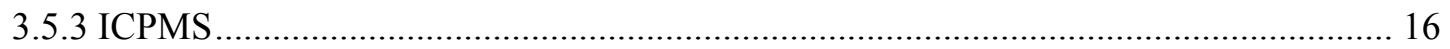

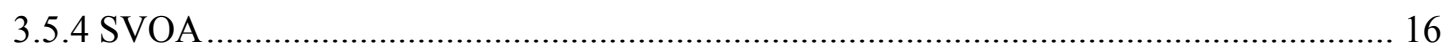

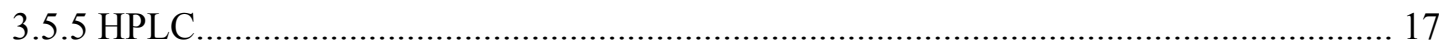

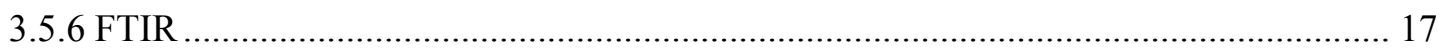




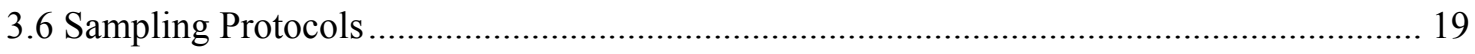

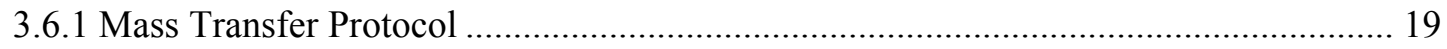

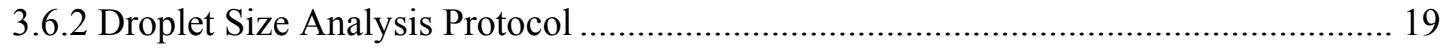

3.6.3 Solvent Concentration Analysis Protocol..................................................................... 19

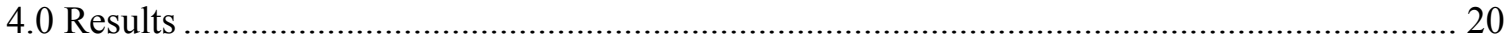

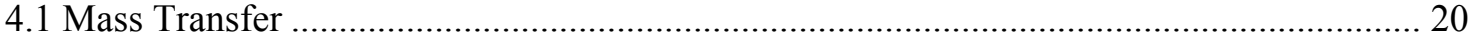

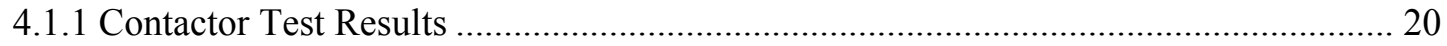

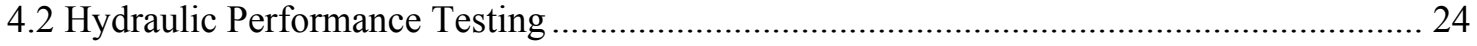

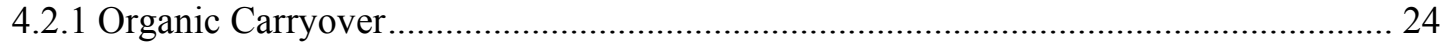

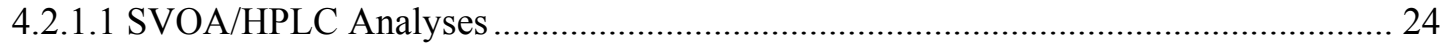

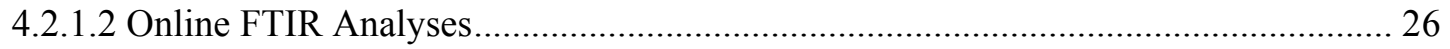

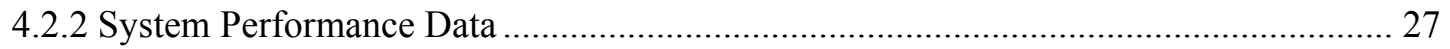

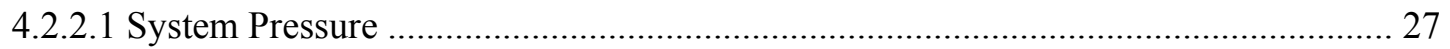

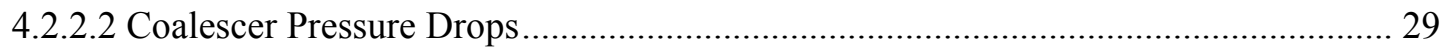

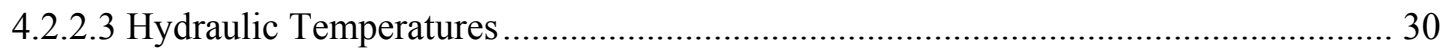

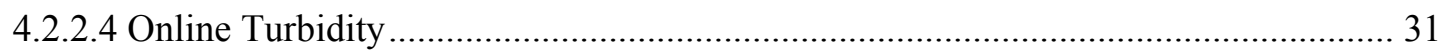

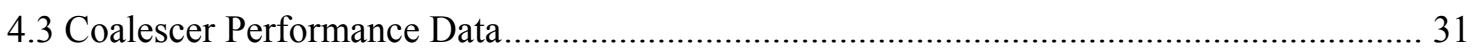

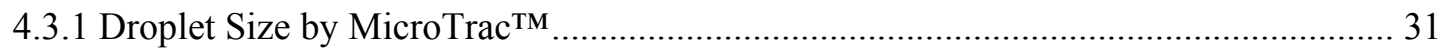

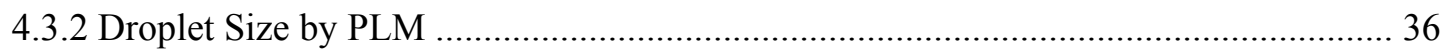

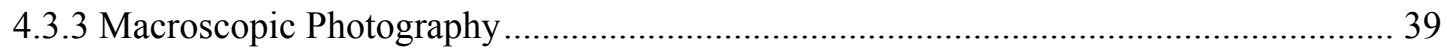

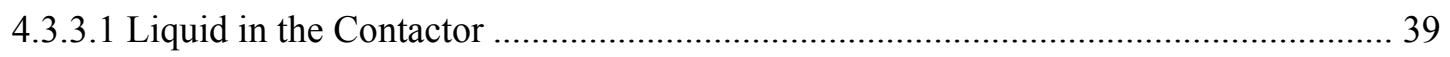

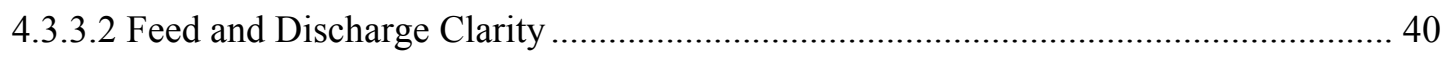

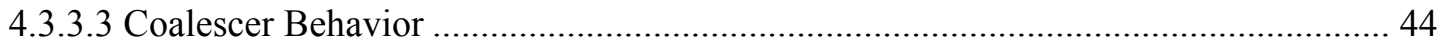

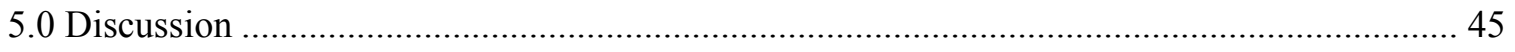

5.1 Contactor Hydraulic Performance …...................................................................... 45

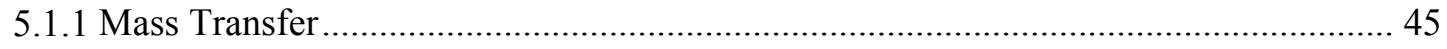

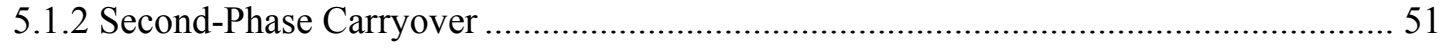

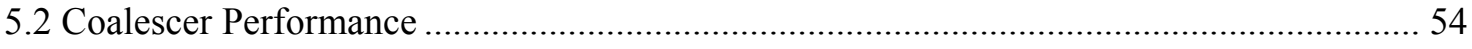

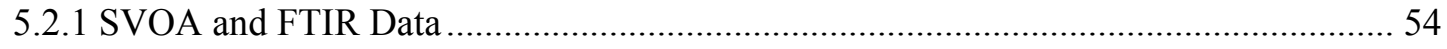

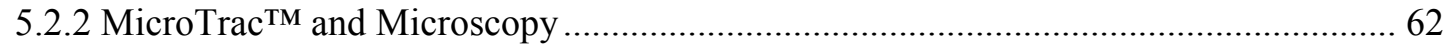

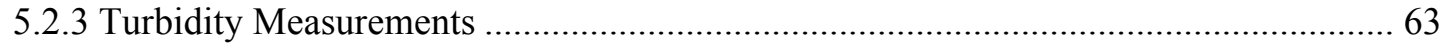

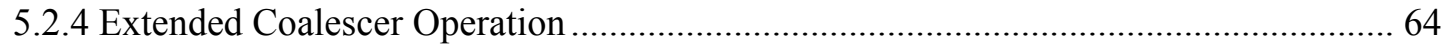

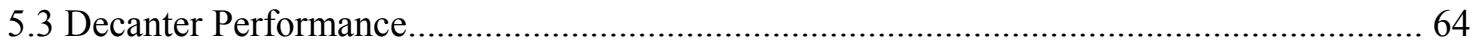

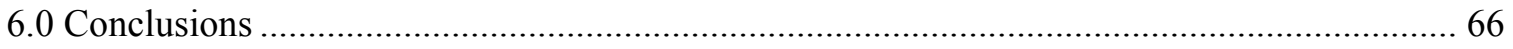




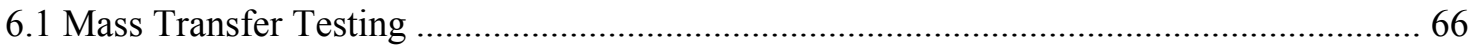

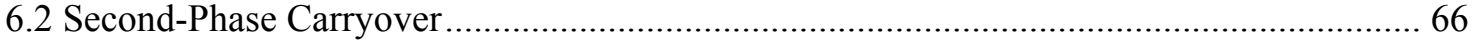

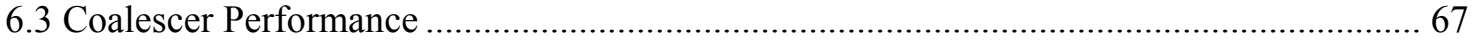

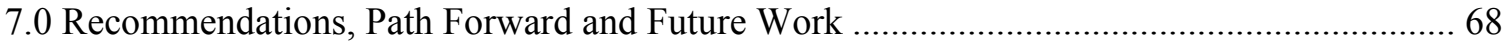

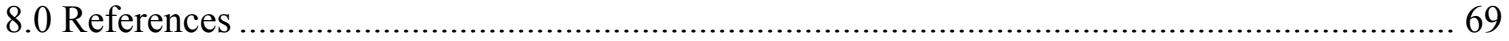

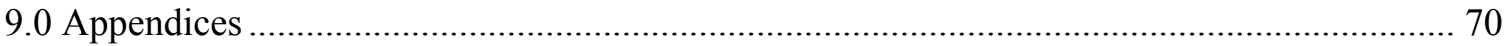

9.1 Appendix A - Design Details of Coalescer Housing ........................................................... 70

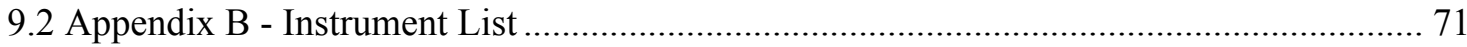

9.3 Appendix C - High Mix Bottom Plate for the V-10 as supplied by CINC MFG ............... 72 


\section{LIST OF TABLES}

Table 3-1. Test Matrix for NGS Contactor/Coalescer Testing .................................................... 3

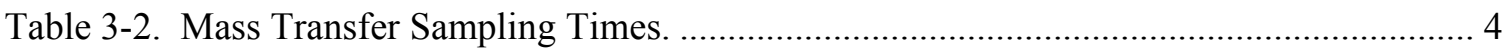

Table 3-3. Organic:Aqueous Volume Ratios for Testing ............................................................ 4

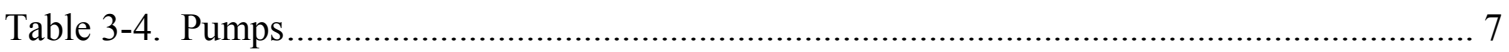

Table 3-5. Contactor Salient Features ............................................................................... 9

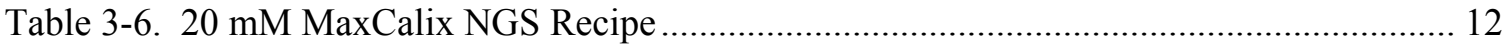

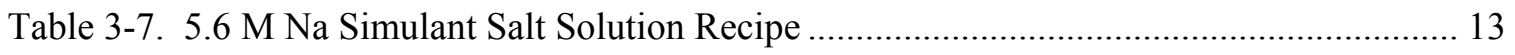

Table 3-8. Analyses of Vendor-Provided 5.6 M Na Simulant Salt Solution................................. 14

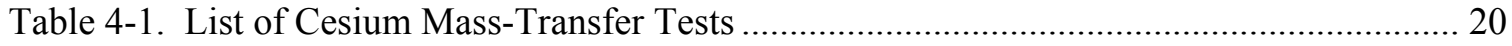

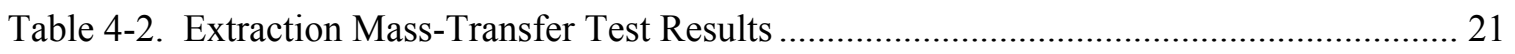

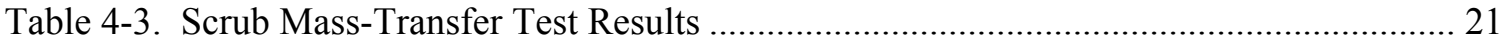

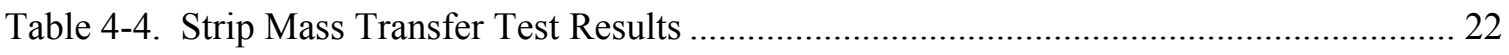

Table 4-5. Mass Transfer Equilibrium Concentrations .............................................................. 24

Table 4-6. SVOA Data during Hydraulic Testing - Strip Operations......................................... 25

Table 4-7. SVOA/HPLC Data during Hydraulic Testing - Extraction Operations...................... 26

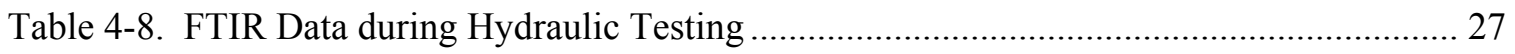

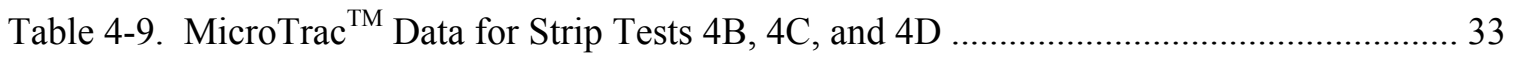

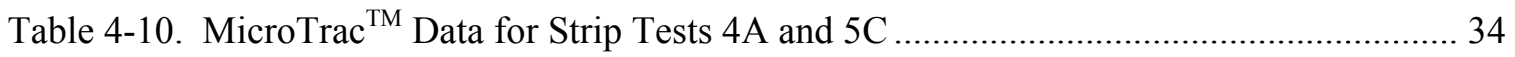

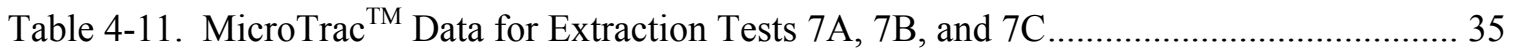

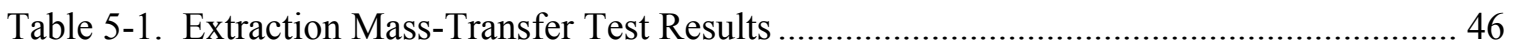

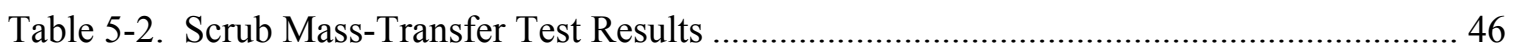

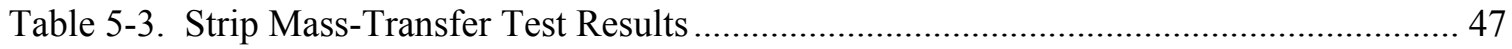

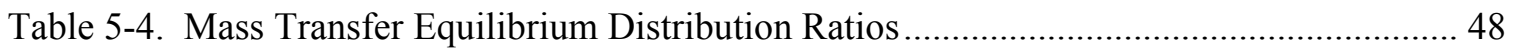

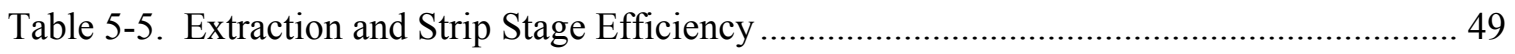

Table 5-6. Stage Efficiency Comparison for V5 and V10 Testing.............................................. 50

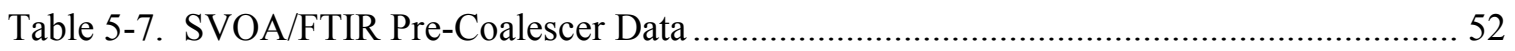


Table 5-8. Average Carryover Concentrations Measured by FTIR .......................................... 52

Table 5-9. Solvent Carry Over from Individual Contactor Tests with BOB CalixC6 $6^{[14]} \ldots \ldots \ldots \ldots . . . . .53$

Table 5-10. Solvent Carry Over from MCU Integrated Tests with BOB CalixC6 ${ }^{[15]}$.................. 53

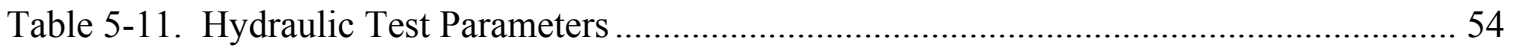

Table 5-12. SVOA/FTIR Data Comparison - Strip Tests.......................................................... 56

Table 5-13. SVOA/HPLC/FTIR Data Comparison - Extraction Tests........................................ 57

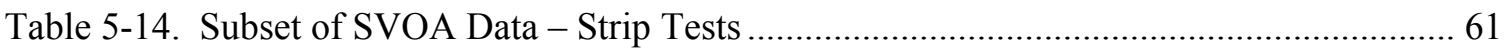

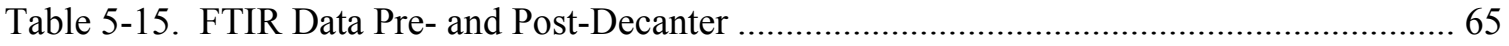




\section{LIST OF FIGURES}

Figure 1-1. Modular CSSX (MCU) Simplified Flow Sheet..................................................... 1

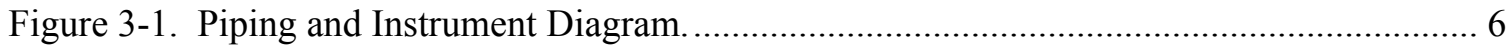

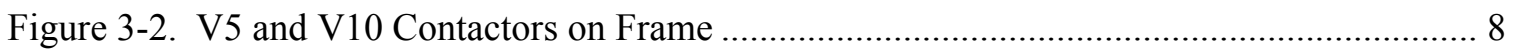

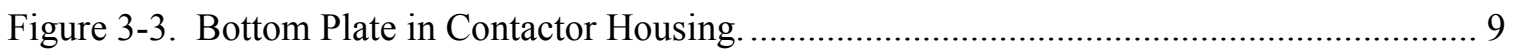

Figure 3-4. Coalescer in Acrylic Housing with 20-inch Coalescer Element............................... 10

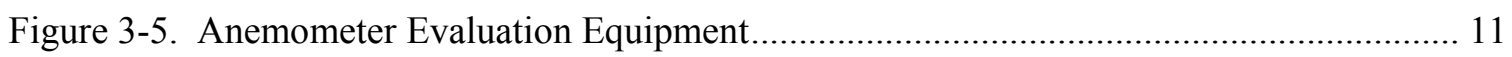

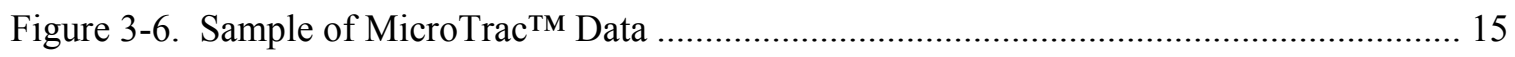

Figure 3-7. McCrone Calibration Slide Used for SZX12 Microscope ........................................ 16

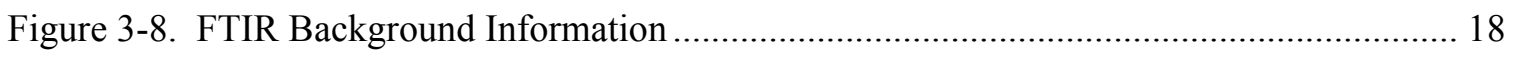

Figure 3-9. FTIR Spectra in $0.01 \mathrm{M} \mathrm{H}_{3} \mathrm{BO}_{3}$ Strip Solution................................................... 18

Figure 3-10. FTIR Spectra in 5.6 M Na Simulant Salt Solution ................................................ 19

Figure 4-1. Temperature Profile for Mass-Transfer Extraction Test 1A .................................... 23

Figure 4-2. Temperature Profile for Mass-Transfer Strip Test 3A............................................ 23

Figure 4-3. System Pressures for Hydraulic Strip Runs........................................................ 28

Figure 4-4. System Pressures for Hydraulic Extraction Runs ................................................. 28

Figure 4-5. Coalescer Pressure Drop-Hydraulic Strip Runs...................................................... 29

Figure 4-6. Coalescer Pressure Drop-Hydraulic Extraction Runs.............................................. 29

Figure 4-7. Temperature Trace for Hydraulic Strip Test 4A.................................................... 30

Figure 4-8. Temperature Trace for Hydraulic Extraction Test 7A ............................................. 30

Figure 4-9. Turbidity at Aqueous Head Pot-Hydraulic Strip Tests .......................................... 31

Figure 4-10. Turbidity at Aqueous Head Pot-Hydraulic Extraction Runs ................................. 31

Figure 4-11. Polarized Light Microscopy Pictures for Test 4C............................................... 36

Figure 4-12. Polarized Light Microscopy Pictures for Test 5C................................................. 37

Figure 4-13. Polarized Light Microscopy Pictures for Test 7A …............................................... 38

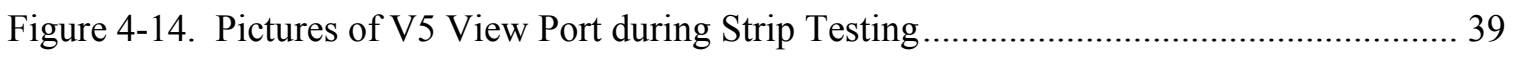

Figure 4-15. Pictures of V10 View Port during Extraction Testing .......................................... 39 
Figure 4-16. Pictures of Solvent Inlet and Outlet Lines during Strip Testing ............................ 40

Figure 4-17. Pictures of Solvent Inlet and Outlet Lines during Extraction Testing .................... 41

Figure 4-18. Pictures of Aqueous Discharge Samples during Strip Testing .............................. 42

Figure 4-19. Pictures of Aqueous Discharge Samples during Scrub Testing.............................. 43

Figure 4-20. Pictures of Aqueous Discharge Samples during Extraction Testing ...................... 44

Figure 4-21. Pictures of Coalescer Performance during Testing............................................... 45

Figure 5-1. Aqueous Discharge Temperatures for Extraction Testing ....................................... 50

Figure 5-2. Analysis of SVOA Strip Data for Admissibility …................................................ 55

Figure 5-3. Pre-Coalescer and Decanter Sampling .................................................................. 59

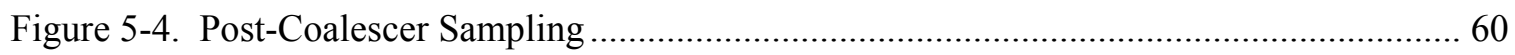

Figure 5-5. Droplet-Size Data from 2005 and 2011 Strip Effluent Streams .............................. 63

Figure 5-6. Coalescer Pressure Drop per 1000 gallons pumped. ……......................................... 64 


\section{LIST OF ABBREVIATIONS}

\begin{tabular}{ll} 
AD & Analytical Development \\
CF & concentration factor \\
CRT & contactor residence time \\
CSSX & Caustic Side Solvent Extraction \\
DAS & data acquisition system \\
DF & decontamination factor \\
DSS & decontaminated salt solution \\
DWPF & Defense Waste Processing Facility \\
EDL & Engineering Development Laboratory \\
FTIR & Fourier Transform Infrared \\
HLW & High Level Waste \\
HPLC & high performance liquid chromatography \\
ICPES & inductively coupled plasma emission spectroscopy \\
ICPMS & inductively coupled plasma mass spectroscopy \\
MCU & Modular CSSX Unit \\
NGS & Next Generation CSSX Solvent \\
O:A & organic-to-aqueous volume ratio \\
ORNL & Oak Ridge National Laboratory \\
PLM & Polarized Light Microscopy \\
SCFM & standard cubic feet per minute \\
SE & strip effluent \\
SRNL & Savannah River National Laboratory \\
SRR & Savannah River Remediation, LLC \\
SRS & Savannah River Site \\
SVOA & semi-volatile organic analysis \\
SWPF & Salt Waste Processing Facility \\
TTQAP & Task Technical Quality Assurance Plan \\
TTR & Technical Task Request \\
VFD & variable frequency drive \\
\hline
\end{tabular}




\subsection{Introduction}

A solvent extraction system for removal of cesium (Cs) from alkaline solutions was developed utilizing a novel solvent invented at ORNL. ${ }^{[1]}$ This solvent consists of a calix[4]arene-crown- 6 extractant dissolved in an inert hydrocarbon matrix. A modifier is added to the solvent to enhance the extraction power of the calixarene and to prevent the formation of a third phase. An additional additive is used to improve stripping performance and to mitigate, or suppress, the effects of any surfactants present in the feed stream. ${ }^{[2]}$ The process that deploys this solvent system is known as Caustic Side Solvent Extraction, or CSSX. The improved solvent extraction system was validated by SRNL in a small-scale integrated demonstration using actual SRS highlevel waste. ${ }^{[3]}$ The solvent system has been deployed at SRS in the MCU since 2008. Figure 1-1 below shows a simplified process diagram for the current MCU process.

\section{Modular CSSX (MCU)}

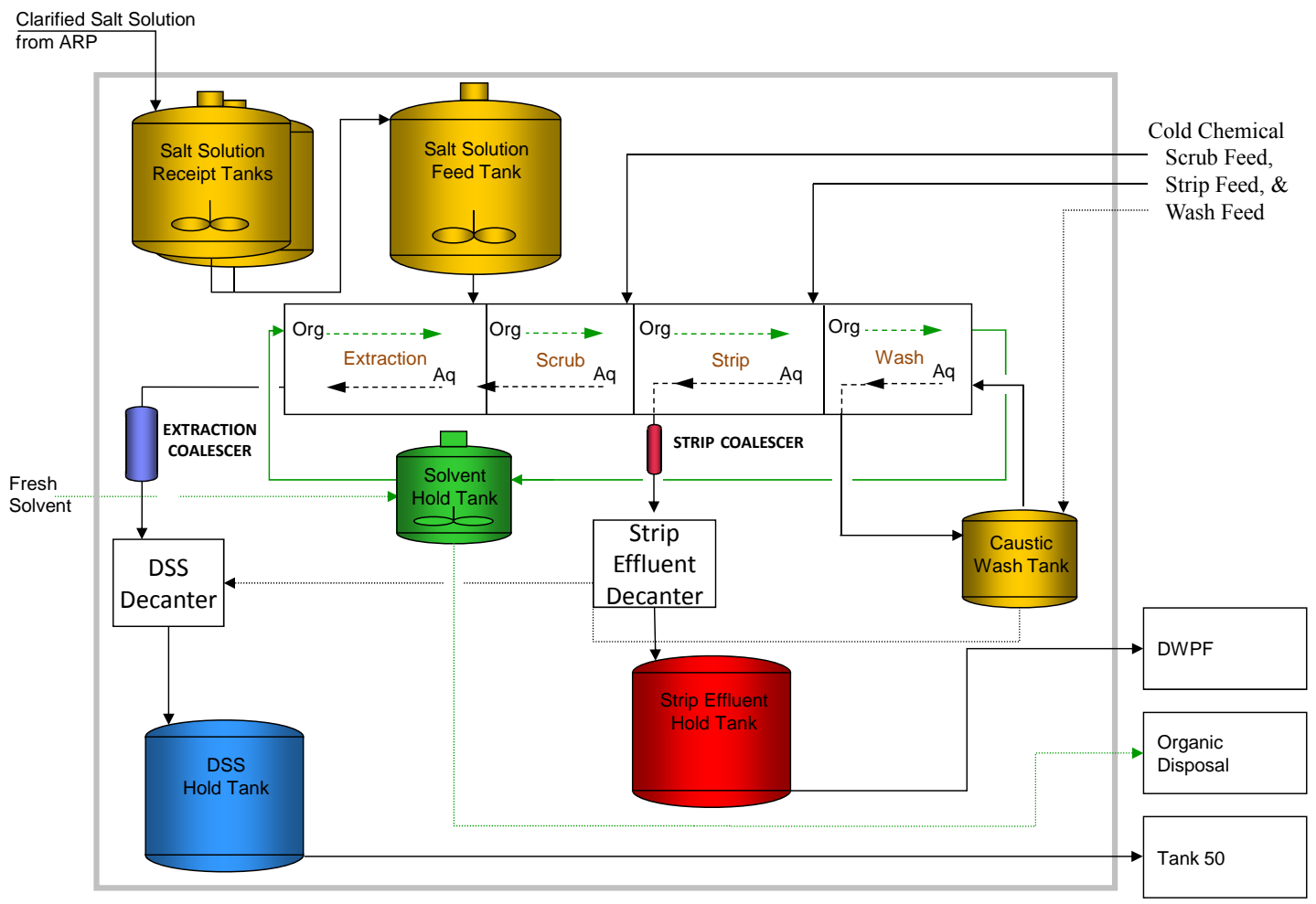

Figure 1-1. Modular CSSX (MCU) Simplified Flow Sheet.

The MCU uses centrifugal contactors from $\mathrm{CINC}^{\circledR}$ for cesium extraction (10-in rotor or "V10") and (5-in rotor or "V5") for solvent scrub and solvent strip stages to provide mechanical mixing and phase separation between the solvent and alkaline waste solutions. The process involves two separations. The first separation extracts cesium (Cs) from the waste solutions into the solvent system; the second separation strips the Cs from the solvent system while providing a nominal Cs concentration factor (CF) of 15. From its radioactive start-up in April 2008 until the end of August 2011, MCU processed approximately 2 million gallons of high-level waste (HLW) solution for disposition. The decontaminated salt solution is sent to the SRS Saltstone Facility and the concentrated Cs stream is transferred to the Defense Waste Processing Facility (DWPF). 
Subsequent development efforts by ORNL have identified an improved solvent system that can raise the expected decontamination factor (DF) in MCU from $\sim 200$ to more than $40,000^{[3]}$. The improved DF is attributed to an increased distribution ratio for cesium $[\mathrm{D}(\mathrm{Cs})]$ in extraction from $\sim 15$ to $\sim 60$ (at $50 \mathrm{mM}$ extractant concentration), due to an increased solubility of the calixarene in the solvent from $0.007 \mathrm{M}$ to $>0.050 \mathrm{M}$, and use of boric acid $\left(\mathrm{H}_{3} \mathrm{BO}_{3}\right)$ stripping that yields $\mathrm{D}(\mathrm{Cs})$ values less than 0.01. Additionally, the changes incorporated into Next Generation Solvent (NGS) are intended to reduce solvent entrainment. The improved solvent system contains four components:

- $\quad 0.050 \mathrm{M}$ 1,3-alt-2S,27-Bis(3,7-dimethyloctyloxy)-calix[4]arene-benzocrown-6, also known as MaxCalix, is the extractant

- $\quad 0.50 \mathrm{M}$ 1-(2,2,3,3-tetrafluoropropoxy)-3-(4-sec-butylphenoxy)-2-propanol, or Cs-7SB, is the modifier

- $\quad 0.003 \mathrm{M} \mathrm{N}, \mathrm{N}$-dicyclohexyl-N"-isotridecylguanidine, or DCiTDG, is the suppressor, and

- $\mathrm{C}_{12}$-isoparaffinic hydrocarbon, or Isopar $\mathrm{L}^{\circledR}$, is the diluent

The MCU and SWPF are actively pursuing the changeover from the current CSSX solvent to the NGS solvent. To support this integration of the NGS to the MCU and SWPF facilities, the Savannah River Remediation (SRR)/ARP/MCU Life Extension Project requested that SRNL perform testing of the new solvent for the removal of Cs from the liquid salt waste stream. The new solvent has been shown to improve the decontamination of Cs from the liquid salt waste material; however, understanding of the hydraulic and mass transfer properties of this solvent is required at a larger scale prior to utilization of the material in the MCU process. Additionally, SRNL was tasked with characterizing performance of both strip (20-in long, 10 micron pore size) and extraction (40-in long, 20 micron pore size) coalescers. These objectives were achieved through the analysis of droplet size distributions upstream and downstream of the coalescer using standard analytical methods and microscopy. Consequently, the SRR project requested that SRNL provide this testing at the pilot scale level. SRR issued a Task Technical Request (TTRWPT-2010-00004) for this study. ${ }^{[4]}$

\subsection{Task Requirements}

Testing goals were established in the Coalescer and Contactor Task Technical and Quality Assurance Plan (TTQAP) ${ }^{[5]}$ and the Savannah River Remediation, LLC, Technical Task Request TTR-WPT-2010-00004, Revision 3.

SRNL designed a pilot-scale testing program to test the full size strip (V5) and extraction (V10) contactors and the associated strip and extraction effluent coalescers to determine the hydraulic and mass transfer characteristics with the NGS. The extractant will be changed from the current calix[4]arene-crown-6 extractant (BOB CalixC6) molecule to the 1,3-alt-2S,27-Bis(3,7dimethyloctyloxy) calix[4]arene-benzocrown-6 (MaxCalix) molecule. For cost efficiency, the solvent in testing used $20 \mathrm{mM}$ extractant; the final deployment is expected to use $50 \mathrm{mM}$ extractant. Also, cesium distribution values at this concentration were available from prior ORNL laboratory studies. ${ }^{[1]}$ The scrub solution is changed from $0.05 \mathrm{M}$ nitric acid $\left(\mathrm{HNO}_{3}\right)$ to $0.025 \mathrm{M}$ sodium hydroxide $(\mathrm{NaOH})$. The strip acid will be changed from $0.001 \mathrm{M} \mathrm{HNO}_{3}$ to a $0.01 \mathrm{M} \mathrm{H}_{3} \mathrm{BO}_{3}$.

To meet the TTR requirements, SRNL pursued the following goals. 
- Determine the Cs mass transfer DFs for a single stage of strip, scrub, and extraction centrifugal contactors.

- Measure the organic carryover using analytical methods and on-line FTIR spectroscopy.

- Determine the droplet size distribution upstream and downstream of the coalescers using analytical methods and Polarized Light Microscopy (PLM).

- Establish hydraulic characteristics of the system, including the pressure drop across the coalescer, any correlation between turbidity and organic carryover, and perform visual observations of solvent coalescence occurring in the coalescer housing. However, the turbidity meter was added late in the design due to lack of a vendor-qualified meter and, as a result, its location was not optimal for establishing a correlation between turbidity and organic carryover.

- Evaluate the ability to increase the clarified salt solution feed rate from 8.5 gallons per minute (gpm) to $12 \mathrm{gpm}$.

\subsection{Experimental Procedure}

\subsection{Test Matrix and Methodology}

\subsubsection{Test Matrix}

Working with SRR, SRNL developed a test matrix that accommodated the amount of NGS that was available at the time of testing, 50 gallons. The amount of NGS available was dictated by the amount of extractant (MaxCalix, 1,3-alt-25,27-Bis(3,7-dimethyloctyloxy) calix[4]arenebenzocrown-6) available, and hence the total volume of NGS was limited. Based on the 50 gallons of NGS available, SRNL developed the test matrix shown in Table 3-1.

Table 3-1. Test Matrix for NGS Contactor/Coalescer Testing

\begin{tabular}{|c|c|c|c|c|c|c|c|c|c|}
\hline \multirow[b]{3}{*}{ Test } & \multirow[b]{3}{*}{ Description } & \multirow{3}{*}{$\begin{array}{c}\text { Test } \\
\text { Duration } \\
\text { Minutes }\end{array}$} & \multirow[b]{3}{*}{ Contactor } & \multirow{3}{*}{$\begin{array}{l}\text { Aqueous } \\
\text { Solution }\end{array}$} & \multirow{2}{*}{\multicolumn{2}{|c|}{$\begin{array}{l}\text { Test Settings } \\
\text { Flowrate }\end{array}$}} & \multirow{3}{*}{$\begin{array}{l}\text { Contactor } \\
\text { RPM }\end{array}$} & \multirow{3}{*}{$\begin{array}{c}\text { Organic } \\
\text { Temp }\end{array}$} & \multirow{3}{*}{$\begin{array}{c}\text { Aqueous } \\
\text { Temp }\end{array}$} \\
\hline & & & & & & & & & \\
\hline & & & & & Organic & Aqueous & & & \\
\hline 1A & Extraction (low) & 9.6 & $\mathrm{~V}-10$ & Salt Sim. & $1 \mathrm{gpm}$ & $4 \mathrm{gpm}$ & 1200 & $23 \mathrm{C}$ & $23 \mathrm{C}$ \\
\hline 1B & Extraction (medium) & $\overline{4.8}$ & $\underline{V-10}$ & $\overline{\text { Salt Sim. }}$ & $\overline{2 \mathrm{gpm}}$ & $8 \mathrm{gpm}$ & $\overline{1700}$ & $\overline{23 \mathrm{C}}$ & $\overline{23 \mathrm{C}}$ \\
\hline 1C & Extraction (high) & 3.2 & $\underline{V-10}$ & Salt Sim. & $3 \mathrm{gpm}$ & $12 \mathrm{gpm}$ & $\underline{1700}$ & $23 \mathrm{C}$ & $\underline{23 \mathrm{C}}$ \\
\hline 1D & Extraction $(8.5 \mathrm{gpm})$ & $\underline{4.5}$ & $\underline{\mathrm{V}-10}$ & Salt Sim. & $2.1 \mathrm{gpm}$ & $8.5 \mathrm{gpm}$ & $\underline{1700}$ & $23 \mathrm{C}$ & $23 \mathrm{C}$ \\
\hline $2 A$ & Scrub Solvent (low) & 50 & V-5 & $0.025 \mathrm{M} \mathrm{NaOH}$ & $1 \mathrm{gpm}$ & $0.27 \mathrm{gpm}$ & 1800 & $23 \mathrm{C}$ & $23 \mathrm{C}$ \\
\hline 2B & Scrub Solvent (high) & $\overline{17}$ & $\overline{V-5}$ & $\underline{0.025 \mathrm{M} \mathrm{NaOH}}$ & $3 \mathrm{gpm}$ & $0.80 \mathrm{gpm}$ & 2100 & $\overline{23 \mathrm{C}}$ & $23 \mathrm{C}$ \\
\hline $3 A$ & Strip (low) & 3.8 & $\mathrm{~V}-5$ & $\overline{0.01 \mathrm{M} \mathrm{H}_{3} \mathrm{BO}_{3}}$ & $1 \mathrm{gpm}$ & $0.27 \mathrm{gpm}$ & $\underline{1800}$ & $\overline{33 \mathrm{C}}$ & $33 \mathrm{C}$ \\
\hline 3B & Strip (medium) & 1.9 & $\underline{V-5}$ & $\underline{0.01 \mathrm{M} \mathrm{H}_{3} \mathrm{BO}_{3}}$ & $2 \mathrm{gpm}$ & $0.53 \mathrm{gpm}$ & $\underline{2100}$ & $\underline{33 \mathrm{C}}$ & $33 \mathrm{C}$ \\
\hline 3C & Strip (high) & $\underline{1.3}$ & $\underline{V-5}$ & $\underline{0.01 \mathrm{M} \mathrm{H}_{3} \mathrm{BO}_{3}}$ & $3 \mathrm{gpm}$ & $0.80 \mathrm{gpm}$ & $\underline{2100}$ & $33 \mathrm{C}$ & $33 \mathrm{C}$ \\
\hline 3D & Strip (Nom. O:A 5:1 Med Flow) & $\underline{2.0}$ & $\underline{\mathrm{V}-5}$ & $\underline{0.01 \mathrm{M} \mathrm{H}_{3} \mathrm{BO}_{3}}$ & $\underline{2 \mathrm{gpm}}$ & $\underline{0.40 \mathrm{gpm}}$ & $\underline{2100}$ & $\underline{33 \mathrm{C}}$ & $\underline{33 \mathrm{C}}$ \\
\hline 3E & Strip (O:A 7:1, Med Flow) & $\underline{\underline{2.1}}$ & $\underline{\mathrm{V}-5}$ & $\overline{0.01 \mathrm{M} \mathrm{H}_{3} \mathrm{BO}_{3}}$ & $\underline{2 \mathrm{gpm}}$ & $0.28 \mathrm{gpm}$ & $\underline{2100}$ & $\overline{33 \mathrm{C}}$ & $\overline{33 \mathrm{C}}$ \\
\hline $3 F$ & Strip (0:A 7:1, High Flow) & $\underline{1.4}$ & $\underline{\mathrm{V}-5}$ & $\underline{0.01 \mathrm{M} \mathrm{H}_{3} \mathrm{BO}_{3}}$ & $3 \mathrm{gpm}$ & $0.43 \mathrm{gpm}$ & $\underline{2100}$ & $\underline{33 \mathrm{C}}$ & $\underline{33 \mathrm{C}}$ \\
\hline $4 \mathrm{~A}$ & Strip Hydraulics w/Coalescer (low) (20", 10 micron Element) & cont. & V-5 & $0.01 \mathrm{M} \mathrm{H}_{3} \mathrm{BO}_{3}$ & $1 \mathrm{gpm}$ & $0.27 \mathrm{gpm}$ & 1800 & $33 \mathrm{C}$ & $33 \mathrm{C}$ \\
\hline $4 \mathrm{~B}$ & Strip Hydraulics w/Coalescer (med) (20", 10 micron Element) & cont. & V-5 & $0.01 \mathrm{M} \mathrm{H}_{3} \mathrm{BO}_{3}$ & $2 \mathrm{gpm}$ & $0.53 \mathrm{gpm}$ & 2100 & $33 \mathrm{C}$ & $33 \mathrm{C}$ \\
\hline $4 \mathrm{C}$ & Strip Hydraulics w/Coalescer (high) (20", 10 micron Element) & cont. & V-5 & $0.01 \mathrm{M} \mathrm{H}_{3} \mathrm{BO}_{3}$ & $3 \mathrm{gpm}$ & $0.80 \mathrm{gpm}$ & 2100 & $33 \mathrm{C}$ & $33 \mathrm{C}$ \\
\hline $4 \mathrm{D}$ & Strip (Nom. O:A 5:1 Med Flow) (20", 10 micron Element) & cont. & V-5 & $0.01 \mathrm{M} \mathrm{H}_{3} \mathrm{BO}_{3}$ & $2 \mathrm{gpm}$ & $0.40 \mathrm{gpm}$ & 2100 & $33 \mathrm{C}$ & $33 \mathrm{C}$ \\
\hline $5 C$ & Strip Hydraulics w/Coalescer (high) (10", 5 micron Element) & cont. & V-5 & $0.01 \mathrm{M} \mathrm{H}_{3} \mathrm{BO}_{3}$ & $3 \mathrm{gpm}$ & $0.80 \mathrm{gpm}$ & 2100 & $33 \mathrm{C}$ & $33 \mathrm{C}$ \\
\hline $7 \mathrm{~A}$ & Extraction Hydraulics w/Coalescer (low) (40", 20 micron Element) & cont. & $\mathrm{V}-10$ & Salt Sim. & $1 \mathrm{gpm}$ & $4 \mathrm{gpm}$ & 1200 & $23 \mathrm{C}$ & $23 \mathrm{C}$ \\
\hline $7 \mathrm{~B}$ & Extraction Hydraulics w/Coalescer (med) (40", 20 micron Element) & cont. & V-10 & Salt Sim. & $2 \mathrm{gpm}$ & $8 \mathrm{gpm}$ & 1700 & $23 \mathrm{C}$ & $23 \mathrm{C}$ \\
\hline $7 \mathrm{C}$ & Extraction Hydraulics w/Coalescer (high) (40", 20 micron Element) & cont. & $\mathrm{V}-10$ & Salt Sim. & $3 \mathrm{gpm}$ & $12 \mathrm{gpm}$ & 1700 & $23 \mathrm{C}$ & $23 \mathrm{C}$ \\
\hline
\end{tabular}

Mass Transfer sampling times were developed based on flow rates and contactor rotor volumes. These are shown in Table 3-2. 
Table 3-2. Mass Transfer Sampling Times.

\begin{tabular}{|c|c|c|c|c|c|c|c|c|c|c|c|}
\hline \multirow[b]{4}{*}{ Test } & \multirow{2}{*}{$\begin{array}{l}\text { V-5 Capacity-0.6 Gallons } \\
\text { V-10 Capacity-6.0 Gallons }\end{array}$} & \multicolumn{2}{|r|}{ Contactor } & & & \multirow{3}{*}{\multicolumn{2}{|c|}{$\begin{array}{l}\text { Test Settings } \\
\text { Flowrate }\end{array}$}} & & & & \\
\hline & & Test & \multirow{3}{*}{$\begin{array}{c}\text { Rotor } \\
\text { Turnover } \\
\text { Volumes }\end{array}$} & \multirow[b]{3}{*}{ Contactor } & \multirow{3}{*}{$\begin{array}{l}\text { Aqueous } \\
\text { Solution }\end{array}$} & & & \multirow{2}{*}{\multicolumn{4}{|c|}{$\begin{array}{l}\text { Contactor Residence Times } \\
\text { minutes and seconds }\end{array}$}} \\
\hline & & \multirow{2}{*}{$\begin{array}{l}\text { Duration } \\
\text { minutes }\end{array}$} & & & & & & & & & \\
\hline & Description & & & & & Organic & Aqueous & 6 CRT & 7 CRT & $8 \mathrm{CRT}$ & $10 \mathrm{CRT}$ \\
\hline $1 \mathrm{~A}$ & Extraction (low) & 9.6 & 8 & $\mathrm{~V}-10$ & Salt Sim. & $1 \mathrm{gpm}$ & $4 \mathrm{gpm}$ & 0:07:12 & 0:08:24 & 0:09:36 & \\
\hline 1B & Extraction (medium) & 4.8 & $\underline{8}$ & $\underline{V-10}$ & Salt Sim. & $2 \mathrm{gpm}$ & $8 \mathrm{gpm}$ & 0:03:36 & 0:04:12 & 0:04:48 & \\
\hline 1C & Extraction (high) & 3.2 & 8 & V-10 & Salt Sim. & $3 \mathrm{gpm}$ & $12 \mathrm{gpm}$ & 0:02:24 & 0:02:48 & 0:03:12 & \\
\hline 1D & Extraction $(8.5 \mathrm{gpm})$ & 4.5 & 8 & $\mathrm{~V}-10$ & Salt Sim. & $2.1 \mathrm{gpm}$ & $8.5 \mathrm{gpm}$ & 0:03:23 & 0:03:57 & 0:04:31 & \\
\hline $2 A$ & Scrub Solvent (low) & 50 & & $\mathrm{~V}-5$ & $0.025 \mathrm{M} \mathrm{NaOH}$ & $1 \mathrm{gpm}$ & $\overline{0.27 \mathrm{gpm}}$ & 0:02:51 & 0:03:19 & 0:03:47 & $0: 04: 44$ \\
\hline 2B & Scrub Solvent (high) & $\underline{17}$ & & $\underline{V-5}$ & $0.025 \mathrm{M} \mathrm{NaOH}$ & $3 \mathrm{gpm}$ & $0.80 \mathrm{gpm}$ & 0:00:57 & 0:01:06 & 0:01:16 & 0:01:35 \\
\hline $3 A$ & Strip (low) & $\underline{3.8}$ & $\underline{8}$ & $\underline{V-5}$ & $\underline{0.01 \mathrm{M} \mathrm{H}_{3} \mathrm{BO}_{3}}$ & $1 \mathrm{gpm}$ & $0.27 \mathrm{gpm}$ & 0:02:51 & & 0:03:47 & 0:04:44 \\
\hline 3B & Strip (medium) & $\underline{1.9}$ & $\underline{8}$ & $\underline{V-5}$ & $\underline{0.01 \mathrm{M} \mathrm{H}_{3} \mathrm{BO}_{3}}$ & $2 \mathrm{gpm}$ & $0.53 \mathrm{gpm}$ & 0:01:25 & & 0:01:54 & 0:02:22 \\
\hline $3 C$ & Strip (high) & $\underline{1.3}$ & $\underline{8}$ & $\underline{\mathrm{V}-5}$ & $\underline{0.01 \mathrm{M} \mathrm{H}_{3} \mathrm{BO}_{3}}$ & $3 \mathrm{gpm}$ & $\underline{0.80 \mathrm{gpm}}$ & 0:00:57 & & 0:01:16 & 0:01:35 \\
\hline 3D & Strip (Nom. O:A 5:1 Med Flow) & 2.0 & 8 & V-5 & $\underline{0.01 \mathrm{M} \mathrm{H}_{3} \mathrm{BO}_{3}}$ & $2 \mathrm{gpm}$ & $0.40 \mathrm{gpm}$ & 0:01:30 & & 0:02:00 & 0:02:30 \\
\hline 3E & Strip (O:A 7:1, Med Flow) & $\underline{2.1}$ & $\underline{8}$ & $\underline{\mathrm{V}-5}$ & $\underline{0.01 \mathrm{M} \mathrm{H}_{3} \mathrm{BO}_{3}}$ & $2 \mathrm{gpm}$ & $0.28 \mathrm{gpm}$ & 0:01:35 & & 0:02:06 & $0: 02: 38$ \\
\hline $3 F$ & Strip (O:A 7:1, High Flow) & $\underline{1.4}$ & $\underline{8}$ & $\underline{\mathrm{V}-5}$ & $\underline{0.01 \mathrm{M} \mathrm{H}_{3} \mathrm{BO}_{3}}$ & $3 \mathrm{gpm}$ & $\underline{0.43 \mathrm{gpm}}$ & 0:01:03 & & 0:01:24 & 0:01:45 \\
\hline
\end{tabular}

To establish the contactor residence times (CRT's), a calculation was made using the contactor rotor hold volume (supplied by SRR) divided by total (i.e., aqueous plus organic) input flow rates. This was converted to minutes and seconds, and used as the base CRT sampling time.

\subsubsection{Test Protocol}

Prior to testing, the equipment was cleaned per SRNL's work instruction, ITS-WI-0046, Revision ${ }_{1}^{[6]}$ The protocol for testing was determined by the amount of NGS available, which was 50 gal. SRNL determined the most judicious use of the limited solvent was to perform mass transfer tests first and then follow with hydraulic testing. Flow rates were chosen using the current MCU flow rates for the respective stream (strip, scrub, or extraction) as the medium flow rate; the low flow rate was established as $50 \%$ of the medium-flow value, and the high flow rate was selected at $150 \%$ of the medium-flow value. Per the test matrix, SRNL performed four extraction tests. The first three tests were at low, medium, and high flow rates, and the fourth test operated the extraction at $8.5 \mathrm{gpm}$ of aqueous flow, which duplicated the Wright Industries Testing performed per reference. ${ }^{[7]}$ Following the extraction testing, which processed the entire 50 gal of solvent, minus losses in sampling and piping, SRNL performed two successive scrub tests (low and high flow rates), contacting the entire solvent inventory in each of the tests. Last, SRNL performed six stripping tests at varying conditions, stripping the entire solvent inventory. These tests included low, medium, and high flow rates at the baseline organic-to-aqueous $(\mathrm{O}: \mathrm{A})$ ratio, and tests at two other O:A ratios of 5 and 7. A summary of the O:A ratios and test temperatures is shown in Table 3-3.

Table 3-3. Organic:Aqueous Volume Ratios for Testing

\begin{tabular}{||c|c|c||}
\hline Test & Volume Ratio (O:A) & Temperature ${ }^{\circ} \mathbf{C}$ ) \\
\hline 1A-1D, 4A-4D (Mass Tranfer Extraction) & $1: 4$ & $23+/-3$ \\
\hline 2A-2B (Mass Transfer Scrub) & $3.75: 1$ & $23+/-3$ \\
\hline 3A-3D (Mass Transfer Strip) & $3.75: 1$ & $33+/-3$ \\
\hline 3E (Mass Transfer Strip) & $7: 1$ & $33+/-3$ \\
\hline 3F (Mass Transfer Strip) & $7: 1$ & $33+/-3$ \\
\hline 5C (Strip Hydraulics) & $3.75: 1$ & $33+/-3$ \\
\hline 4A-4C (Strip Hydraulics) & $3.75: 1$ & $33+/-3$ \\
\hline 4D (Strip Hydraulics) & $5: 1$ & $33+/-3$ \\
\hline 7A-7C (Extraction Hydraulics) & $1: 4$ & $23+/-3$ \\
\hline
\end{tabular}

Following the mass-transfer tests, SRNL performed hydraulic testing per the Test Matrix (Table 3-1). This included three strip tests (Low/Medium/High) using a 20-in long, 10-micron polysulfide coalescer from Pall ${ }^{\circledR}$ (Part Number T5512, Item RLS2FPS100). Test 4A, Strip Low Flow, was repeated after Test $4 \mathrm{D}$ because of hydraulic problems (i.e., excessive air entrainment) during Test 4A. No data for the failed test are reported. Prior to Test 5C, the coalescer was 
changed to a 10-in long, 5-micron polysulfide coalescer from Pall ${ }^{\circledR}$ (Part Number T5501, Item RLS1FPS050). Strip testing was followed by extraction hydraulic testing, including the low, medium, and high flow rates using a 40-in, 20-micron polysulfide coalescer from Pall ${ }^{\circledR}$, Part Number T5524, Item RLS4FPS200).

\subsection{Experimental Design/Test Apparatus/Configuration}

\subsubsection{General Arrangement}

The pilot-scale test system is represented schematically in Figure 3-1, MCU Coalescer/Contactor Testing Piping and Instrument Diagram. The system consisted of an aqueous side and a solvent side. The aqueous side of the test rig consisted of tankage for aqueous phase inventory (i.e., the Aqueous Feed Tank for mass transfer testing and the 400 Gallon Aqueous Tank for hydraulic studies). Additionally, an Aqueous Receipt Tank was necessary for receipt of contacted aqueous phase during the mass transfer testing. The solvent side required both an Organic Feed Tank and an Organic Receipt Tank. The Organic Receipt Tank was used during mass transfer testing as a receipt tank for contacted solvent. The Organic Feed Tank was used as both feed and receipt tank during hydraulic studies. 
SRNL-STI-2011-00695

Revision 0

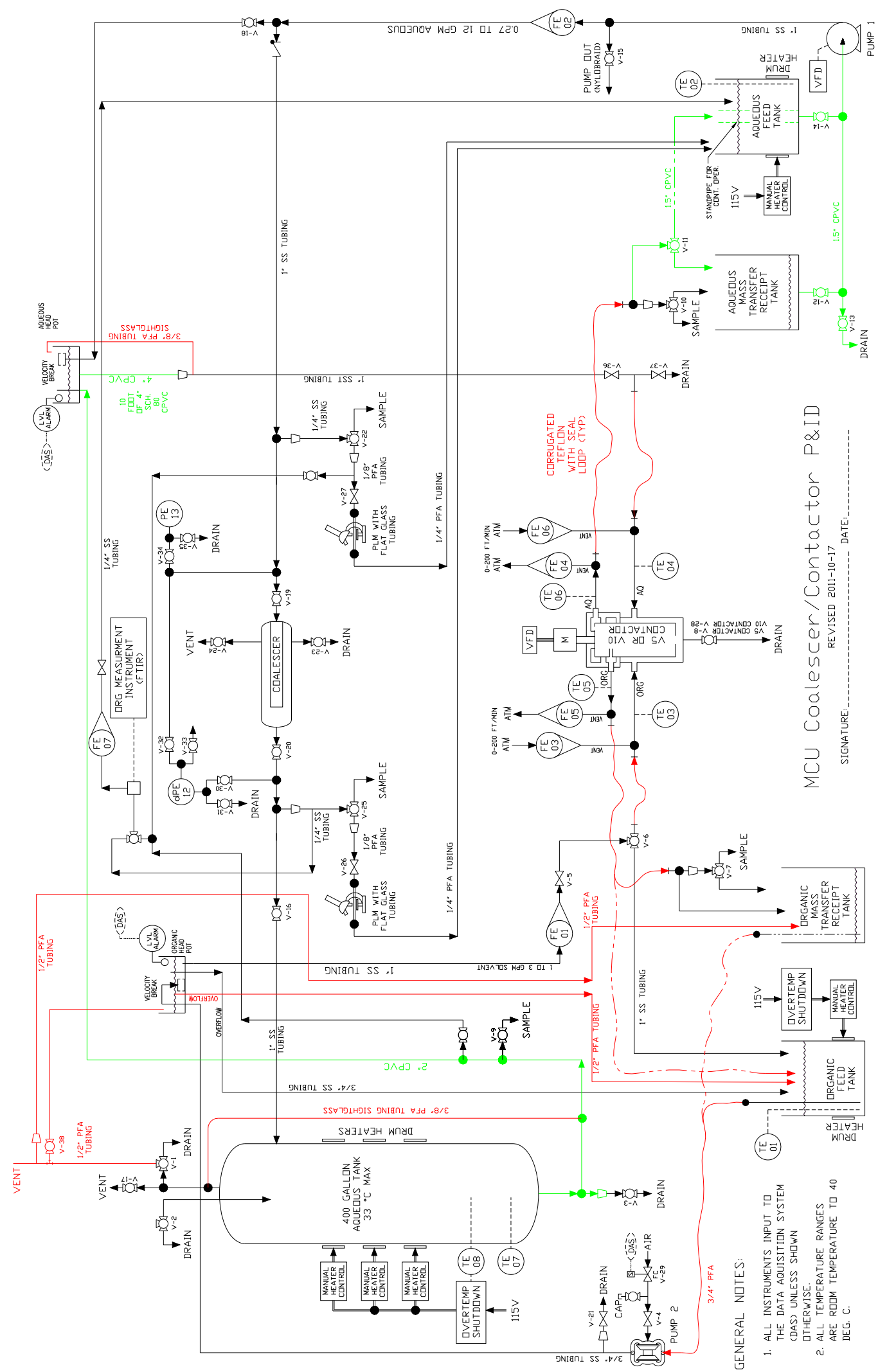

Figure 3-1. Piping and Instrument Diagram. 


\subsubsection{Pumps}

Two pumps were required for the system, one for the aqueous side and one for the solvent side. The specifications for the two pumps are shown in Table 3-4.

Table 3-4. Pumps

\begin{tabular}{||c|c|c|c|}
\hline PUMP & Manufacturer & Model & Controller \\
\hline Pump 1 & Teel (Grainger) & 2P392 & VFD-Leeson PN 174919 \\
\hline Pump 2 & Wilden & T2/SSPPB/TNU/TF/STF & Controlled by manual air valve \\
\hline
\end{tabular}

Pump 1 was controlled through the use of a variable frequency drive (VFD) at the flow rates listed in Table 3-1. The VFD was controlled by the Data Acquisition System (DAS). Pump 2, an air driven diaphragm pump, was controlled through V-4, a manual valve which metered air to Pump 2. Additionally, a normally closed valve, V-29, was used to provide safety shutdown upon head pot overflow (controlled from DAS).

\subsubsection{Head Pots}

Head inventory control pots were used on both the aqueous and solvent sides. The original intent of the design was to provide one test rig for both mass-transfer testing and hydraulic testing. It was intended that the pots would allow the solvent to float on top of the aqueous phase inventory in the 400-gal decanter, allowing for continuous solvent phase separation during hydraulic testing. To prevent additional re-piping for mass-transfer tests, the pots would still be used but the solvent pot would be isolated from the 400 gallon decanter. It was discovered during shakedown testing that air entrainment on the solvent side was present in significant quantities, and so it was decided to lower the solvent pot to approximately $10 \mathrm{ft}$ (from $30 \mathrm{ft}$ ) above the contactor organic side inlets. This significantly reduced air entrainment from the overflow connection on the solvent tank. To allow for continuous solvent recovery during hydraulic testing, a $1 / 2$-in Teflon ${ }^{\mathrm{TM}}$ PFA tube was installed above valve V-38 to the Organic Feed Tank. This configuration allowed continuous solvent recovery from the decanter during hydraulic testing.

Cameras were installed to monitor both head pots to provide visual feedback to flow conditions, and allow tuning of the organic feed rate to the head pot to minimize air entrainment. By providing a sufficient flow rate to flood the $1 / 2$-in Teflon ${ }^{\mathrm{TM}}$ PFA overflow line, but minimizing use of the $3 / 4$-in SS overflow line, SRNL was able to provide a steady flow of solvent with significantly reduced air entrainment.

\subsubsection{Decanter}

To provide solvent/aqueous phase disengagement, a decanter was installed (labeled 400 Gallon Aqueous Tank). The design intent of the decanter was to be of sufficient diameter to minimize the superficial flow velocity of the bulk fluid, and consequently the flow velocity of buoyant solvent, thus allowing for continuous accumulation and re-inventory of solvent during hydraulic testing. No effort was made in these tests to replicate the MCU decanter design and operation.

\subsubsection{Air De-entrainment Column}

Prior to shakedown testing, a technical review performed internal to SRNL determined that the original line size flowing from the aqueous head pot to the contactor was insufficiently large to accommodate $12 \mathrm{gpm}$ in gravity flow conditions. Calculations based on air droplet sizes and superficial down flow velocities indicated that a minimum of 3-in diameter pipe was required for proper air disengagement. SRNL replaced 1-in tubing downstream of the Aqueous Head Pot with a 4-in CPVC de-entrainment column that was $10 \mathrm{ft}$ long. 


\subsubsection{Heaters}

Heaters were required to maintain the $33{ }^{\circ} \mathrm{C}$ required for strip test conditions. All heaters used were 1000-W (external) band heaters, and were installed on the Aqueous Feed Tank, the Solvent Feed Tank, and the 400 Gallon Aqueous Tank.

\subsubsection{Contactors}

The $\mathrm{CINC}^{\circledR}$ Contactor utilizes the force generated by rotating an object about a central axis. By spinning two fluids of different densities within a rotating cylinder, or rotor, the heavier fluid is forced to the wall at the inside of the rotor while the lighter fluid is forced toward the center of the rotor. As additional fluid is introduced to the rotor the fluid within the rotor is forced upward to the rotor underflows and weirs. The light phase fluid having a lower density flows toward the center of the rotor where it exits the rotor over the lighter phase weir through the lighter phase outlets. The heavy phase fluid continues up the rotor through the underflows, then exits over the heavy phase weir. Each fluid is collected in its own collector ring and then leaves the separator through the heavy and light phase outlets.

The contactors were received on a frame from SRR as shown in Figure 3-2.

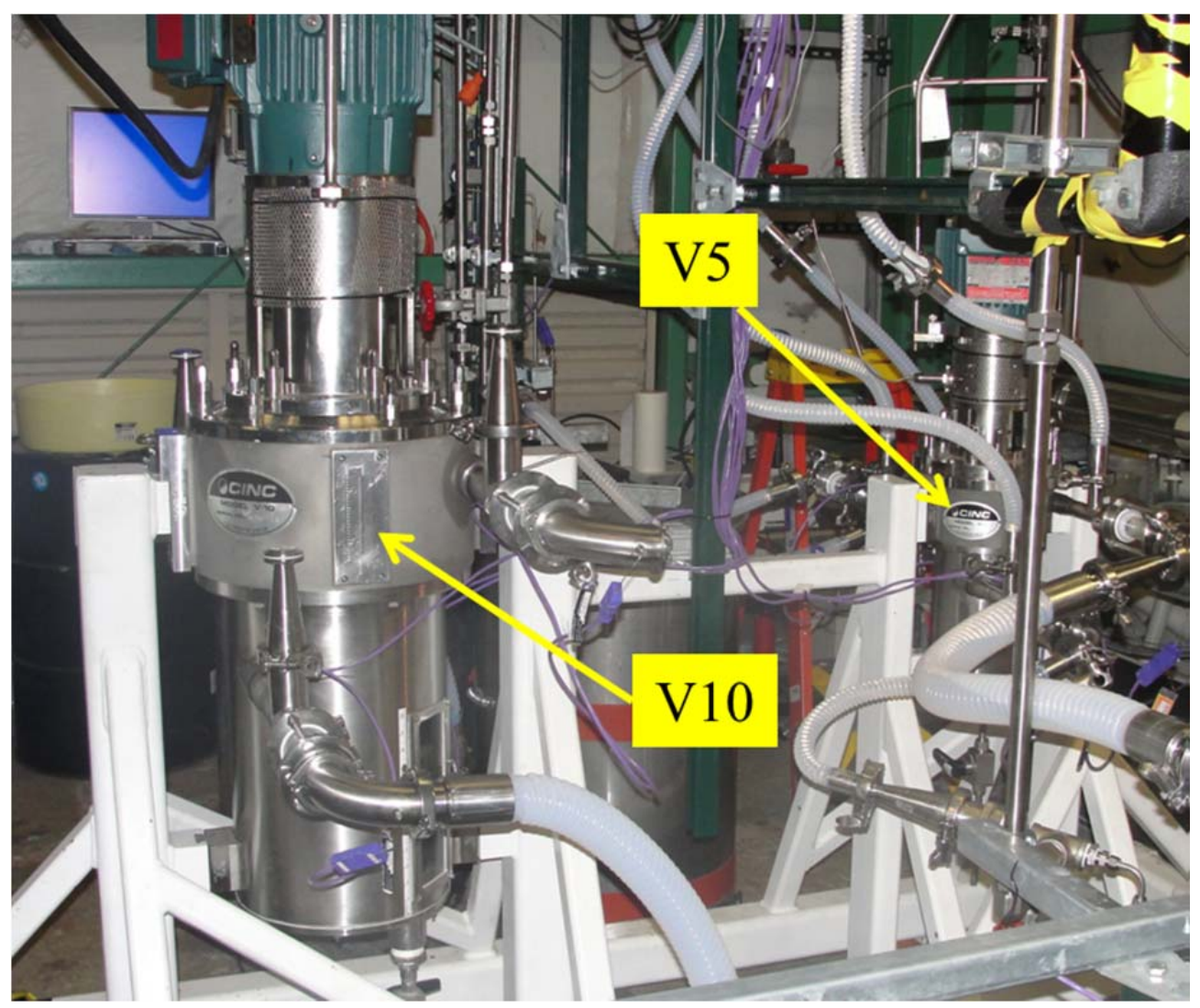

Figure 3-2. V5 and V10 Contactors on Frame

The bottom vane design for both contactors can be seen in Figure 3-3. The design provides high mixing in the contactor chamber beneath and on the outside of the rotor. 

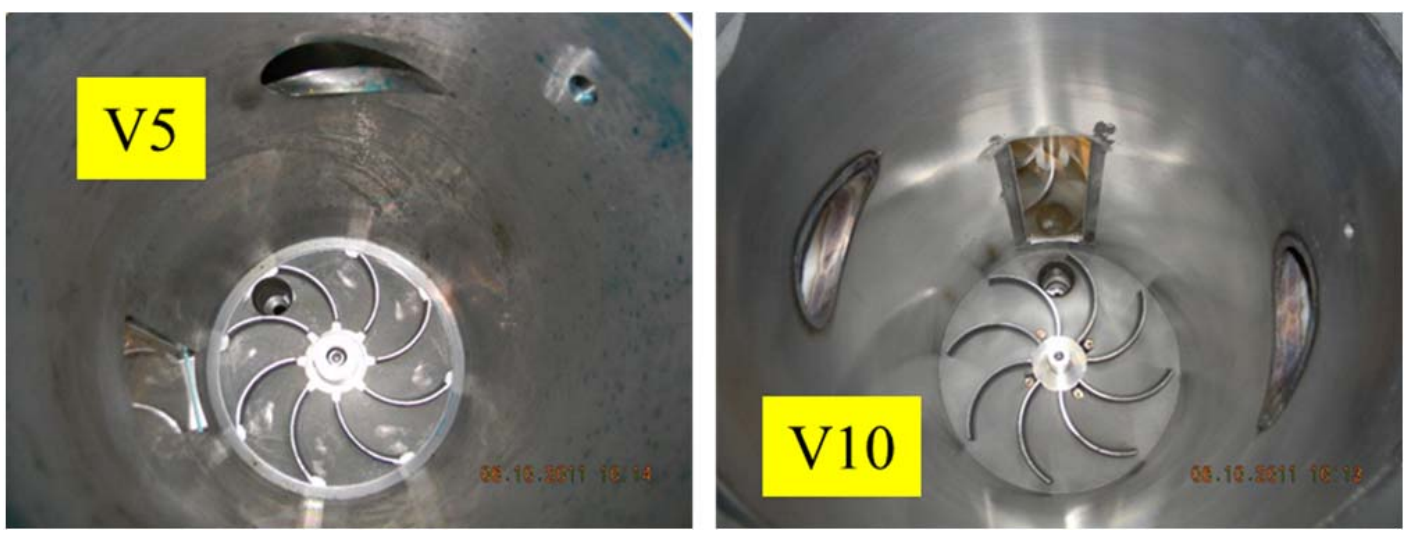

Figure 3-3. Bottom Plate in Contactor Housing.

Table 3-5 describes the salient features of both contactors.

Table 3-5. Contactor Salient Features

\begin{tabular}{||c|c|c|c|}
\hline Contactor & $\begin{array}{c}\text { Heavy Phase Weir Size } \\
\text { (Diameter), inches }\end{array}$ & $\begin{array}{c}\text { Bottom Vane } \\
\text { Design }\end{array}$ & $\begin{array}{c}\text { Variable Frequency } \\
\text { Drive }\end{array}$ \\
\hline CINC V-5 & 2.70 ” Weir, PN 0512320-2 & High Mix & Leeson PN 174919 \\
\hline CINC V-10 & 5.10 " Weir, PN 1012320-2/5.10 & High Mix & Leeson PN 174552 \\
\hline
\end{tabular}

The V-5 and V-10 contactors are the same as those used at Wright Industries for testing of the CSSX process. ${ }^{[14,15]}$ Once received, the contactors were disassembled to verify proper weir sizing and general internal conditions. The $\mathrm{V}-10$ as received required the fabrication of a new bottom plate, as the contactor as supplied did not have a bottom plate. The design for the V-10 high mix bottom plate is shown in Appendix C.

The V-5 as received and inspected was found to have a yellow contaminant of unknown composition. The contactors received minimal flushing in 2005 following testing at Wright Industries and were stored idle for more than 5 years. The contaminant seems almost certain to be from prolonged storage of the residual solvent film under acidic conditions based upon spectroscopic analyses and prior knowledge of solvent decomposition behavior. A cleaning strategy was developed to remove the contaminant. After several cleaning steps and analyses, SRNL and SRR concurred that the contactor was sufficiently clean for testing. Cleaning consisted of sequences of rinses in acid, Isopar $L^{\circledR}$, and dichloromethane (used for cleaning the rotor remotely from the contactor body). After multiple rinse cycles, samples were collected and analyzed by FTIR for impurities. The unidentified impurity concentration decreased appreciably during cleaning as did discoloration of the Isopar $L^{\circledR}$. Based on this data and apparently acceptable hydraulics for the Isopar-water mixture, SRNL and SRR agreed to start testing.

\subsubsection{Coalescer}

A coalescer housing was installed that allowed the use of 10-in, 20-in and 40-in coalescer elements as required per the test matrix. The coalescer housing with a 20 -in element is shown in Figure 3-4. 


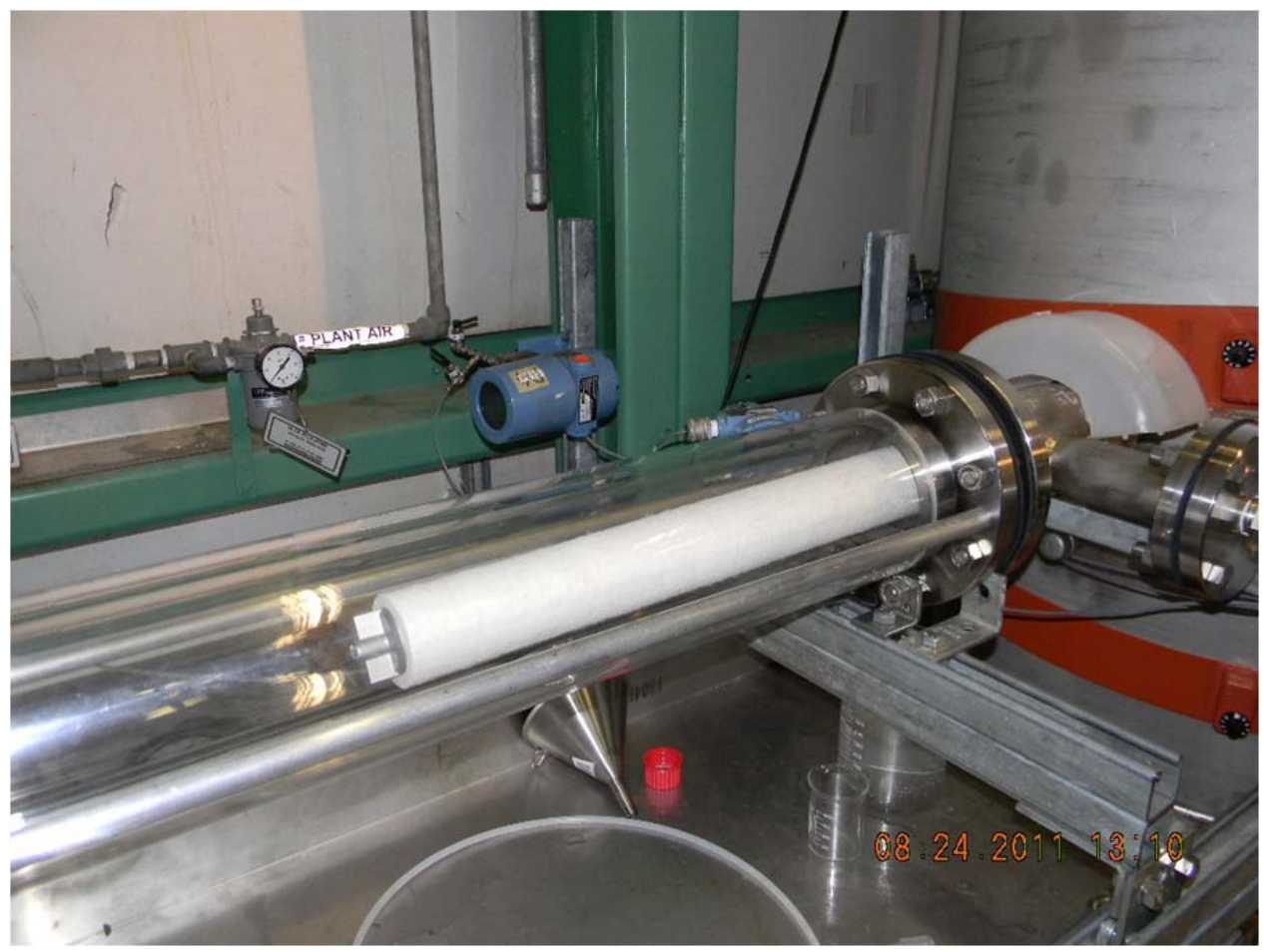

Figure 3-4. Coalescer in Acrylic Housing with 20-inch Coalescer Element.

The main housing was fabricated of glass (with an acrylic outer pipe to meet ASME B31.3 piping requirements). ${ }^{[8]}$ This design allowed real-time visual observations of solvent coalescence. This design feature proved invaluable in understanding some of the droplet size data and carryover data. Additional design details are given in Appendix A. The coalescers were supplied by Pall ${ }^{\circledR}$, and are constructed of polyphenylene sulfide. Testing sizes included a 10-in with 5-micron pores, 20 -in with 10 -micron pores, and 40 -in with 20 -micron pores.

\subsubsection{Drums/Tankage}

The Organic Feed and Receipt Tanks were Skolnik PN SLP5501, open-headed 55-gal drums with a seamless design at the bottom to minimize leakage. The tanks are fabricated from 304-L stainless steel with a 2B finish. The Organic Feed and Receipt Tank were cleaned per SRNL procedure $^{[9]}$ as new drums prior to use.

\subsubsection{Instruments}

Appendix B lists the instruments used for testing. A magnetic flow meter was used to measure the aqueous flow, and a turbine flow meter measured the solvent flow. Hot wire anemometers were installed to measure the influent and effluent of air from the vents on the contactors, and provided readings in standard cubic feet per minute (SCFM). An evaluation check (independent of the calibration) was performed on the anemometers with the apparatus shown below in Figure 3-5. 


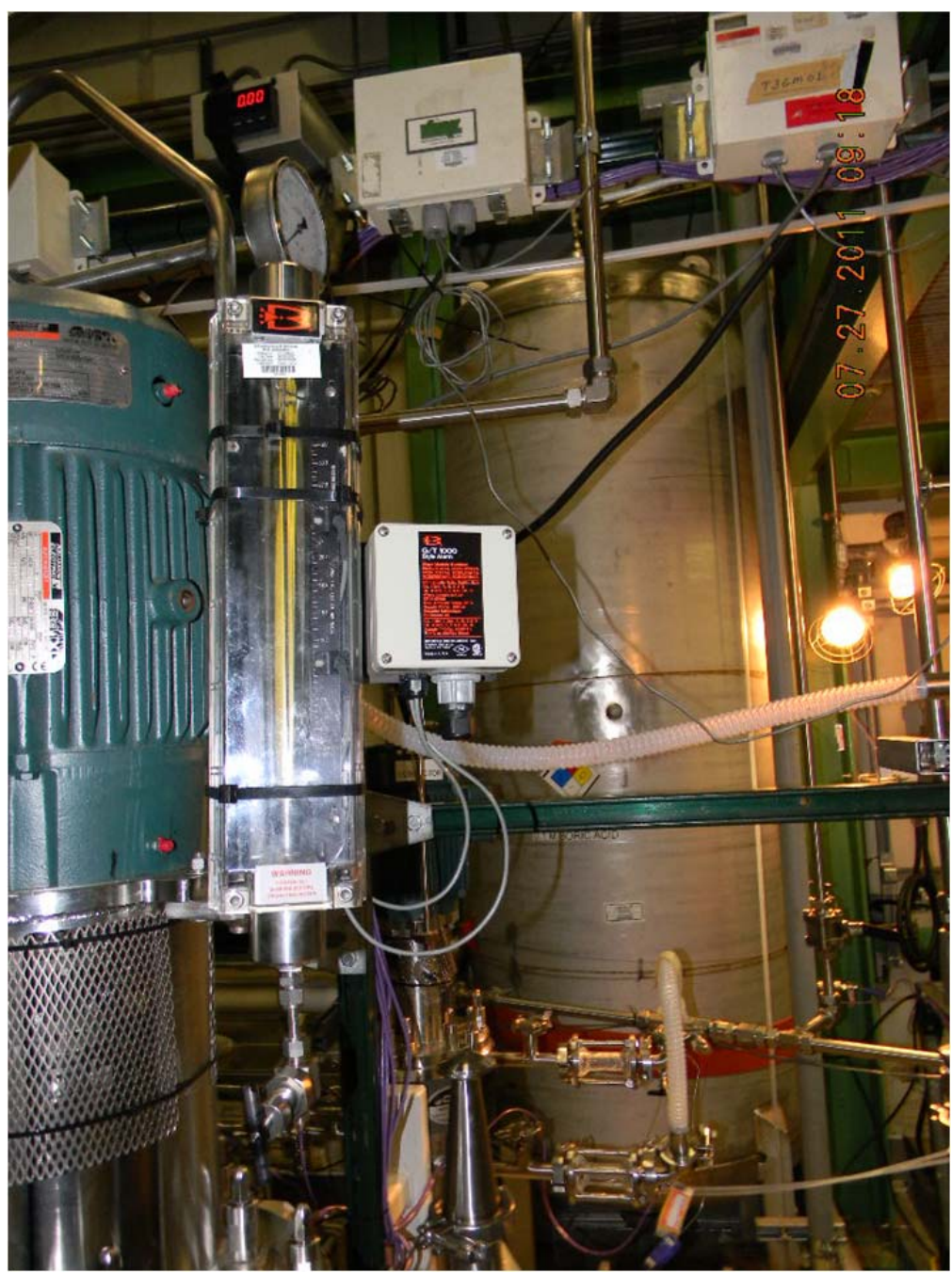

Figure 3-5. Anemometer Evaluation Equipment

Readings obtained during the evaluation check were within 5\% of the DAS readings, indicating that the anemometers were operating correctly.

For liquid flow rates, two flow meters were obtained and calibrated for use. The aqueous flow was measured by an $\mathrm{ABB}^{\circledR}$ magnetic flow meter, Model 10D1475J, 0-15 gpm. The organic flow was measured by a turbine flow meter, Omega ${ }^{\circledR}$ Model FTB-1422, 0-7.5 gpm. Temperature measurements were achieved using Type E thermocouples, 1/16" diameter, Omega ${ }^{\circledR}$ Models GEQSS-116(G)-various lengths. The system pressure was measured using a Rosemount ${ }^{\mathbb{B}}$ pressure transducer, Model 1144G, 0-150 psig. The differential pressure across the coalescer was measured using a Rosemount ${ }^{\circledR} \mathrm{dP}$ transducer, Model 1151DP, 0-100 psid. Rotational speed was measured using a phototachometer, Cole-Parmer ${ }^{\mathbb{B}}$ Model 08199-41, 2.5-100,000 RPM.

Turbidity was measured using Thermo Scientific ${ }^{\circledR}$ AquaSensor ${ }^{\text {TM }}$ Turbidity system, coupled with an AV38 Local Display. The turbidity meter was installed downstream of the decanter, in the Aqueous Head Pot. 
Air flow measurements were made using the Kurz Air Flowmeter, Models 505-8-08, 505-9-00, and 505-9A-0, ranges from 0-25 SCFM.

Pre-test calibrations were performed on all the instrumentation per SRNL procedures. All instruments were calibrated to within manufacturer's stated tolerances. Additionally, the turbidity was calibrated once installed. The rotational speed of the contactors was measured using a calibrated non-contact tachometer.

\subsubsection{Data Acquisition System}

Signal processing and control was accomplished using a IBM compatible PC running National Instruments Labview ${ }^{\circledR}$ software. The signal hardware used included the following components:

SCXI-1000 4 slot chassis, with SCXI 1600 USB Control Module,

SCXI-1102B, 32 Channel T/C and Voltage Input Module, with SCXI-1303 Terminal Block, SCXI-1124, 6 Channel D to A converter for signal output, with SCXI-1325 Terminal Block, and SCXI-1161 General Purpose Relay Module, with SCXI-1324 Terminal Block.

A program was written using Labview ${ }^{\circledR}$ to read all the instruments and control several pieces of equipment, including the contactors and pumps.

\subsection{Solvent Composition/Preparation}

The solvent (50 gal) was prepared according to SRNL procedure ITS-0173, Rev. $0^{[10]}$ (see Appendix for reference information). The Isopar $\mathrm{L}^{\circledR}$ was first filtered to 0.2 microns prior to addition to the NGS recipe. Due to the limited MaxCalix availability, the NGS was prepared at $20 \mathrm{mM}$ MaxCalix instead of the planned concentration (50 $\mathrm{mM}$ MaxCalix) for use in $\mathrm{MCU} / \mathrm{SWPF}$.

Table 3-6. 20 mM MaxCalix NGS Recipe

\begin{tabular}{|c|c|c|c|}
\hline Component & $\begin{array}{c}\text { Concentration in } \\
\text { Isopar } \mathbf{L}^{\circledR}, \mathbf{M}\end{array}$ & $\mathbf{k g}$ & $\begin{array}{c}\text { Density } \\
(\mathbf{g} / \mathbf{m L} \mathbf{~ a t} \\
\mathbf{2 0} \mathbf{C})\end{array}$ \\
\hline MAXCalixC6 & 0.020 & 3.7 & \\
\hline CS-7B & 0.50 & 32.02 & \\
\hline LIX-79 guanidine & 0.003 & 0.230 & \\
\cline { 1 - 3 } IsoparL ${ }^{\circ}$ & Balance & $\begin{array}{c}\text { Balance } \\
(\sim 118.5)\end{array}$ & \\
\hline Composite & & & $\sim 0.795$ \\
\hline
\end{tabular}

The final density prior to testing was confirmed as $0.796 \mathrm{~g} / \mathrm{mL}$. This value was consistently achieved throughout testing, with a slight downward trend to a final density of $0.795 \mathrm{~g} / \mathrm{mL}$ obtained for Test $7 \mathrm{C}$, the last test of the test matrix. The change in density was within the measurement accuracy. The expected density (for $20 \mathrm{mM}$ MaxCalix) is $0.821 \mathrm{~g} / \mathrm{mL}$. This difference can be produced by a 2.6 vol \% ( $\sim 1.3$ gal) excess of Isopar $L^{\circledR}$. However, an inspection of the solvent-preparation data sheets identified no errors during solvent preparation to account for the lower-than-expected density. Although there is not explicit evidence to indicate it, perhaps significant quantities of Isopar $\mathrm{L}^{\circledR}$ were resident in process piping from shake-down testing. 


\subsection{Strip/Scrub/Salt Solution Compositions}

\subsubsection{Strip Solution}

The strip solution is a $0.010 \mathrm{M} \mathrm{H}_{3} \mathrm{BO}_{3}$ in de-ionized (DI) water solution prepared in SRNL. Specifically, 300 gal of DI water was added to a new clean 330-gal plastic container. To the container was added $702.14 \mathrm{~g}$ of $\mathrm{H}_{3} \mathrm{BO}_{3}$ which dissolved with DI water to produce a $108 \mathrm{mg} / \mathrm{L} \mathrm{B}$ concentration. A sample of the solution, Lab-ID: 11-2011, was analyzed by ICPES and found to contain $106 \mathrm{mg} / \mathrm{L}$ of $\mathrm{B}$. This result for boron is well within the analytical uncertainty of $10 \%$.

\subsubsection{Scrub Solution}

The scrub solution is $0.025 \mathrm{M} \mathrm{NaOH}$ in DI water that was prepared in SRNL. Specifically, $53 \mathrm{~kg}$ of DI water was added to a clean poly drum. To this drum was added $106 \mathrm{~g}$ of $50 \mathrm{wt} \% \mathrm{NaOH}$ solution. The contents were then mixed vigorously to yield a $0.025 \mathrm{M} \mathrm{NaOH}$ solution. No confirmatory analyses were made of the final solution.

\subsubsection{MCU Salt Simulant}

To support the MCU contactor and coalescer testing, SRNL with SRR approval developed a 5.6 M Na Simulant Salt Solution recipe (Table 3-7).

Table 3-7. 5.6 M Na Simulant Salt Solution Recipe

\begin{tabular}{|c|c|c|c|}
\hline \multicolumn{4}{|c|}{ Chemical Additions for 1200 gal } \\
\hline \begin{tabular}{|l} 
Batch Sheet \\
Chemical Name
\end{tabular} & $\begin{array}{l}\text { Chemical } \\
\text { Formula }\end{array}$ & $\begin{array}{l}\text { Weight } \\
\text { (lb) }\end{array}$ & MW \\
\hline Potassium Nitrate & $\mathrm{KNO}_{3}$ & 15.21 & 101.09 \\
\hline Sodium Hydroxide & $\mathrm{NaOH}$ & 1275.60 & 40 \\
\hline Sodium Nitrate & $\mathrm{NaNO}_{3}$ & 1003.07 & 84.98 \\
\hline Sodium Nitrite & $\mathrm{NaNO}_{2}$ & 345.79 & 68.98 \\
\hline Aluminum Nitrate hydrated & $\mathrm{Al}\left(\mathrm{NO}_{3}\right)_{3} * 9 \mathrm{H}_{2} \mathrm{O}$ & 1050.69 & 375.04 \\
\hline Sodium Carbonate hydrate & $\mathrm{Na}_{2} \mathrm{CO}_{3} * \mathrm{H}_{2} \mathrm{O}$ & 186.45 & 123.98 \\
\hline Sodium Sulfate & $\mathrm{Na}_{2} \mathrm{SO}_{4}$ & 199.14 & 142.02 \\
\hline Sodium Chloride & $\mathrm{NaCl}$ & 14.06 & 58.44 \\
\hline Sodium Fluoride & $\mathrm{NaF}$ & 11.84 & 41.99 \\
\hline Sodium Phosphate dibasic & $\mathrm{Na}_{2} \mathrm{HPO}_{4} * 7 \mathrm{H}_{2} \mathrm{O}$ & 18.81 & 268.01 \\
\hline Sodium Oxalate & $\mathrm{Na}_{2} \mathrm{C}_{2} \mathrm{O}_{4}$ & 10.74 & 133.98 \\
\hline Sodium Metasilicate hydrate & $\mathrm{Na}_{2} \mathrm{SiO}_{3} * 9 \mathrm{H}_{2} \mathrm{O}$ & 21.28 & 284.14 \\
\hline Sodium Molybdate dihydrate & $\mathrm{Na}_{2} \mathrm{MoO}_{4} * 2 \mathrm{H}_{2} \mathrm{O}$ & 0.171 & 241.92 \\
\hline DI Water & $\mathrm{H}_{2} \mathrm{O}$ & 8445.359 & 18.02 \\
\hline & & & \\
\hline & Total Mass $=$ & 12598.21 & lb \\
\hline & or & 5714.457 & $\mathrm{~kg}$ \\
\hline & Specific Gravity= & 1.258 & \\
\hline
\end{tabular}

A purchase requisition (3U2709) was initiated to order the Simulant Salt Solution for MCU testing from a vendor. Harrell Industries, Inc., was awarded (PO \#AC87217H) to provide 1200 gal of this solution. The 1200 gal was shipped from the vendor (on April 22, 2011) in five 275-gallon containers with a certificate of analysis (COA) and batch sheet. The SRNL Process Science Analytical Laboratory (PSAL) and Analytical Development (AD) analyzed samples to confirm that analyte concentrations were in accordance with recipe requirements except for low variances in carbonate and oxalate content. The analyses are provided in Table 3-8. 
Table 3-8. Analyses of Vendor-Provided 5.6 M Na Simulant Salt Solution

\begin{tabular}{|c|c|c|c|c|c|}
\hline \begin{tabular}{c|} 
COA \\
Analyte
\end{tabular} & \begin{tabular}{|l|} 
Target Molar \\
Concentration
\end{tabular} & $\begin{array}{l}\text { Harrell Industries } \\
\text { COA \#8525-01 }\end{array}$ & \begin{tabular}{|l|} 
Specification \\
Uncertainty
\end{tabular} & PSAL & $\mathrm{AD}$ \\
\hline $\mathrm{K}$ & 0.015 & $0.013 \mathrm{M}$ & $\pm 0.002 \mathrm{M}$ & $0.015 \mathrm{M}$ & \\
\hline $\mathrm{NO}_{3}$ & 2.030 & $2.03 \mathrm{M}$ & $+0.2 \mathrm{M}$ & $1.82 \mathrm{M}$ & \\
\hline $\mathrm{Na}$ & 5.539 & $5.42 \mathrm{M}$ & $\pm 0.55 \mathrm{M}$ & $5.61 \mathrm{M}$ & \\
\hline $\mathrm{NO}_{2}$ & 0.500 & $0.50 \mathrm{M}$ & $\pm 0.05 \mathrm{M}$ & $0.51 \mathrm{M}$ & \\
\hline $\mathrm{Al}$ & 0.280 & $0.26 \mathrm{M}$ & $+0.03 \mathrm{M}$ & $0.26 \mathrm{M}$ & \\
\hline free $\mathrm{OH}$ & 2.060 & $2.06 \mathrm{M}$ & $\pm 0.2 \mathrm{M}$ & & $\begin{array}{c}1.85 \mathrm{M} \\
(\text { Other Base }=0.34 \mathrm{M})\end{array}$ \\
\hline $\mathrm{CO}_{3}$ & 0.150 & $0.15 \mathrm{M}$ & $\pm 0.02 \mathrm{M}$ & & $0.040 \mathrm{M}$ \\
\hline $\mathrm{SO}_{4}$ & 0.140 & $0.14 \mathrm{M}$ & $\pm 0.02 \mathrm{M}$ & $0.13 \mathrm{M}$ & \\
\hline $\mathrm{Cl}$ & 0.024 & $0.024 \mathrm{M}$ & $\pm 0.002 \mathrm{M}$ & $<0.0028 \mathrm{M}$ & \\
\hline $\mathrm{F}$ & 0.028 & $0.028 \mathrm{M}$ & $\pm 0.003 \mathrm{M}$ & $<0.0053 \mathrm{M}$ & \\
\hline $\mathrm{C}_{2} \mathrm{O}_{4}$ & 0.008 & $0.008 \mathrm{M}$ & $+0.001 \mathrm{M}$ & $0.0038 \mathrm{M}$ & $0.0018 \mathrm{M}$ \\
\hline $\mathrm{Si}$ & 0.007 & $0.006 \mathrm{M}$ & $+0.001 \mathrm{M}$ & $0.0068 \mathrm{M}$ & \\
\hline Mo & 7.20E-05 & $7.50 \mathrm{E}-05 \mathrm{M}$ & $\pm 0.01 \mathrm{M}$ & & \\
\hline $\mathrm{PO}_{4}$ & 0.007 & $0.007 \mathrm{M}$ & $\pm 0.001 \mathrm{M}$ & $0.0089 \mathrm{M}$ & \\
\hline Cs & 0 & & & & 3.4E-07 M \\
\hline
\end{tabular}

Cesium was added to $\sim 80$ gal of the salt solution after receipt from Harrell Industries, Inc. The Cs was added as cesium nitrate $\left(\mathrm{CsNO}_{3}\right),>95 \%$ purity. The $\mathrm{CsNO}_{3}(34 \mathrm{~g})$ was dissolved in one liter or more of simulant salt solution and then added to enough simulant salt solution to produce 80 gal. Specifically, a minimum of $75 \mathrm{mg} / \mathrm{L}$ cesium was selected to match test conditions from the 2-cm contactor NGS tests. ${ }^{[3]}$ A sample of the simulant salt solution containing Cs was analyzed by ICPMS and found to contain $79 \mathrm{mg} / \mathrm{L}$ of Cs (mass 133). This result for Cs is well within the SRNL analytical uncertainty of $20 \%$.

\subsection{Analytical Methods}

\subsubsection{MicroTrac ${ }^{\mathrm{TM}}$ Droplet Size Measurements}

SRNL used droplet size analysis to quantify the efficacy of coalescer operations. To characterize the operations of the coalescer, SRNL analyzed the upstream and downstream droplet size distribution. To analyze the droplet size distribution, SRNL's Analytical Development (AD) used a MicroTrac ${ }^{\mathrm{TM}}$ S3500 particle size analyzer. This is the same equipment used in measuring droplet sizes during the 2004-2005 testing of the CSSX solvent at Wright Industries. ${ }^{[15]}$ To achieve results, the ADS used the MicroTrac ${ }^{\mathrm{TM}}$ S3500 in the following manner.

1. The instrument (S3500 with separate circulating control unit) is charged with approximately $300 \mathrm{~mL}$ of matrix-matched aqueous liquid after routine flushing of the machine is performed.

2. The S3500 provides a baseline reading of particles in the liquid. The count rate must be less than a given limit to determine that the instrument and fluid are clean and free of air bubbles.

3. Normally a few $\mathrm{mL}$ of sample is introduced into the circulating stream. Particles, droplets, or bubbles in the sample will immediately boost the count rate. Further sample is added to adjust the count rate to a new level specified by S3500 operating procedure.

4. Number-weighted count scans are recorded and averaged. 
5. The S3500 calculates volume-weighted particle distribution from the number-weighted data.

6. Results for the sample are printed in the form of tabulated percentages of particles less than machine-defined bin sizes, along with a bar graph of the levels in each bin.

An example of the data received is shown in Figure 3-6 from Test 7C.

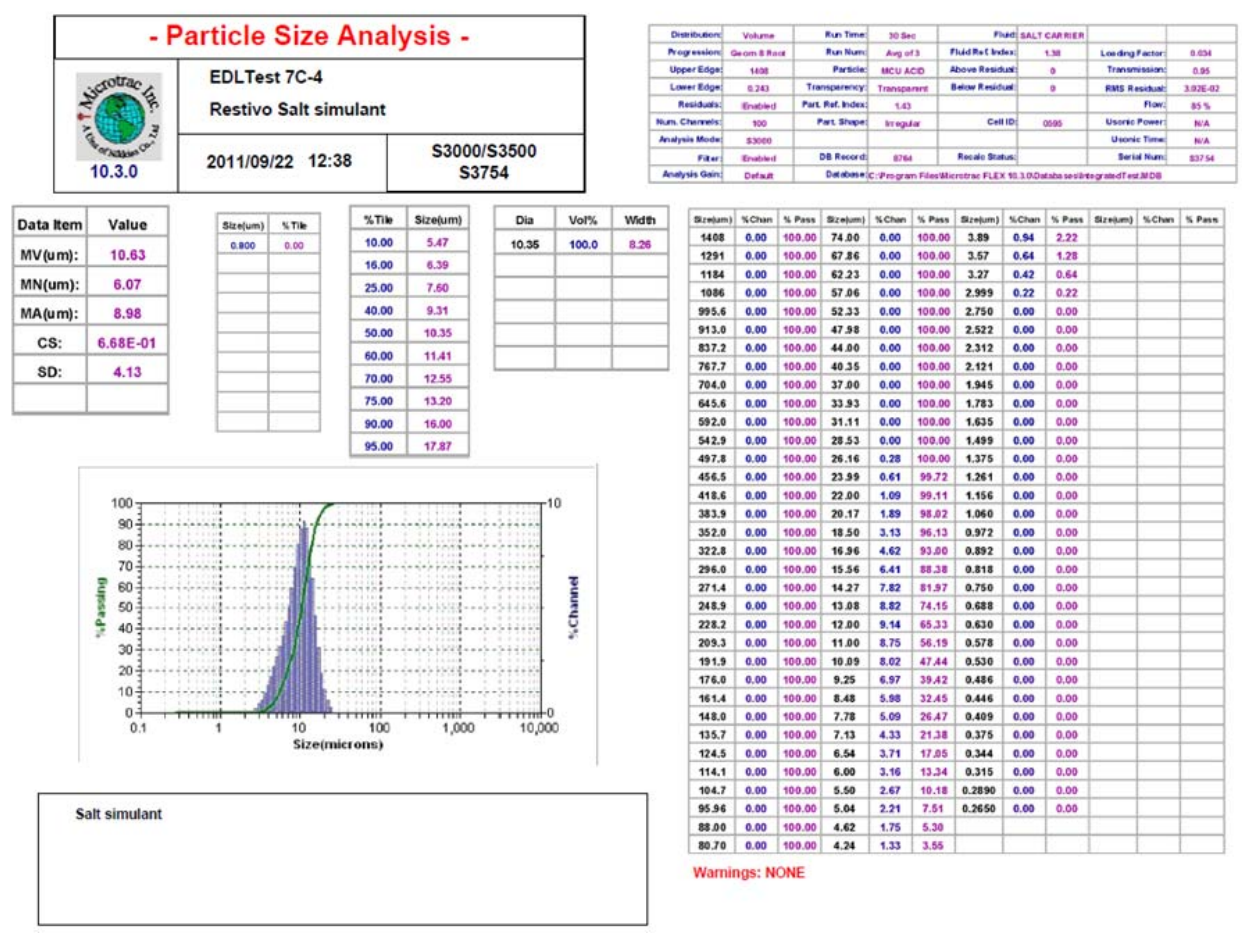

Figure 3-6. Sample of MicroTrac ${ }^{\mathrm{TM}}$ Data

\subsubsection{Polarized Light Microscopy}

An Olympus SZX12 microscope was selected for use in the MCU testing. It is a stereoscope with a PAX-IT camera that is driven by a laptop process computer. The lenses and stage were adapted by McCrone parts with polarizing capability. The calibration using a calibrated slide confirmed the capability of the microscope to resolve the expected 6 to 8 micron droplets of NGS potentially carried through the coalescer (Figure 3-7). The resolution of the calibration slide was determined to be 1 micron. 


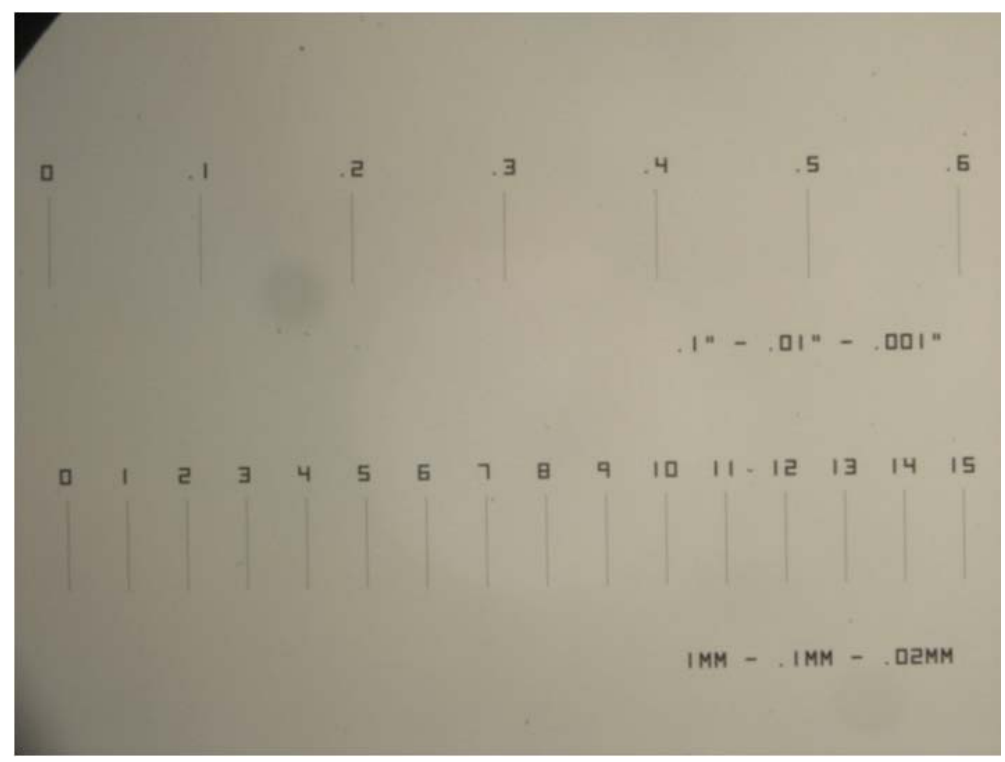

Figure 3-7. McCrone Calibration Slide Used for SZX12 Microscope

The microscope stage was replaced with a flow through slide designed by the SRNL Engineering Development Laboratory (EDL) and fabricated by the SRNL Machine Shop. A sample of aqueous solution and Isopar $\mathrm{L}^{\circledR}$ droplet mixture was flowed through the microscope slide from a beaker in a manner similar to the sampling for the pre- and post-coalescer flow during testing.

\subsubsection{ICPMS}

Inductively Coupled Plasma Mass Spectrometry (ICPMS) was used to determine the concentrations of mass-133 in samples from the mass-transfer tests. Mass-133 is solely attributed to ${ }^{133} \mathrm{Cs}$, so this method can be reliably used to determine the concentration of cesium in the sample. Aqueous samples were sent directly to ICPMS for analysis with no adjustment or dilution. Organic samples were sent first for digestion via a Parr Bomb, and the digestate sent directly to ICPMS. Any dilutions due to the digestion are already accounted for in the reported results.

The Plasma Quad II Radiological ICPMS manufactured by Fisons provides multi-element analyses of aqueous solutions based on the measurement of atomic species from their ions created in the plasma. Liquid samples are nebulized and the aerosol transported to an argon plasma. In the high temperature plasma, metallic species are ionized. The ions generated by the plasma enter the mass spectrometer through a sampling cone set near the end of the plasma. The ions are separated by a quadrapole mass filter and focused on an electron multiplier that measures pulse counts. The signal from the detector is amplified, measured, and processed by the detection electronics. These measurements are used to calibrate the instrument, perform sample analyses, and display spectra.

\subsubsection{SVOA}

The semi-volatile organic analysis (SVOA) method was used to determine the concentrations of Isopar $\mathrm{L}^{\circledR}$ and Modifier in aqueous samples. The typical sample size of $\sim 60 \mathrm{~mL}$ was sent to SVOA, and the entire sample was extracted with hexane. This protocol recovered the analytes into the hexane. The hexane solution was then distilled into a smaller volume and directly analyzed. One milliliter of hexane extract is spiked with phenyloctane internal standard, and then analyzed by Gas Chromatography with Flame Ionization Detector (GC - FID) to identify organic 
compounds in the extracts. Analytical separations were carried out on a Hewlett Packard 6890 gas chromatograph, equipped with a $25 \mathrm{~m}$ DB-5ms column, with $0.20 \mathrm{~mm}$ diameter and $0.33 \mu \mathrm{m}$ film thickness. Quantitation was performed using a flame ionization detector.

\subsubsection{HPLC}

An Agilent 1100 High Pressure Liquid Chromatography (HPLC) equipped with a photodiode array detector was used. The controlling computer was equipped with Agilent Chemstation 9.01 software. Samples were extracted with hexane $(\mathrm{O} / \mathrm{A}=0.25 / 1)$ by mixing on a vortex mixer. Reversed-phase chromatography was used for the extractant analysis and normal-phase chromatography was used for Modifier analysis.

\subsubsection{FTIR}

A ReactionView ${ }^{\circledR}$ spectrometer from REMSPEC was selected for measuring the insoluble and soluble organic concentrations of the aqueous streams in the at-line analyses. The unit consists of a cube type interferometer that modulated the infrared to a frequency range where the electronics (detector) is most sensitive. The modulated infrared beam was delivered to a $\mathrm{ZnS}$ crystal (shaped like a sharpened pencil) where the infrared beam bounced at least twice inside the crystal before being returned back to the spectrometer. The crystal was physically inserted into a pipe and through the actions of upstream valves; the crystal sampled the aqueous flow before the coalescer and after exiting the coalescer. The crystal was able to measure the aqueous stream (denser phase) return from the decanter. As the liquid flowed past the crystal, the liquid absorbs the small portion of the infrared beam that extend outside the crystal (due to an optical impedance mismatch between the crystal and the aqueous solution) as the infrared beam bounces inside the crystal. That adsorption contains the fingerprint of the organic components in the aqueous solution.

Since the organic adsorption of the infrared beam is small, data was collected for more than three minutes to obtain a signal to noise ratio of approximately 90 . Since infrared measurements are relative measurements, a spectrum of the aqueous stream (with no organic) was collected before each test. The concentration estimates for the Isopar $\mathrm{L}^{\circledR}$ and Modifier were obtained by integrating the area under their respective peaks. The peak at $1375 \mathrm{~cm}^{-1}$ was used to determine the Isopar $\mathrm{L}^{\circledR}$ concentration while the peak at $1510 \mathrm{~cm}^{-1}$ was used to determine the Modifier concentration. A calibration line (determined in early June 2011) was used to relate the peak area to concentration estimates (Figure 3-8). Infrared sampling coincided with other samplings (like for example, SVOA) to determine the accuracy of earlier calibration line such as the one shown below. Samples of spectra for the strip tests (Figure 3-9) and extraction tests (Figure 3-10) are included. Based on prior studies, the FTIR analytical uncertainty is approximately $15 \%$ for Isopar $^{\circledR} \mathrm{L}$ and $10 \%$ for Modifier. 

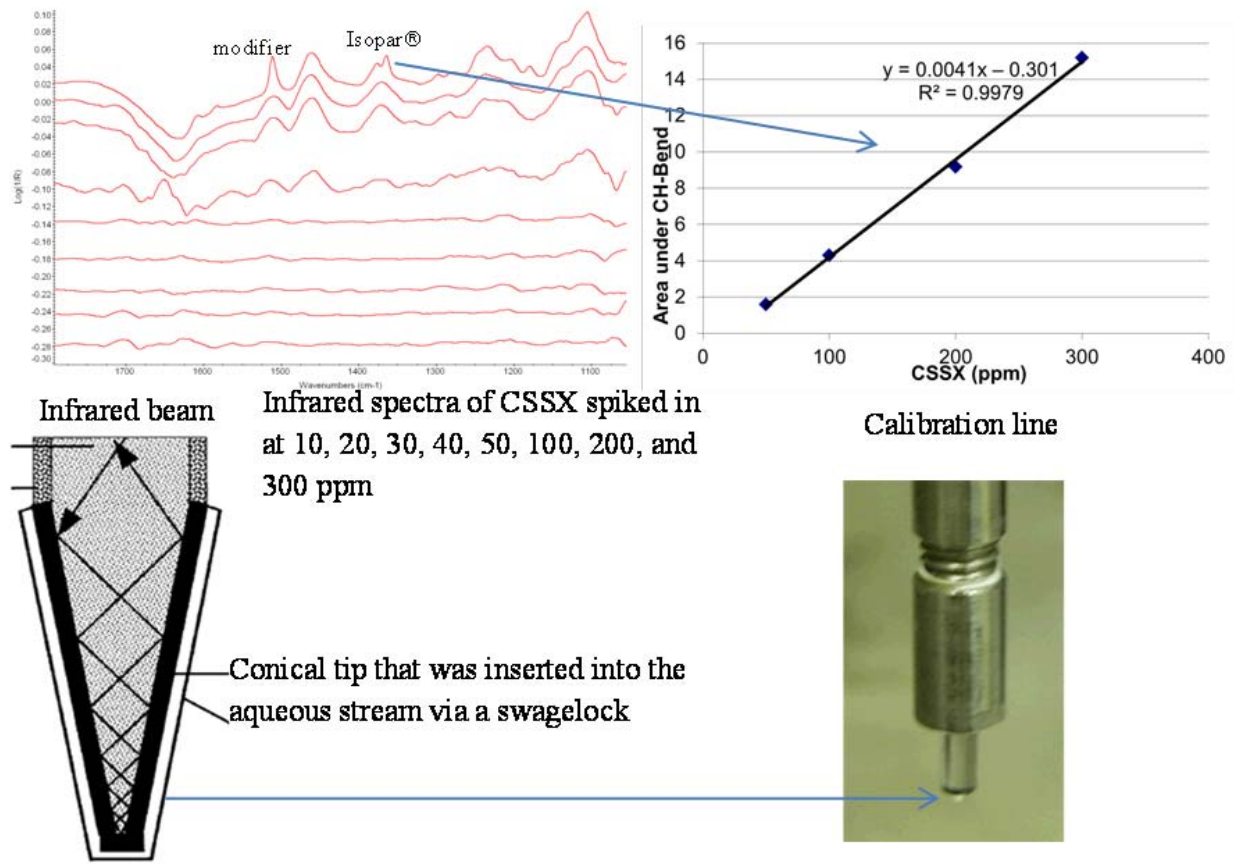

Figure 3-8. FTIR Background Information

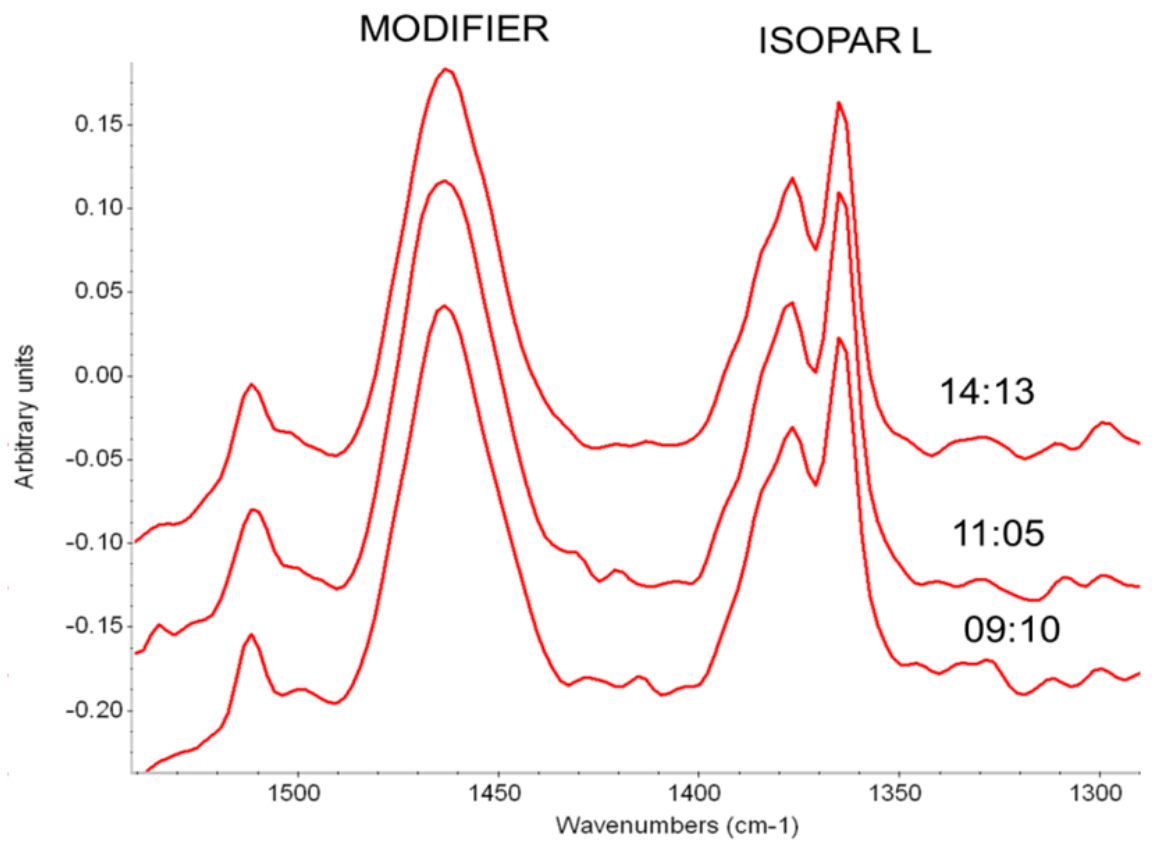

Figure 3-9. FTIR Spectra in $0.01 \mathrm{M} \mathrm{H}_{3} \mathrm{BO}_{3}$ Strip Solution 
SRNL-STI-2011-00695

Revision 0

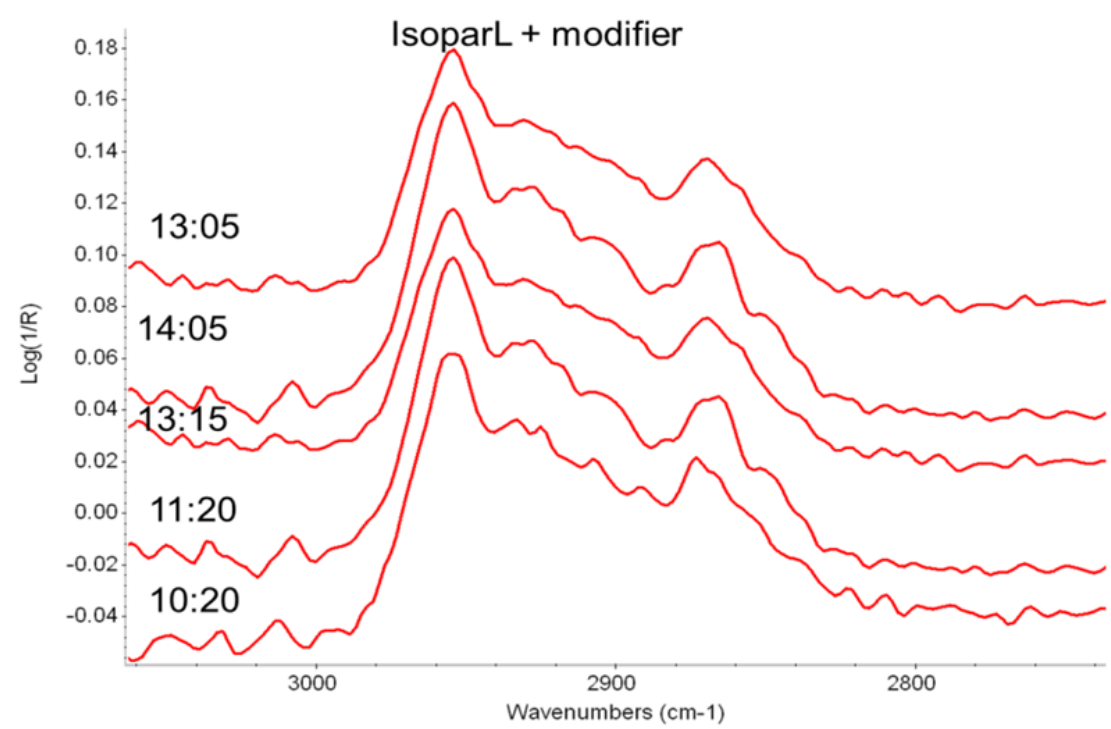

Figure 3-10. FTIR Spectra in 5.6 M Na Simulant Salt Solution

\subsection{Sampling Protocols}

\subsubsection{Mass Transfer Protocol}

During the mass transfer tests, samples were pulled from two distinct sets of sample points. Organic samples were pulled from valve V-7, while aqueous samples were pulled from valve V10. Portions of these samples were removed and sent for ICPMS analysis.

\subsubsection{Droplet Size Analysis Protocol}

The sample age was previously determined to be a critical factor in droplet size analysis. Organic material entrained in the aqueous phase will relatively quickly coalesce and rise to the top. To minimize data skew associated with this behavior, a sample time protocol was developed for all droplet size analysis. The time from the taking of a sample to the time the sample was placed into the MicroTrac ${ }^{\mathrm{TM}} \mathrm{S} 3500$ was procedurally controlled to $5 \mathrm{~min}$; prior Wright Industires and SRNL testing of contactors used this duration. ${ }^{[15]}$ When a sample was taken, a stop watch was started, and the sample was placed into the MicroTrac ${ }^{\text {TM }} \mathrm{S} 3500$ at exactly 5 min after the sample draw.

Pictures for microscopy using PLM were generally taken at times to correspond to MicroTrac ${ }^{\mathrm{TM}}$ analyses or FTIR data collection. There were times when the instrument was not available for collecting data and other times when report-quality pictures could not be obtained, so the data set for PLM is more limited than it is for MicroTrac ${ }^{\mathrm{TM}}$.

Still and video camera shots of the macroscopic performance of the coalescer were also obtained at random times throughout hydraulic testing. Although the pictures do not offer quantitative evidence of the coalescer performance, they show a distinct difference between the behavior of the strip and extraction coalescers.

\subsubsection{Solvent Concentration Analysis Protocol}

For the hydraulic tests, samples were pulled upstream of the coalescer from valve V-22 and downstream of the coalescer at valve V-25. Samples were collected in clean glass jars with Teflon $^{\mathrm{TM}}$ lids. The samples were sent to $\mathrm{AD}$ without delay and stored in a refrigerator before use. Samples for Tests 4A, 4B, 4C, 4D, and 5C were analyzed using SVOA within a few days of 
receipt in $\mathrm{AD}$. The samples for Tests $7 \mathrm{~A}, 7 \mathrm{~B}$, and $7 \mathrm{C}$ were analyzed by SVOA after multiple weeks passed. Because of the delay in analysis, the samples from Tests $7 \mathrm{~A}, 7 \mathrm{~B}$, and $7 \mathrm{C}$ were also analyzed using HPLC to determine Modifier content.

Note that the current testing design obtained samples not directly from the outlet of the contactors - as in prior SRNL and Wright Industries testing - but after an intermediate sampling tank. This design variance limits the ability to directly compare the data sets. The "stilling" tank was added to help facilitate air de-entrainment from the streams as well as to emulate a similar "accumulation" tank included in the MCU design.

\subsection{Results}

\subsection{Mass Transfer}

\subsubsection{Contactor Test Results}

A series of large-scale contactor tests examined the extraction, scrub and strip behavior of the solvent against the respective aqueous solutions. Given the test objectives and the limitations of solvent volume, the extraction, scrub, and strip experiments were operated individually with one stage. In each of the three sets of tests, SRNL examined the effects of the contactor speed and flow rate on the Cs distribution ratio. There were four extraction tests, two scrub tests, and six strip tests. Table 4-1 lists the experimental matrix.

Table 4-1. List of Cesium Mass-Transfer Tests

\begin{tabular}{|c|c|c|c|c|}
\hline $\begin{array}{c}\text { Test } \\
\text { ID }\end{array}$ & $\begin{array}{c}\text { Flow } \\
\text { Stream }\end{array}$ & $\begin{array}{c}\text { Contactor } \\
\text { Type }\end{array}$ & $\begin{array}{c}\text { Contactor } \\
\text { Rotor } \\
\text { Speed } \\
\text { (rpm) }\end{array}$ & $\begin{array}{c}\text { Aqueous/organic } \\
\text { Flow Rates } \\
\text { (gpm) }\end{array}$ \\
\hline 1A & Extraction & V10 & 1200 & $4 / 1$ \\
\hline 1B & Extraction & V10 & 1700 & $8 / 2$ \\
\hline 1C & Extraction & V10 & 1700 & $12 / 3$ \\
\hline 1D & Extraction & V10 & 1700 & $8.5 / 2.1$ \\
\hline 2A & Scrub & V5 & 1800 & $0.27 / 1$ \\
\hline 2B & Scrub & V5 & 1700 & $0.8 / 3$ \\
\hline 3A & Strip & V5 & 1800 & $0.27 / 1$ \\
\hline 3B & Strip & V5 & 2100 & $0.53 / 1$ \\
\hline 3C & Strip & V5 & 2100 & $0.80 / 3$ \\
\hline 3D & Strip & V5 & 2100 & $0.4 / 2$ \\
\hline 3E & Strip & V5 & 2100 & $0.28 / 2$ \\
\hline 3F & Strip & V5 & 2100 & $0.43 / 3$ \\
\hline
\end{tabular}

For each of the tests, we used the following protocol. Samples from both the organic and aqueous phases were removed at discrete intervals that corresponded to specific contactor volumes. A contactor volume is defined as the volume inside of the contactor rotor during operation. For the V5, the rotor volume is 0.6 gal, and for the V10, it is 6 gal. For example, in the extraction tests, we pulled samples at 6,7 , and 8 contactor volumes. Because the extraction tests used the V10, a sample collected after 6 contactor volumes corresponds to 36 gal passed through the contactor at the time of sampling.

The aqueous and organic samples were analyzed by ICPMS for Cs (mass 133). In the case of the organic samples, they were digested first via Parr Bomb. By dividing the Cs concentration for the organic phase by the Cs concentration in the aqueous phase, a Cs distribution ratio $[D(C s)]$ was calculated. For the extraction tests, the results are displayed in Table 4-2. 
Table 4-2. Extraction Mass-Transfer Test Results

\begin{tabular}{|c|c|c|c|}
\hline $\begin{array}{c}\text { Test } \\
\text { ID }\end{array}$ & $\begin{array}{c}\text { Contactor } \\
\text { Volumes When } \\
\text { Sampled }\end{array}$ & $\begin{array}{c}\text { Aqueous } \\
\text { Cs-133 } \\
(\mathrm{mg} / \mathrm{L})\end{array}$ & $\begin{array}{c}\text { Organic } \\
\text { Cs-133 } \\
(\mathrm{mg} / \mathrm{L})\end{array}$ \\
\hline 1A & Feed & 75.3 & 254 \\
\hline 1A & 6 & 14.3 & 268 \\
\hline 1A & 7 & 14.9 & 249 \\
\hline 1A & 8 & 14.9 & 248 \\
\hline 1B & Feed & 75.8 & 256 \\
\hline 1B & 6 & 15.6 & 246 \\
\hline 1B & 7 & 15.7 & 223 \\
\hline 1B & 8 & 15.7 & 235 \\
\hline 1C & Feed & 76.1 & 232 \\
\hline 1C & 6 & 16.9 & 230 \\
\hline 1C & 7 & 16.9 & 232 \\
\hline 1C & 8 & 16.9 & 224 \\
\hline 1D & Feed & 76.9 & \\
\hline 1D & 6 & 19.3 & \\
\hline 1D & 7 & 19.7 & \\
\hline 1D & 8 & 19.9 & \\
\hline
\end{tabular}

For the extraction tests, high values are desired to indicate that the solvent successfully removed the Cs from the aqueous phase. The results of the two scrub tests are listed in Table 4-3.

Table 4-3. Scrub Mass-Transfer Test Results

\begin{tabular}{|c|c|c|c|}
\hline Test ID & $\begin{array}{c}\text { Contactor } \\
\text { Volumes When } \\
\text { Sampled }\end{array}$ & $\begin{array}{c}\text { Aqueous } \\
\text { Cs-133 } \\
\text { (mg/L) }\end{array}$ & $\begin{array}{c}\text { Organic } \\
\text { Cs-133 } \\
\text { (mg/L) }\end{array}$ \\
\hline 2A & Feed & 0.0945 & 252 \\
\hline 2A & 6 & 135 & 187 \\
\hline 2A & 7 & 158 & 186 \\
\hline 2A & 8 & 168 & 200 \\
\hline 2A & 10 & 174 & 192 \\
\hline 2B & Feed & 0.101 & 183 \\
\hline 2B & 6 & 146 & 192 \\
\hline 2B & 7 & 165 & 107 \\
\hline 2B & 8 & 191 & 123 \\
\hline 2B & 10 & 205 & 104 \\
\hline
\end{tabular}

The results of the six strip tests are listed in Table 4-4. For stripping behavior, lower values are desired, indicating that the cesium in the solvent is being released into the strip aqueous stream. 
Table 4-4. Strip Mass Transfer Test Results

\begin{tabular}{|c|c|c|c|}
\hline Test ID & $\begin{array}{c}\text { Contactor } \\
\text { Volumes When } \\
\text { Sampled } \\
\end{array}$ & $\begin{array}{l}\text { Aqueous } \\
\text { Cs-133 } \\
(\mathrm{mg} / \mathrm{L}) \\
\end{array}$ & $\begin{array}{l}\text { Organic } \\
\text { Cs-133 } \\
(\mathrm{mg} / \mathrm{L}) \\
\end{array}$ \\
\hline $3 \mathrm{~A}$ & Feed & 0.0175 & 122 \\
\hline $3 \mathrm{~A}$ & 6 & 286 & 32.6 \\
\hline $3 \mathrm{~A}$ & 8 & 338 & 23.1 \\
\hline $3 \mathrm{~A}$ & 10 & 358 & 22.8 \\
\hline $3 \mathrm{~B}$ & Feed & 0.0217 & 107 \\
\hline $3 \mathrm{~B}$ & 6 & 283 & 17.1 \\
\hline $3 \mathrm{~B}$ & 8 & 324 & 16.6 \\
\hline $3 \mathrm{~B}$ & 10 & 352 & 15.5 \\
\hline $3 \mathrm{C}$ & Feed & 1.85 & 128 \\
\hline $3 \mathrm{C}$ & 6 & 279 & 16.9 \\
\hline $3 \mathrm{C}$ & 8 & 341 & 14.8 \\
\hline $3 \mathrm{C}$ & 10 & 369 & 19.7 \\
\hline $3 \mathrm{D}$ & Feed & 5.04 & 125 \\
\hline $3 \mathrm{D}$ & 6 & 302 & 23.1 \\
\hline $3 \mathrm{D}$ & 8 & 380 & 21.0 \\
\hline $3 \mathrm{D}$ & 10 & 415 & 18.4 \\
\hline $3 \mathrm{E}$ & Feed & 6.11 & 120 \\
\hline $3 \mathrm{E}$ & 6 & 266 & 32.8 \\
\hline $3 \mathrm{E}$ & 8 & 338 & 30.2 \\
\hline $3 \mathrm{E}$ & 10 & 432 & 31.7 \\
\hline $3 \mathrm{~F}$ & Feed & 6.73 & 119 \\
\hline $3 \mathrm{~F}$ & 6 & 250 & 28.3 \\
\hline $3 \mathrm{~F}$ & 8 & 328 & 27.9 \\
\hline $3 \mathrm{~F}$ & 10 & 425 & 29.6 \\
\hline
\end{tabular}

During mass-transfer tests, the temperatures of the feed solution were controlled. For extraction and scrub testing, the feed solutions were fed at $23 \pm 3{ }^{\circ} \mathrm{C}$. Strip test solutions were fed at $33 \pm 3{ }^{\circ} \mathrm{C}$. A typical mass-transfer temperature trace for extraction is shown in Figure 4-1. A similar temperature trace for stripping is provided in Figure 4-2. 


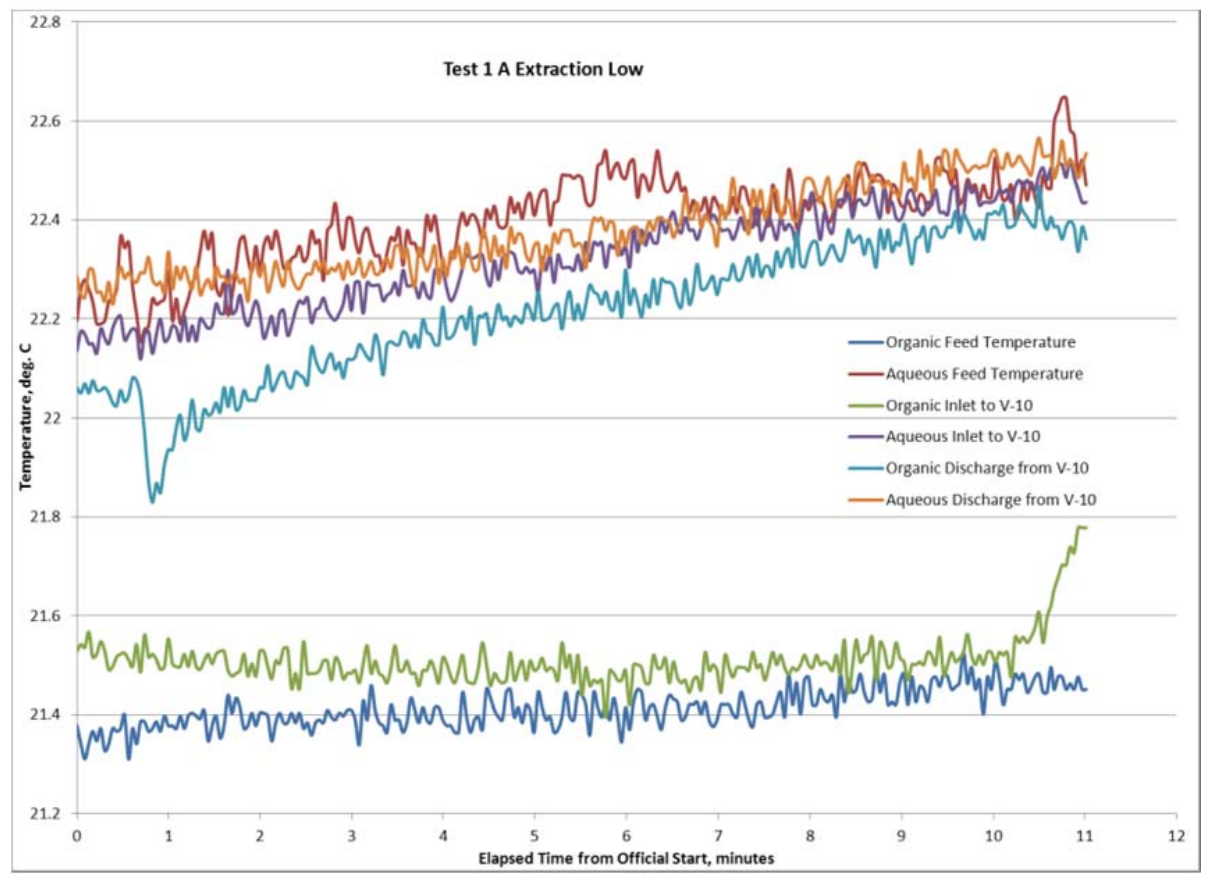

Figure 4-1. Temperature Profile for Mass-Transfer Extraction Test 1A

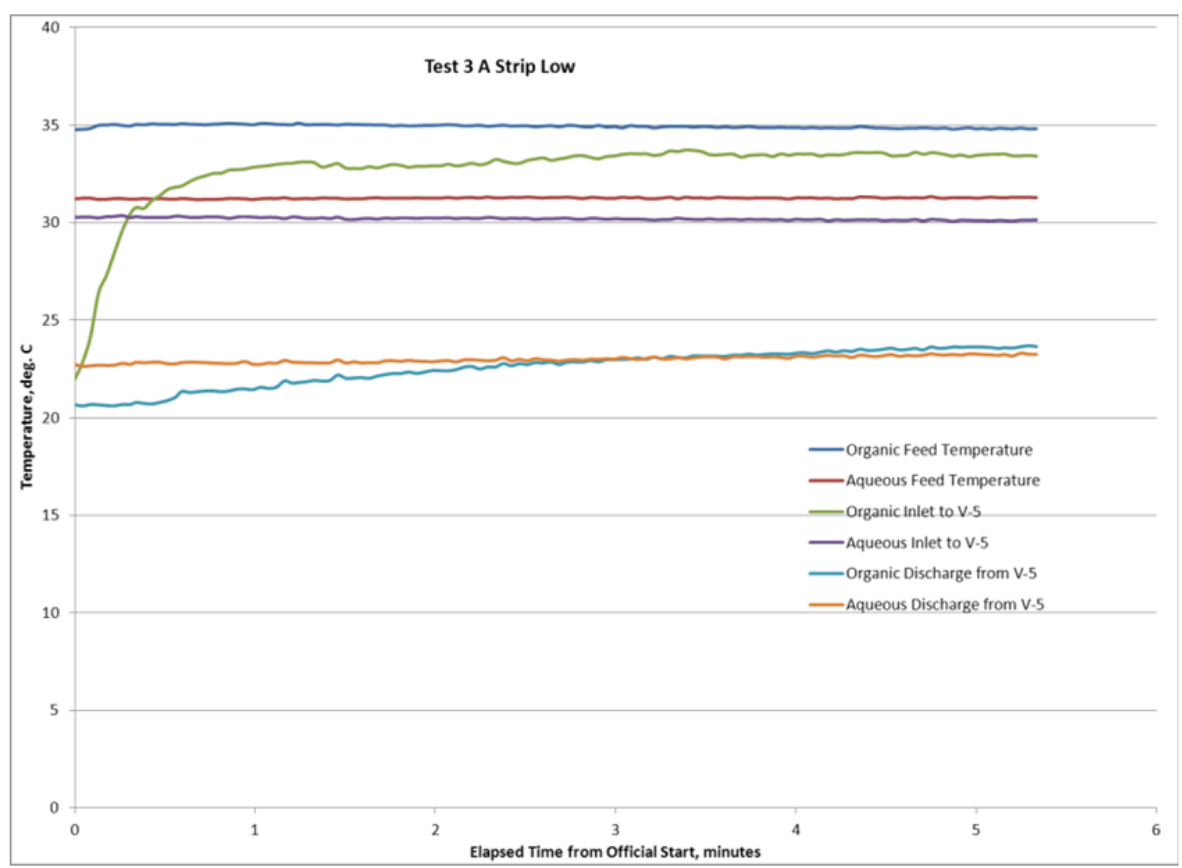

Figure 4-2. Temperature Profile for Mass-Transfer Strip Test 3A

\subsubsection{Equilibrium Sample Results}

In addition to the samples regularly pulled from the organic and aqueous streams, the researchers also removed samples at the end of Tests $1 \mathrm{~A}$ (extraction), 2A (scrub), and 3A (strip). In these cases, after the test was stopped, the contents of the contactor were drained into a clean large 
stainless steel pot. Samples from both the organic and aqueous phases were removed via electronic pipette and stored in a glass vial for future use.

From these archived samples, the researchers performed six contact tests (three tests in duplicate), each in a single glass vial. In the first two vials, the researchers added portions from the archived organic and aqueous phases from Test $1 \mathrm{~A}$ in a 1:4 volume ratio. In the third and fourth vials, the researchers added portions from the archived organic and aqueous phases from Test $2 \mathrm{~A}$ in a $3.75: 1$ volume ratio. In the fifth and sixth vials, the researchers added portions from the archived organic and aqueous phases from Test $3 \mathrm{~A}$ in a 3.75:1 volume ratio. The vials were put on a rotary mixer, and allowed to agitate for $24 \mathrm{~h}$. By allowing the samples to contact for an extended period of time, we can determine the final equilibrium point for the phases. At the end of that time, samples from each phase from each vial were sent for ICPMS for cesium analysis. The averages of the duplicate results are reported in Table 4-5. The values in parentheses are the standard deviations.

Table 4-5. Mass Transfer Equilibrium Concentrations

\begin{tabular}{|c|c|c|c|c|}
\hline Test ID & $\begin{array}{c}\text { Temperature } \\
\left({ }^{\circ} \mathrm{C}\right)\end{array}$ & Process Stream & $\begin{array}{c}\text { Aqueous } \\
\text { Cs-133 } \\
(\mathrm{mg} / \mathrm{L})\end{array}$ & $\begin{array}{c}\text { Organic } \\
\text { Cs-133 } \\
(\mathrm{mg} / \mathrm{L})\end{array}$ \\
\hline 1A & 23.7 & Extract & $14.1( \pm 0.0636)$ & $288( \pm 1.69)$ \\
\hline 2A & 23.7 & Scrub & $47.6( \pm 1.98)$ & $19.0( \pm 0.844)$ \\
\hline 3A & 23.7 & Strip & $215( \pm 23.5)$ & $9.55( \pm 2.14)$ \\
\hline \multicolumn{4}{|l}{ Analytical measurement uncertainty $=20 \%$} \\
\hline
\end{tabular}

\subsection{Hydraulic Performance Testing}

\subsubsection{Organic Carryover}

The extent of organic carryover into the strip effluent (SE) and decontaminated salt solution (DSS) streams is very important. Both streams eventually transfer to facilities that are subject to strict controls on the amount of entering combustibles and flammables. The DSS stream goes to Saltstone, and the SE stream goes to DWPF. Therefore, both streams are constantly monitored for the major carryover component, Isopar $\mathrm{L}^{\circledR}$. Isopar $\mathrm{L}^{\circledR}$ content over $64 \mathrm{mg} / \mathrm{L}$ in the SE stream, or $50 \mathrm{mg} / \mathrm{L}$ in the DSS triggers a shutdown at MCU. The process with NGS will be subject to the same controls, and thus it is important to determine if the NGS has a greater propensity for carryover.

To address these questions, hydraulic tests were performed for both extraction and stripping operations. Feed temperatures for the strip tests (Tests 4A, 4B, 4C, 4D, and 5C) were maintained at $33 \pm 3{ }^{\circ} \mathrm{C}$. Feed temperatures for the extraction tests (Tests $7 \mathrm{~A}, 7 \mathrm{~B}$, and $7 \mathrm{C}$ ) were provided at $23 \pm 3{ }^{\circ} \mathrm{C}$. Because scrub stages do not have a direct discharge stream to the downstream facilities, organic carryover for scrub testing is not necessary.

\subsubsection{SVOA/HPLC Analyses}

During the hydraulic tests, SVOA samples were routinely pulled throughout the duration of the hydraulic performance tests. Samples were collected from two different locations. For samples upstream of the coalescer ("pre"), the samples were removed via valve V-22; samples downstream from the coalescer ("post") were obtained using valve V-25. Some of these samples were sent forward for SVOA analysis for Isopar $\mathrm{L}^{\circledR}$ and Modifier and many others were archived. It was intended that the SVOA analysis be used to corroborate the data from an FTIR online monitoring system. The samples from Tests 4A, 4B, 4C, 4D and 5C were analyzed for SVOA 
alone (Table 4-6). Due to a delay in the time between sampling and analyses for Tests 7A, 7B, and 7C, samples from those tests were also analyzed using HPLC (Table 4-7).

Table 4-6. SVOA Data during Hydraulic Testing - Strip Operations

\begin{tabular}{|c|c|c|c|c|}
\hline Test ID & $\begin{array}{c}\text { Pre or Post } \\
\text { Coalescer }\end{array}$ & Sample Time & $\begin{array}{c}\text { Isopar L } \\
(\mathrm{mg} / \mathrm{L})\end{array}$ & $\begin{array}{c}\text { Modifier } \\
(\mathrm{mg} / \mathrm{L})\end{array}$ \\
\hline 4B & pre & $09: 00,9 / 7 / 11$ & 16 & 86 \\
\hline 4B & post & $09: 30,9 / 7 / 11$ & 23 & 100 \\
\hline 4B & pre & $10: 00,9 / 7 / 11$ & 10 & 63 \\
\hline 4C & pre & $09: 30,9 / 8 / 11$ & 1733 & 151 \\
\hline 4C & post & $10: 00,9 / 8 / 11$ & 1161 & 130 \\
\hline 4C & pre & $10: 30,9 / 8 / 11$ & 1336 & 135 \\
\hline 4C & post & $11: 00,9 / 8 / 11$ & 6786 & 328 \\
\hline 4C & pre & $11: 30,9 / 8 / 11$ & 1426 & 154 \\
\hline 4C & post & $12: 00,9 / 8 / 11$ & 1477 & 167 \\
\hline 4D & pre & $13: 06,9 / 12 / 11$ & 1891 & 189 \\
\hline 4D & post & $13: 06,9 / 12 / 11$ & 13 & 103 \\
\hline 4D & pre & $14: 06,9 / 12 / 11$ & 1885 & 204 \\
\hline 4D & post & $14: 06,9 / 12 / 11$ & 6013 & 366 \\
\hline 4D & pre & $15: 06,9 / 12 / 11$ & 1878 & 197 \\
\hline 4D & post & $15: 06,9 / 12 / 11$ & 12725 & 614 \\
\hline 4A & pre & $10: 00,9 / 13 / 11$ & 225 & 110 \\
\hline 4A & post & $10: 00,9 / 13 / 11$ & 14125 & 654 \\
\hline 4A & pre & $11: 00,9 / 13 / 11$ & 508 & 119 \\
\hline 4A & post & $11: 00,9 / 13 / 11$ & 431 & 130 \\
\hline 4A & pre & $12: 00,9 / 13 / 11$ & 318 & 113 \\
\hline 4A & post & $12: 00,9 / 13 / 11$ & 1818 & 206 \\
\hline 5C & pre & $10: 00,9 / 14 / 11$ & 788 & 166 \\
\hline 5C & post & $10: 00,9 / 14 / 11$ & 725 & 161 \\
\hline 5C & pre & $11: 00,9 / 14 / 11$ & 802 & 182 \\
\hline 5C & post & $11: 00,9 / 14 / 11$ & 146 & 115 \\
\hline 5C & pre & $12: 00,9 / 14 / 11$ & 793 & 165 \\
\hline 5C & post & $12: 00,9 / 14 / 11$ & 96 & 98 \\
\hline 5C & pre & $13: 00,9 / 14 / 11$ & 689 & 160 \\
\hline 5C & post & $13: 00,9 / 14 / 11$ & 344 & 126 \\
\hline 5C & pre & $14: 00,9 / 14 / 11$ & 787 & 170 \\
\hline 5C & post & $14: 00,9 / 14 / 11$ & 36871 & 1575 \\
\hline & & & & \\
\hline
\end{tabular}


Table 4-7. SVOA/HPLC Data during Hydraulic Testing - Extraction Operations

\begin{tabular}{|c|c|c|c|c|c|}
\hline Test ID & $\begin{array}{l}\text { Pre or Post } \\
\text { Coalescer? }\end{array}$ & Sample Time & $\begin{array}{c}\text { SVOA } \\
\text { Isopar L }{ }^{\circledR} \\
(\mathrm{mg} / \mathrm{L})\end{array}$ & $\begin{array}{l}\text { SVOA } \\
\text { Modifier } \\
(\mathrm{mg} / \mathrm{L})\end{array}$ & $\begin{array}{c}\text { HPLC } \\
\text { Modifier } \\
(\mathrm{mg} / \mathrm{L})\end{array}$ \\
\hline $7 \mathrm{~A}$ & Pre & $9: 30,9 / 19 / 11$ & 93 & 73 & \\
\hline $7 \mathrm{~A}$ & Post & $10: 15,9 / 19 / 11$ & 1085 & 294 & \\
\hline $7 \mathrm{~A}$ & Pre & $11: 30,9 / 19 / 11$ & 161 & 50 & 43 \\
\hline $7 \mathrm{~A}$ & Post & $12: 15,9 / 19 / 11$ & 597 & 217 & 161 \\
\hline $7 \mathrm{~A}$ & Pre & $13: 00,9 / 19 / 11$ & 113 & 53 & \\
\hline $7 \mathrm{~A}$ & Post & $13: 45,9 / 19 / 11$ & 1744 & 628 & \\
\hline $7 \mathrm{~B}$ & Pre & $11: 15,9 / 20 / 11$ & 261 & 75 & \\
\hline $7 \mathrm{~B}$ & Post & $12: 00,9 / 20 / 11$ & 474 & 134 & \\
\hline $7 \mathrm{~B}$ & Pre & $12: 45,9 / 20 / 11$ & 361 & 98 & 77 \\
\hline $7 \mathrm{~B}$ & Post & $13: 30,9 / 20 / 11$ & 1820 & 449 & 345 \\
\hline $7 \mathrm{~B}$ & Pre & $14: 15,9 / 20 / 11$ & 220 & 123 & \\
\hline $7 \mathrm{~B}$ & Post & $15: 00,9 / 20 / 11$ & 2130 & 675 & \\
\hline $7 \mathrm{C}$ & Pre & $10: 00,9 / 22 / 11$ & 388 & 155 & \\
\hline $7 \mathrm{C}$ & Post & $10: 45,9 / 22 / 11$ & 1145 & 360 & \\
\hline $7 \mathrm{C}$ & Pre & $11: 30,9 / 22 / 11$ & 225 & 150 & 99 \\
\hline $7 \mathrm{C}$ & Post & $12: 15,9 / 22 / 11$ & 1208 & 375 & 246 \\
\hline $7 \mathrm{C}$ & Pre & $13: 00,9 / 22 / 11$ & 375 & 140 & \\
\hline $7 \mathrm{C}$ & Post & $13: 45,9 / 22 / 11$ & 492 & 232 & \\
\hline
\end{tabular}

\subsubsection{Online FTIR Analyses}

During hydraulic testing, FTIR analyses of the aqueous solution pre- and post-coalescer were conducted. To provide a point of comparison with the SVOA and HPLC data (Table 4-6 and Table 4-7), FTIR data were tabulated at nearly the same times that SVOA samples were collected. (The grab sample for the offline analyses was collected and then immediately - within seconds -afterward the valves actuated to allow FTIR analyses. FTIR spectra were collected for several minutes.) Additional analyses of solutions downstream of the process decanter are also provided for comparison with the pre- and post-coalescer data. The FTIR data are listed in Table 4-8. 
Table 4-8. FTIR Data during Hydraulic Testing

\begin{tabular}{|c|c|c|c|c|c|c|c|c|}
\hline Test 4B & pre & post & pre & post & pre & post & decanter & \\
\hline MicroTrac Sample & 5 & 6 & 7 & 8 & 9 & 10 & & \\
\hline Isopar L (mg/L) & 606 & 516 & 550 & 621 & & 514 & 610 & \\
\hline Modifier (mg/L) & 230 & 220 & 214 & 270 & & 227 & 244 & \\
\hline Test 4C & pre & post & pre & post & pre & post & decanter & decanter \\
\hline MicroTrac Sample & 1 & 2 & 3 & 4 & 5 & 6 & & \\
\hline Isopar L (mg/L) & 400 & 211 & 387 & 371 & 364 & 349 & 375 & 396 \\
\hline Modifier (mg/L) & 106 & 110 & 103 & 95 & 94 & 93 & 103 & 95 \\
\hline
\end{tabular}

\begin{tabular}{|l|c|c|c|c|c|c|}
\hline Test 4D & pre & post & pre & post & pre & decanter \\
\hline MicroTrac Sample & 5 & 6 & 7 & 8 & 9 & \\
\hline Isopar L $(\mathrm{mg} / \mathrm{L})$ & 487 & 522 & 533 & 506 & 518 & 573 \\
\hline Modifier $(\mathrm{mg} / \mathrm{L})$ & 137 & 108 & 144 & 130 & 139 & 148 \\
\hline
\end{tabular}

\begin{tabular}{|l|c|c|c|c|c|c|c|c|c|}
\hline Test 4A & pre & post & pre & post & pre & post & decanter & decanter & decanter \\
\hline MicroTrac Sample & 1 & 2 & 3 & 4 & 5 & 6 & & & \\
\hline Isopar L (mg/L) & 1298 & 1359 & 1289 & 1269 & 1305 & 1287 & 1331 & 1321 & 1301 \\
\hline Modifier (mg/L) & 342 & 347 & 370 & 358 & 463 & 442 & 370 & 420 & 359 \\
\hline
\end{tabular}

\begin{tabular}{|l|c|c|c|c|c|c|c|c|c|c|}
\hline Test 5C & pre & post & pre & post & pre & post & pre & post & decanter & decanter \\
\hline MicroTrac Sample & 1 & 2 & 3 & 4 & 5 & 6 & 7 & 8 & & \\
\hline Isopar L (mg/L) & 1323 & 1369 & 1304 & 1327 & 1323 & 1325 & 1322 & 1387 & 1370 & 1297 \\
\hline Modifier (mg/L) & 346 & 323 & 328 & 395 & 346 & 466 & 442 & 446 & 362 & 454 \\
\hline
\end{tabular}

\begin{tabular}{|l|c|c|c|c|c|c|c|}
\hline Test 7B & pre & post & pre & post & pre & post & decanter \\
\hline MicroTrac Sample & 1 & 2 & 3 & 4 & 5 & 6 & \\
\hline Isopar L (mg/L) & 247 & 211 & 357 & 325 & 353 & 359 & 313 \\
\hline Modifier (mg/L) & 11 & 6 & 63 & 54 & 51 & 39 & 17 \\
\hline
\end{tabular}

\begin{tabular}{|l|c|c|c|c|c|c|}
\hline Test 7C & pre & post & pre & post & pre & post \\
\hline MicroTrac Sample & 1 & 2 & 3 & 4 & 5 & 6 \\
\hline Isopar L (mg/L) & 60 & 70 & 71 & 72 & 88 & 72 \\
\hline Modifier (mg/L) & & & & & \\
\hline
\end{tabular}

\subsubsection{System Performance Data}

\subsubsection{System Pressure}

System pressure was measured using instrument PE-13, a Rosemount ${ }^{\circledR} 1144 \mathrm{G}$ pressure transducer located downstream of the aqueous pump. The sensing lines to the pressure transducer were bled prior to the initial testing, and after every aqueous fluid change out. The pressure data are given below in Figure 4-3and Figure 4-4. A moving average of 50 points for each test is provided to facilitate trend determinations. 


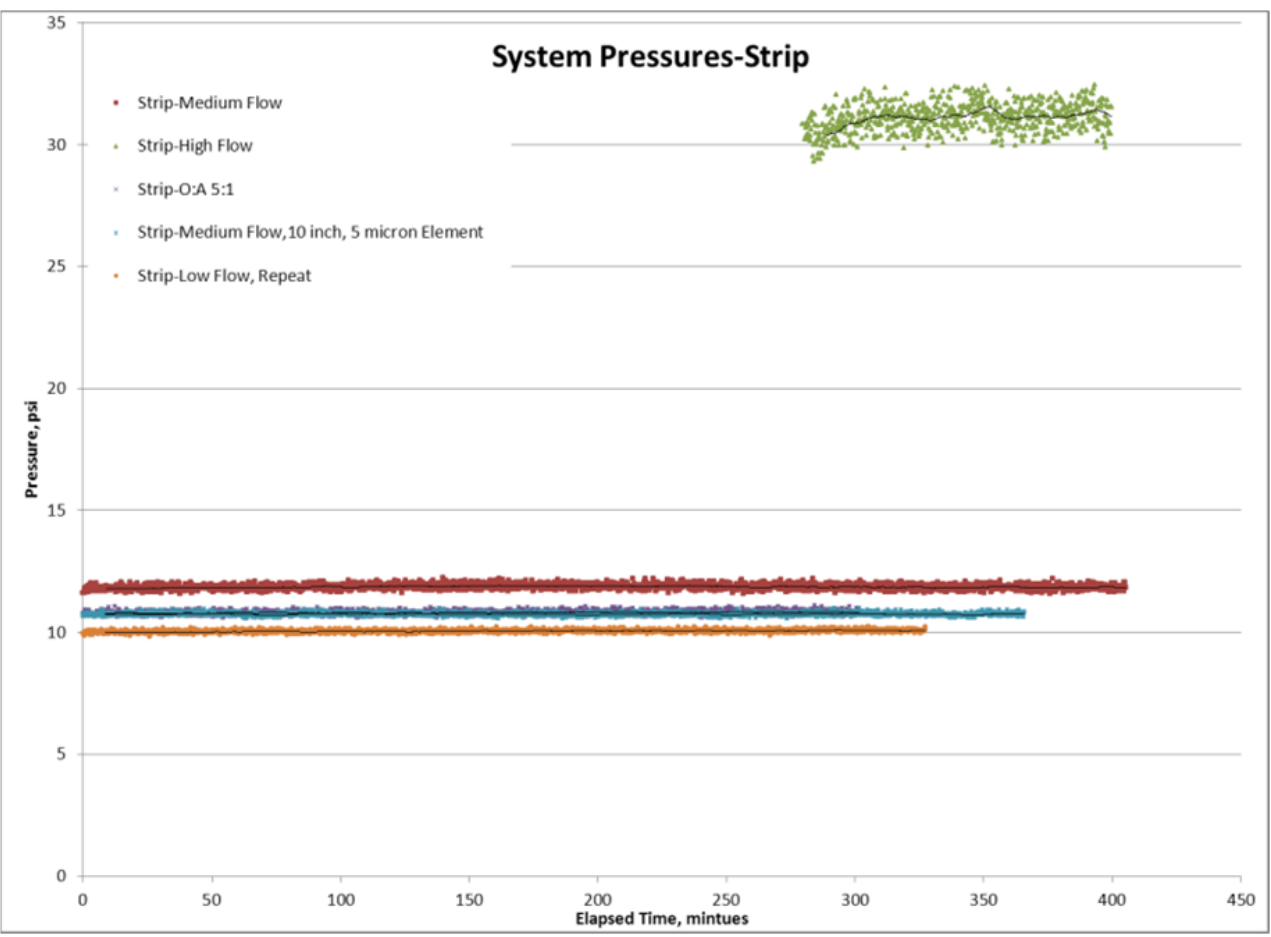

Figure 4-3. System Pressures for Hydraulic Strip Runs.

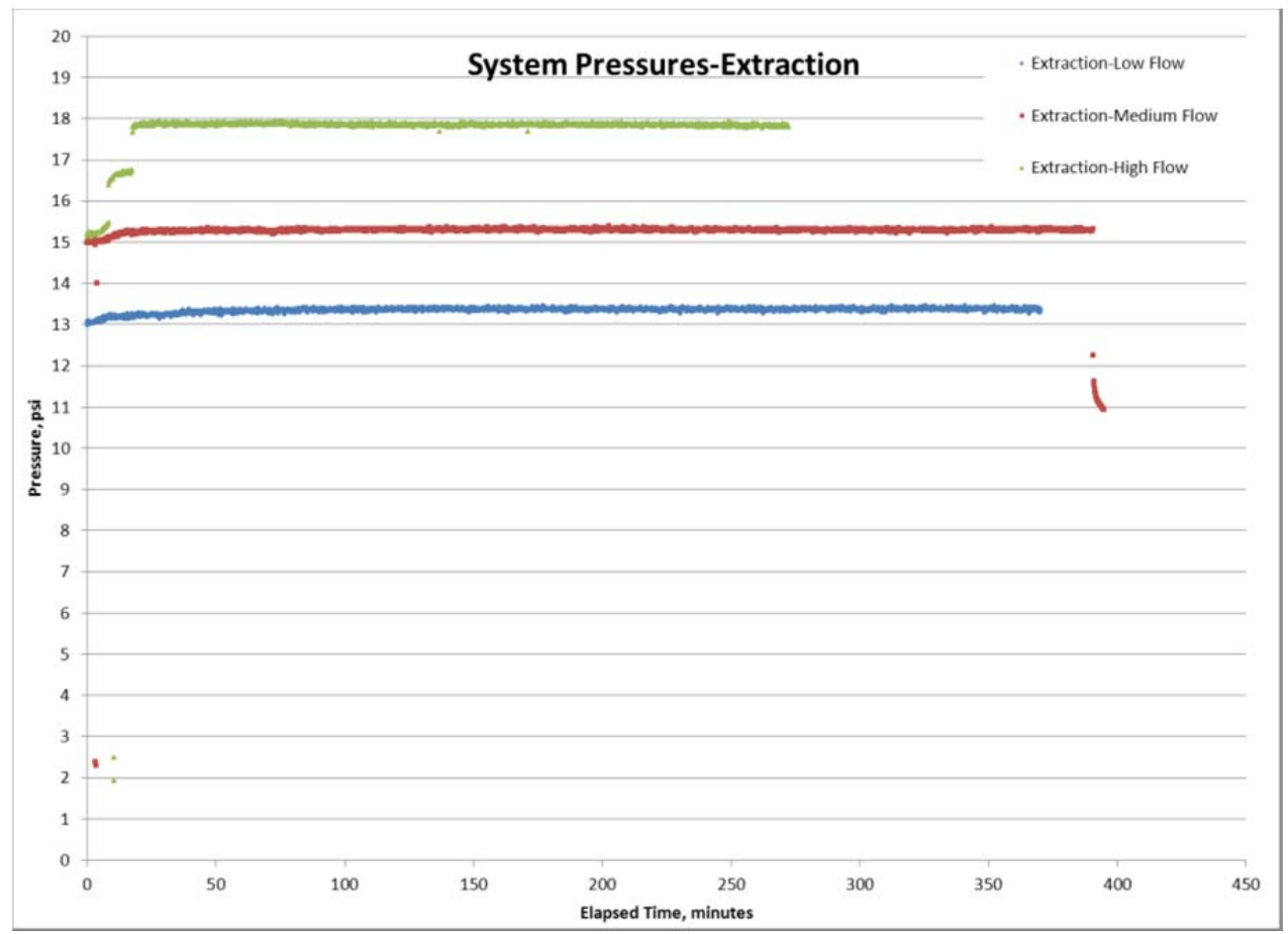

Figure 4-4. System Pressures for Hydraulic Extraction Runs

The increased system pressure associated with Test $4 \mathrm{C}$, high flow strip, may be the result of the sensing line being previously closed prior to operation. Towards the end of Test $4 \mathrm{C}$, it was noticed that the logging switch on the DAS was not turned on. The switch was subsequently 
turned on 279 min into testing. All other pressures correlate well with the calculated hydrostatic pressure developed due to the height of the Aqueous Head Pot.

\subsubsection{Coalescer Pressure Drops}

Pressure drop across the coalescer was measured using dPE12, a Rosemount ${ }^{\circledR} 1151 \mathrm{DP} \mathrm{dP}$ gauge. MCU typically measures the pressure drop across the coalescer as a function of total gallons pumped (Figure 4-5 for strip tests and Figure 4-6 for extraction tests).

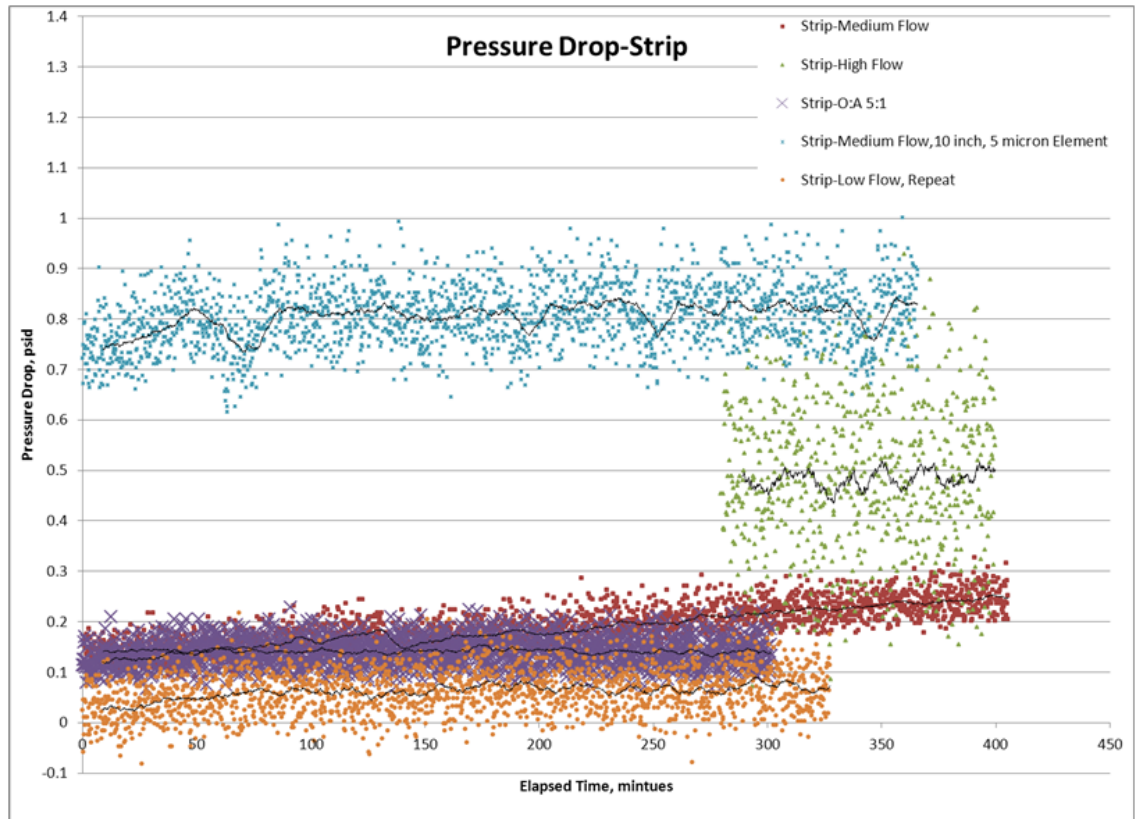

Figure 4-5. Coalescer Pressure Drop-Hydraulic Strip Runs.

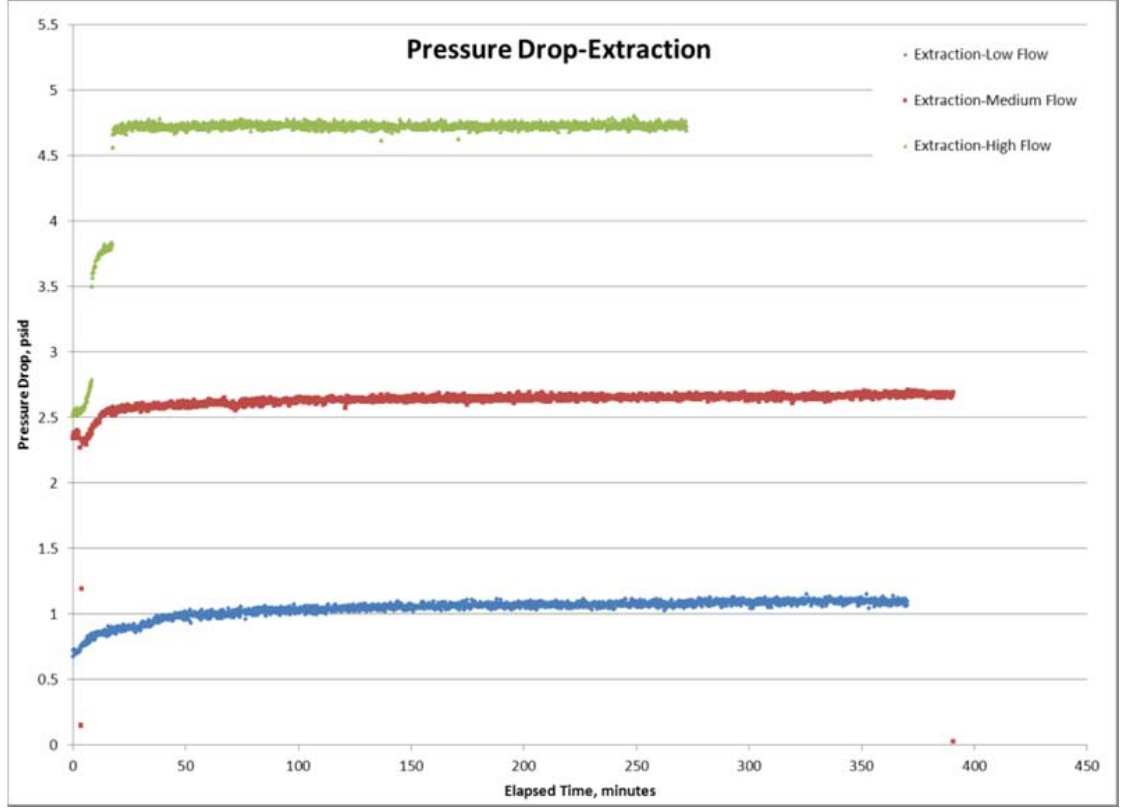

Figure 4-6. Coalescer Pressure Drop-Hydraulic Extraction Runs. 


\subsubsection{Hydraulic Temperatures}

A representative hydraulic temperature trace for stripping tests is shown below in Figure 4-7. A representative temperature trace for extraction hydraulic testing is provided in Figure 4-8.

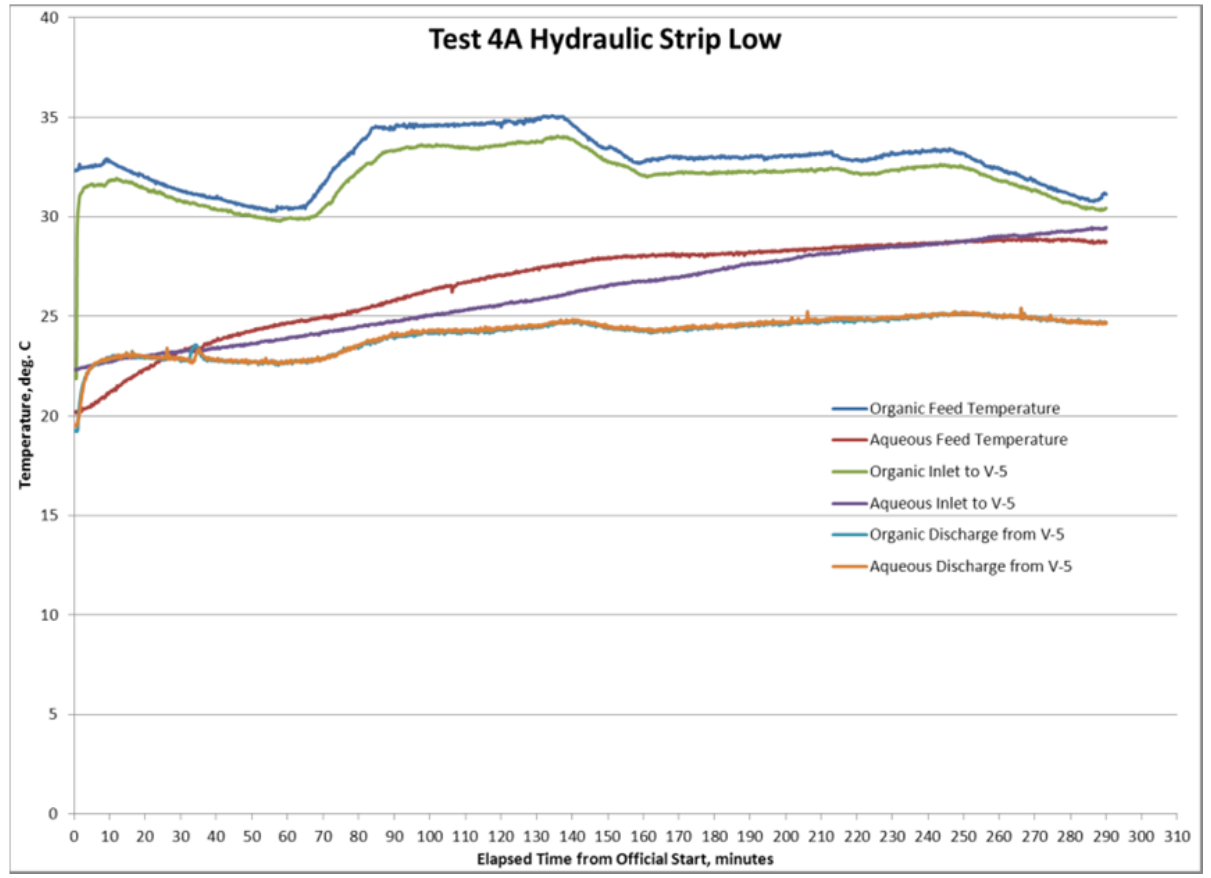

Figure 4-7. Temperature Trace for Hydraulic Strip Test 4A

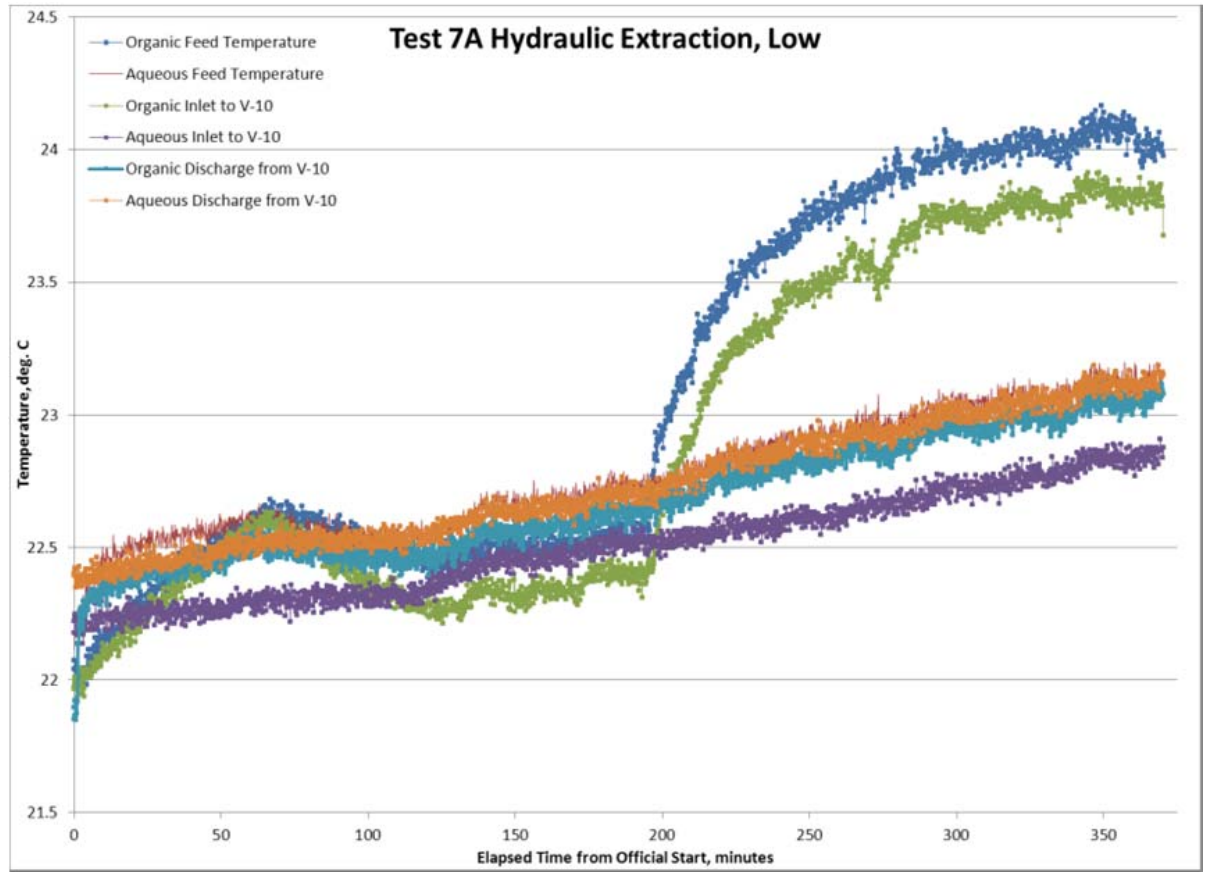

Figure 4-8. Temperature Trace for Hydraulic Extraction Test 7A 


\subsubsection{Online Turbidity}

SRNL installed an on-line turbidity meter to measure the turbidity of the aqueous phase over time. The turbidity of the aqueous phase during testing is shown below in Figure 4-9 for stripping tests and Figure 4-10 for extraction tests.

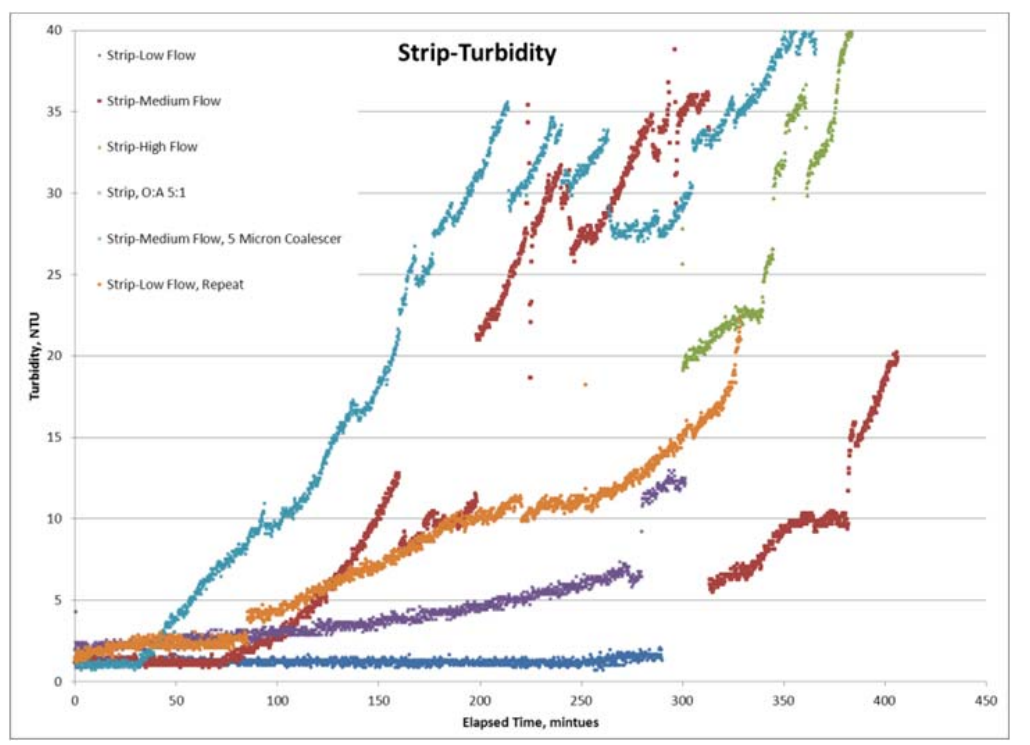

Figure 4-9. Turbidity at Aqueous Head Pot-Hydraulic Strip Tests

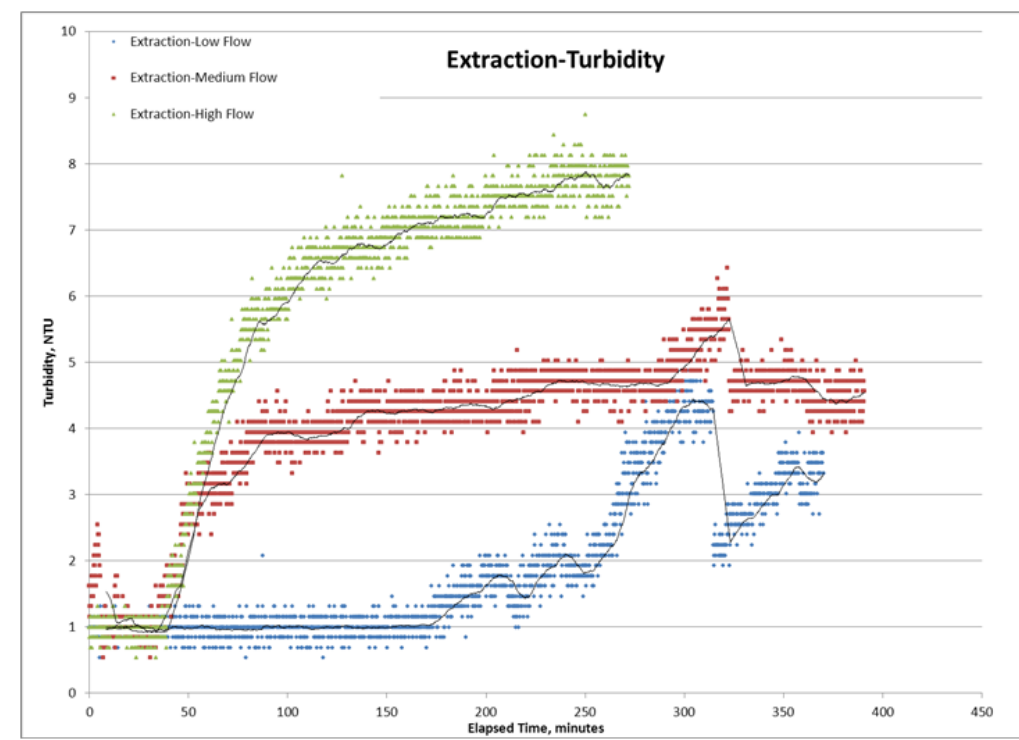

Figure 4-10. Turbidity at Aqueous Head Pot-Hydraulic Extraction Runs

\subsection{Coalescer Performance Data}

\subsubsection{Droplet Size by MicroTrac ${ }^{\mathrm{TM}}$}

The MicroTrac ${ }^{\text {TM }}$ data have been tabulated (Table 4-9, Table 4-10, and Table 4-11). The data reported are mean diameters (in $\mu \mathrm{m}$ ) as a function of volume distribution. The MicroTrac ${ }^{\mathrm{TM}}$ data reports were configured to report droplet diameters at the following percentiles: 10, 16, 25, 40, 50, $60,70,75,90$, and 95 . For the sake of this report, only the 10, 25, 50, 75, and 90 percentiles are 
tabulated. Also provided in the tables are calculations of the change in particle size at the $50^{\text {th }}$ percentile between the post-coalescer sample and the previous pre-coalescer sample.

The table is also configured in a manner to provide feedback regarding the sample loading index for the analysis. The loading index is a semi-quantitative analysis by the MicroTrac ${ }^{\mathrm{TM}}$ of the amount of analyte in the sample. It also provides an index regarding whether an optimal amount of sample was provided for the MicroTrac ${ }^{\mathrm{TM}}$ analysis. Low loading indices are identified (highlighted in the tables) to indicate that the data set is out of the preferred operating window for the MicroTrac ${ }^{\mathrm{TM}}$. 
Table 4-9. MicroTrac ${ }^{\mathrm{TM}}$ Data for Strip Tests 4B, 4C, and 4D

\begin{tabular}{|c|c|c|c|c|c|c|c|c|c|c|c|c|}
\hline Test 4B & pre & post & pre & post & pre & post & pre & post & pre & post & pre & post \\
\hline Sample & 1 & 2 & 3 & 4 & 5 & 6 & 7 & 8 & 9 & 10 & 11 & 12 \\
\hline Percentile & $(\mu \mathrm{m})$ & $(\mu \mathrm{m})$ & $(\mu \mathrm{m})$ & $(\mu \mathrm{m})$ & $(\mu \mathrm{m})$ & $(\mu \mathrm{m})$ & $(\mu \mathrm{m})$ & $(\mu \mathrm{m})$ & $(\mu \mathrm{m})$ & $(\mu \mathrm{m})$ & $(\mu \mathrm{m})$ & $(\mu \mathrm{m})$ \\
\hline 10 & 2.328 & 1.639 & 2.210 & 2.677 & 2.279 & 1.973 & 2.457 & 3.76 & 2.348 & 3.54 & 2.703 & 4.31 \\
\hline 25 & 3.27 & 1.722 & 3.37 & 3.12 & 3.47 & 2.801 & 4.67 & 5.30 & 3.70 & 4.27 & 4.23 & 5.09 \\
\hline 50 & 4.93 & 1.839 & 6.03 & 4.05 & 6.09 & 5.33 & 8.60 & 9.32 & 6.78 & 13.32 & 7.46 & 6.34 \\
\hline 75 & 6.97 & 1.984 & 9.01 & 8.68 & 9.25 & 8.61 & 11.75 & 16.50 & 10.08 & 16.22 & 10.17 & 8.94 \\
\hline 90 & 8.99 & 2.140 & 12.22 & 9.92 & 12.74 & 10.58 & 15.23 & 63.75 & 13.64 & 69.11 & 12.54 & 62.99 \\
\hline 50 pctl increase & & $-63 \%$ & & $-33 \%$ & & $-12 \%$ & & $8 \%$ & & $96 \%$ & & $-15 \%$ \\
\hline
\end{tabular}

\begin{tabular}{|c|c|c|c|c|c|c|c|c|c|c|c|c|}
\hline Test 4C & pre & post & pre & post & pre & post & pre & post & pre & post & pre & post \\
\hline Sample & 1 & 2 & 3 & 4 & 5 & 6 & 7 & 8 & 9 & 10 & 11 & 12 \\
\hline Percentile & $(\mu \mathrm{m})$ & $(\mu \mathrm{m})$ & $(\mu \mathrm{m})$ & $(\mu \mathrm{m})$ & $(\mu \mathrm{m})$ & $(\mu \mathrm{m})$ & $(\mu \mathrm{m})$ & $(\mu \mathrm{m})$ & $(\mu \mathrm{m})$ & $(\mu \mathrm{m})$ & $(\mu \mathrm{m})$ & $(\mu \mathrm{m})$ \\
\hline 10 & 2.412 & 1.672 & 2.091 & 0.718 & 2.259 & 2.585 & 2.282 & 2.404 & 3.00 & 2.392 & 2.294 & 3.47 \\
\hline 25 & 2.954 & 2.061 & 2.772 & 1.591 & 3.28 & 5.45 & 3.22 & 4.37 & 3.74 & 3.70 & 3.42 & 4.38 \\
\hline 50 & 3.69 & 2.479 & 3.65 & 3.26 & 5.05 & 9.43 & 4.56 & 7.59 & 4.74 & 6.33 & 5.72 & 6.06 \\
\hline 75 & 4.58 & 2.931 & 4.75 & 5.09 & 7.42 & 12.55 & 6.26 & 10.64 & 6.04 & 8.97 & 8.46 & 7.59 \\
\hline 90 & 5.49 & 3.37 & 6.01 & 6.34 & 10.10 & 16.06 & 8.31 & 16.47 & 7.63 & 11.89 & 11.49 & 8.88 \\
\hline 50 pctl increase & & $-33 \%$ & & $-11 \%$ & & $87 \%$ & & $66 \%$ & & $34 \%$ & & $6 \%$ \\
\hline
\end{tabular}

\begin{tabular}{|c|c|c|c|c|c|c|c|c|c|c|}
\hline Test 4D & pre & post & pre & post & pre & post & pre & post & pre & post \\
\hline Sample & 1 & 2 & 3 & 4 & 5 & 6 & 7 & 8 & 9 & 10 \\
\hline Percentile & $(\mu \mathrm{m})$ & $(\mu \mathrm{m})$ & $(\mu \mathrm{m})$ & $(\mu \mathrm{m})$ & $(\mu \mathrm{m})$ & $(\mu \mathrm{m})$ & $(\mu \mathrm{m})$ & $(\mu \mathrm{m})$ & $(\mu \mathrm{m})$ & $(\mu \mathrm{m})$ \\
\hline 10 & 2.280 & 2.356 & 2.765 & 2.683 & 2.138 & 0.988 & 1.959 & 5.76 & 2.178 & 7.39 \\
\hline 25 & 3.28 & 4.21 & 4.64 & 6.93 & 3.11 & 1.719 & 2.799 & 9.27 & 3.19 & 10.94 \\
\hline 50 & 6.76 & 7.35 & 7.23 & 9.28 & 5.36 & 3.08 & 4.33 & 11.73 & 5.53 & 13.80 \\
\hline 75 & 8.67 & 9.99 & 9.73 & 11.18 & 8.23 & 5.10 & 6.61 & 14.52 & 8.77 & 17.05 \\
\hline 90 & 10.13 & 19.78 & 11.30 & 13.08 & 11.09 & 6.33 & 9.19 & 17.93 & 12.19 & 21.10 \\
\hline $50 \mathrm{pctl}$ increase & & $9 \%$ & & $28 \%$ & & $-43 \%$ & & $171 \%$ & & $150 \%$ \\
\hline
\end{tabular}


Table 4-10. MicroTrac ${ }^{\mathrm{TM}}$ Data for Strip Tests $4 \mathrm{~A}$ and $5 \mathrm{C}$

\begin{tabular}{|l|c|c|c|c|c|c|}
\hline Test 4A & pre & post & pre & post & pre & post \\
\hline Sample & 1 & 2 & 3 & 4 & 5 & 6 \\
\hline Perce ntile & $(\mu \mathbf{m})$ & $(\mu \mathbf{m})$ & $(\mu \mathbf{m})$ & $(\mu \mathbf{m})$ & $\mathbf{( \mu \mathbf { m } )}$ & $\mathbf{( \mu \mathbf { m } )}$ \\
\hline 10 & 1.879 & 6.1 & 2.134 & 2.616 & 2.121 & 2.831 \\
\hline 25 & 2.637 & 9.21 & 3.13 & 6.25 & 3.11 & 4.62 \\
\hline 50 & 4.05 & 11.48 & 5.76 & 9.33 & 5.45 & 7.47 \\
\hline 75 & 5.83 & 14.06 & 8.72 & 12.21 & 8.46 & 9.41 \\
\hline 90 & 7.43 & 17.18 & 11.60 & 15.90 & 11.81 & 11.03 \\
\hline 50 pctl increase & & $183 \%$ & & $62 \%$ & & $37 \%$ \\
\hline
\end{tabular}

\begin{tabular}{|c|c|c|c|c|c|c|c|c|c|c|c|c|}
\hline Test 5C & pre & post & pre & post & pre & post & pre & post & pre & post & pre & post \\
\hline Sample & 1 & 2 & 3 & 4 & 5 & 6 & 7 & 8 & 9 & 10 & 11 & 12 \\
\hline Percentile & $(\mu \mathrm{m})$ & $(\mu \mathrm{m})$ & $(\mu \mathrm{m})$ & $(\mu \mathrm{m})$ & $(\mu \mathrm{m})$ & $(\mu \mathrm{m})$ & $(\mu \mathrm{m})$ & $(\mu \mathrm{m})$ & $(\mu \mathrm{m})$ & $(\mu \mathrm{m})$ & $(\mu \mathrm{m})$ & $(\mu \mathrm{m})$ \\
\hline 10 & 2.198 & 1.788 & 2.435 & 1.945 & 2.330 & 2.306 & 2.295 & 4.68 & 3.19 & 4.09 & 4.35 & 4.06 \\
\hline 25 & 3.02 & 2.508 & 4.33 & 2.521 & 3.50 & 3.05 & 3.59 & 9.13 & 5.88 & 8.91 & 6.38 & 9.06 \\
\hline 50 & 4.40 & 4.84 & 8.34 & 4.02 & 6.35 & 4.36 & 6.89 & 11.74 & 9.15 & 11.76 & 9.96 & 12.62 \\
\hline 75 & 6.12 & 9.87 & 11.48 & 7.52 & 10.00 & 6.89 & 10.36 & 14.62 & 12.01 & 14.69 & 14.41 & 16.26 \\
\hline 90 & 7.84 & 13.02 & 14.83 & 11.28 & 15.25 & 17.45 & 14.00 & 18.19 & 15.02 & 18.10 & 58.08 & 20.52 \\
\hline 50 pctl increase & & $10 \%$ & & $-52 \%$ & & $-31 \%$ & & $70 \%$ & & $29 \%$ & & $27 \%$ \\
\hline
\end{tabular}


Table 4-11. MicroTrac ${ }^{\mathrm{TM}}$ Data for Extraction Tests 7A, 7B, and 7C

\begin{tabular}{|l|c|c|c|c|c|c|c|c|}
\hline Test 7A & pre & post & pre & post & pre & post & pre & post \\
\hline Sample & 1 & 2 & 3 & 4 & 5 & 6 & 7 & 8 \\
\hline Percentile & $(\mu \mathbf{m})$ & $(\mu \mathbf{m})$ & $(\mu \mathbf{m})$ & $\mathbf{( \mu \mathbf { m } )}$ & $(\mu \mathbf{m})$ & $(\mu \mathbf{m})$ & $(\mu \mathbf{m})$ & $(\mu \mathbf{m})$ \\
\hline 10 & 5.04 & 4.63 & 5.71 & 4.68 & 4.97 & 5.08 & 5.45 & 5.14 \\
\hline 25 & 6.74 & 7.28 & 7.45 & 7.35 & 6.66 & 7.31 & 6.86 & 7.30 \\
\hline 50 & 8.86 & 11.05 & 9.45 & 11.25 & 8.76 & 10.05 & 8.57 & 9.95 \\
\hline 75 & 11.31 & 14.41 & 11.50 & 14.66 & 11.14 & 12.99 & 10.44 & 12.62 \\
\hline 90 & 14.13 & 17.85 & 13.47 & 18.06 & 13.73 & 16.35 & 12.34 & 15.32 \\
\hline 50 pctl increase & & $25 \%$ & & $19 \%$ & & $15 \%$ & & $16 \%$ \\
\hline
\end{tabular}

\begin{tabular}{|l|c|c|c|c|c|c|c|c|}
\hline Test 7B & pre & post & pre & post & pre & post & pre & post \\
\hline Sample & 1 & 2 & 3 & 4 & 5 & 6 & 7 & 8 \\
\hline Perce ntile & $(\mu \mathbf{m})$ & $\mathbf{(} \boldsymbol{m} \mathbf{m})$ & $\mathbf{(} \boldsymbol{\mathbf { m }})$ & $\mathbf{( \mu \mathbf { m } )}$ & $\mathbf{( \mu \mathbf { m } )}$ & $\mathbf{( \mu \mathbf { m } )}$ & $\mathbf{( \mu \mathbf { m } )}$ & $(\mu \mathbf{m})$ \\
\hline 10 & 5.59 & 4.84 & 5.17 & 4.99 & 5.37 & 4.88 & 5.36 & 5.09 \\
\hline 25 & 7.38 & 7.41 & 7.31 & 7.40 & 7.32 & 7.61 & 7.38 & 7.34 \\
\hline 50 & 9.37 & 10.89 & 9.89 & 10.50 & 9.67 & 11.35 & 9.72 & 10.16 \\
\hline 75 & 11.32 & 14.34 & 12.67 & 13.58 & 12.01 & 14.79 & 12.15 & 13.02 \\
\hline 90 & 13.09 & 18.14 & 15.77 & 16.75 & 14.20 & 18.42 & 14.66 & 15.99 \\
\hline 50 pctl increase & & $16 \%$ & & $6 \%$ & & $17 \%$ & & $5 \%$ \\
\hline
\end{tabular}

\begin{tabular}{|l|c|c|c|c|c|c|}
\hline Test 7C & pre & post & pre & post & pre & post \\
\hline Sample & 1 & 2 & 3 & 4 & 5 & 6 \\
\hline Percentile & $(\mu \mathbf{m})$ & $(\mu \mathbf{m})$ & $(\mu \mathbf{m})$ & $(\mu \mathbf{m})$ & $(\mu \mathbf{m})$ & $(\mu \mathbf{m})$ \\
\hline 10 & 5.08 & 5.43 & 5.60 & 5.47 & 5.22 & 5.50 \\
\hline 25 & 6.97 & 7.66 & 7.40 & 7.60 & 7.11 & 7.91 \\
\hline 50 & 9.34 & 10.68 & 9.48 & 10.35 & 9.34 & 11.13 \\
\hline 75 & 11.68 & 13.78 & 11.62 & 13.20 & 11.77 & 14.49 \\
\hline 90 & 13.89 & 16.80 & 13.69 & 16.00 & 14.35 & 17.92 \\
\hline 50 pctl increase & & $14 \%$ & & $9 \%$ & & $19 \%$ \\
\hline
\end{tabular}




\subsubsection{Droplet Size by PLM}

PLM was operational and provided satisfactory pictures for three of the hydraulic tests. Two pictures each from three tests - Test $4 \mathrm{C}$ (Figure 4-11), Test 5C (Figure 4-12), and Test 7A (Figure 4-13) - have been provided with a description of which MicroTrac ${ }^{\mathrm{TM}}$ sample corresponds to the picture. The circles with the thick refraction edges are air bubbles versus the smaller thin-wall circles which are Isopar $\mathrm{L}^{\circledR}$.

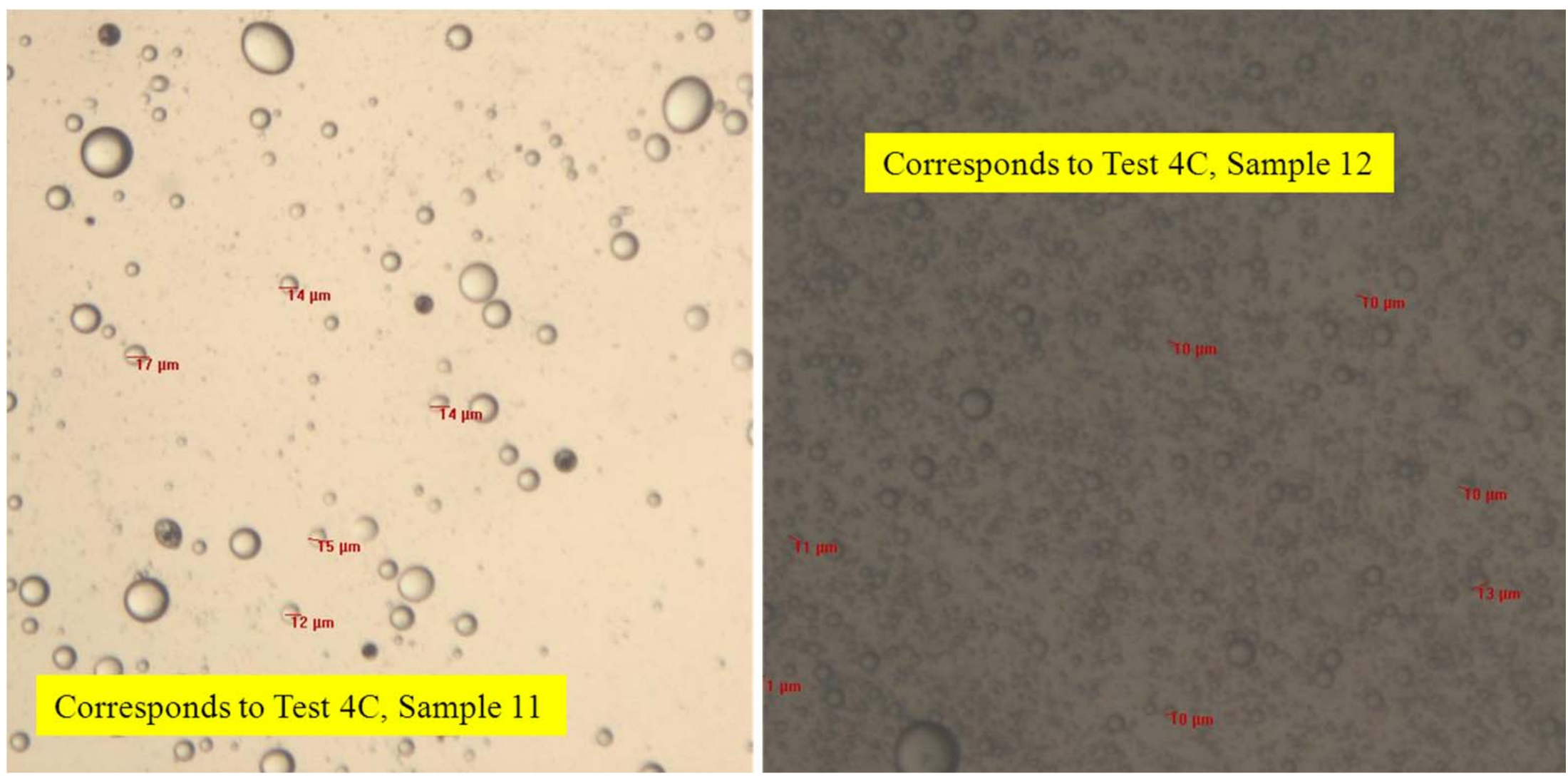

Figure 4-11. Polarized Light Microscopy Pictures for Test 4C 


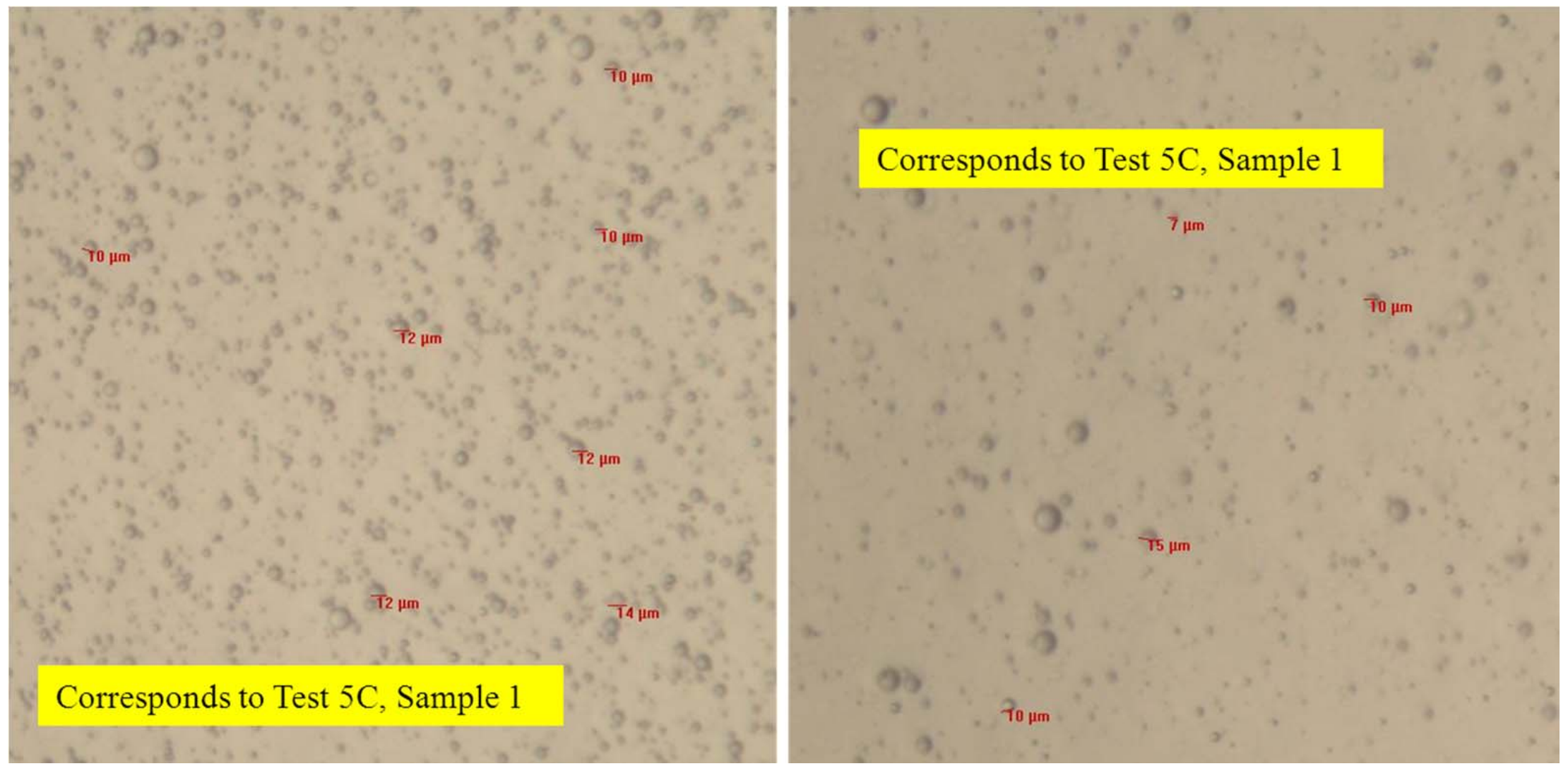

Figure 4-12. Polarized Light Microscopy Pictures for Test 5C 


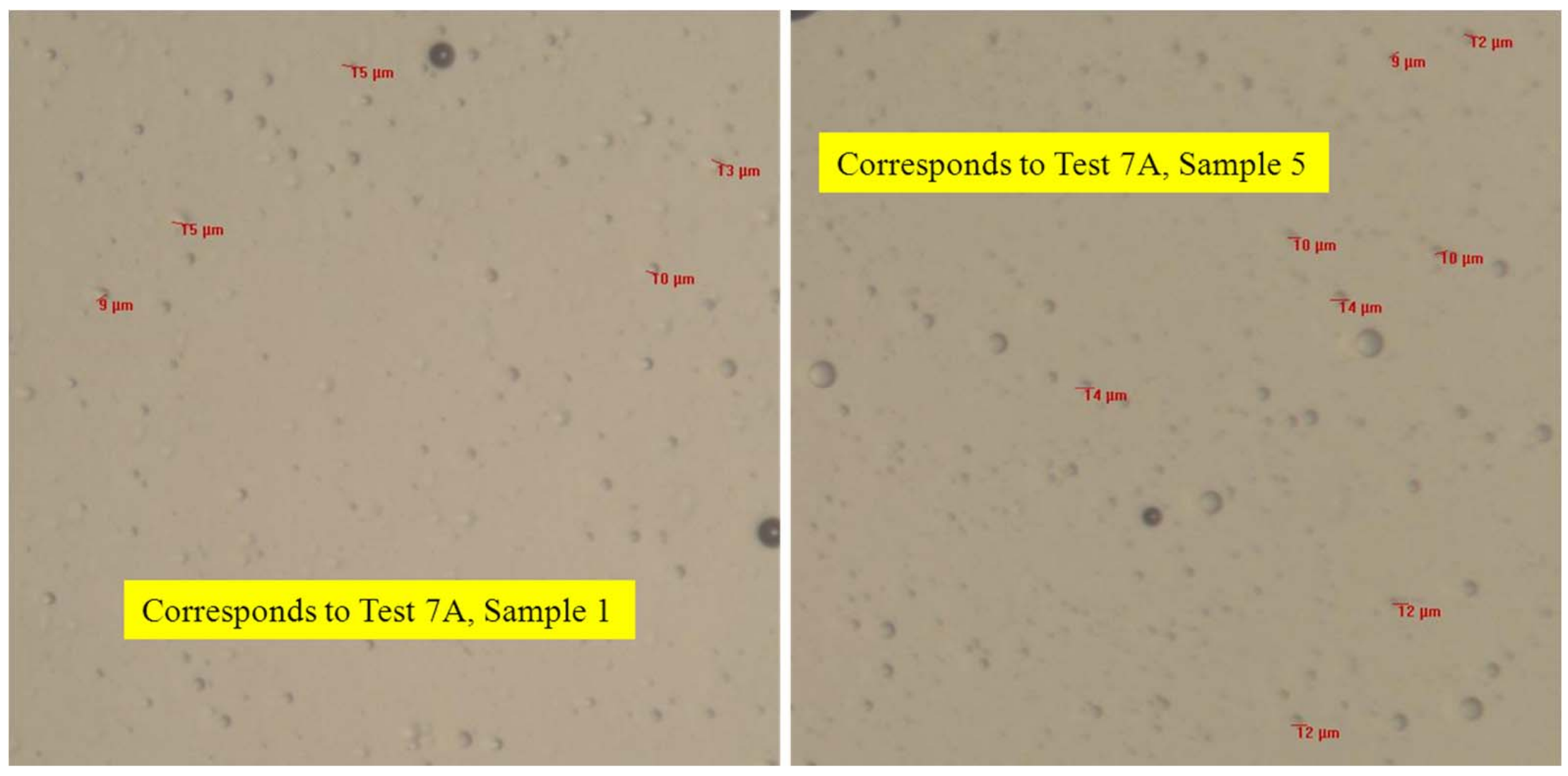

Figure 4-13. Polarized Light Microscopy Pictures for Test 7A 


\subsubsection{Macroscopic Photography}

While the SVOA, HPLC, MicroTrac ${ }^{\mathrm{TM}}$, and PLM data offer a detailed perspective of hydraulic and coalescer performance, standard photography provides its own perspective. During testing, four primary observations were possible due to view ports and sampling. These observations included liquid level in the contactor, appearance of solvent entering and exiting the contactor, solvent and air entrainment in the aqueous discharge, and coalescer behavior characteristics.

\subsubsection{Liquid in the Contactor}

Both the V5 and V10 contactors were configured with a side viewing window and ruler. The window enables an approximate assessment of the liquid level in the contactor on the outside of the rotor. Observations of the liquid level in the contactors may indicate whether a liquid level in the contactor is sufficiently high to promote good mixing.. Pictures for stripping in the V5 (Figure 4-14) and extraction in the V10 (Figure 4-15) are shown.
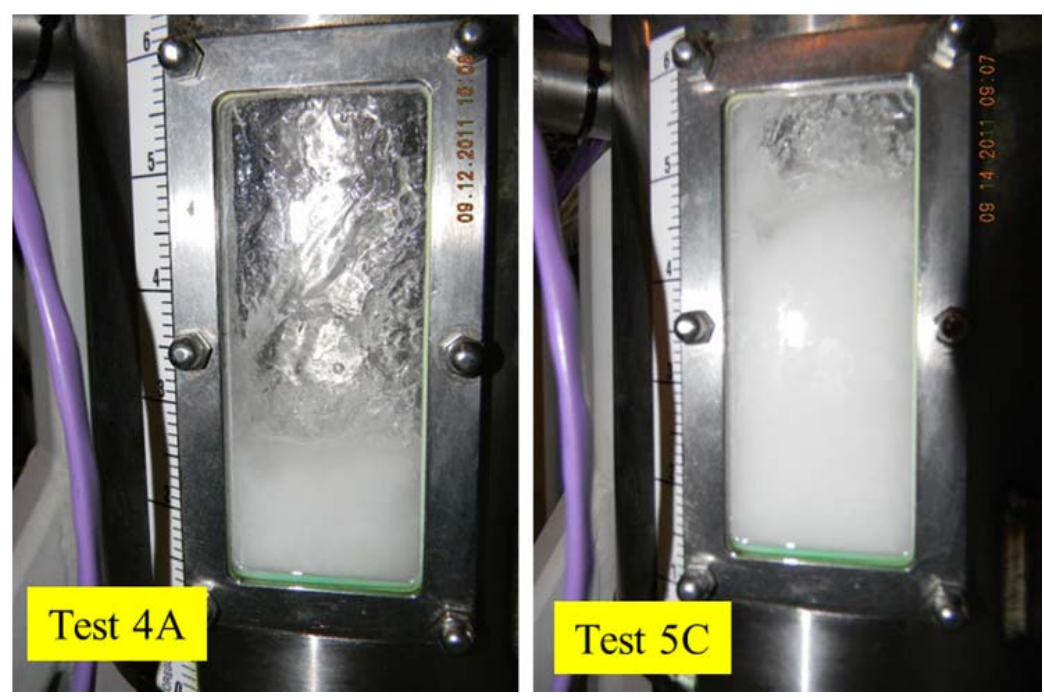

Figure 4-14. Pictures of V5 View Port during Strip Testing
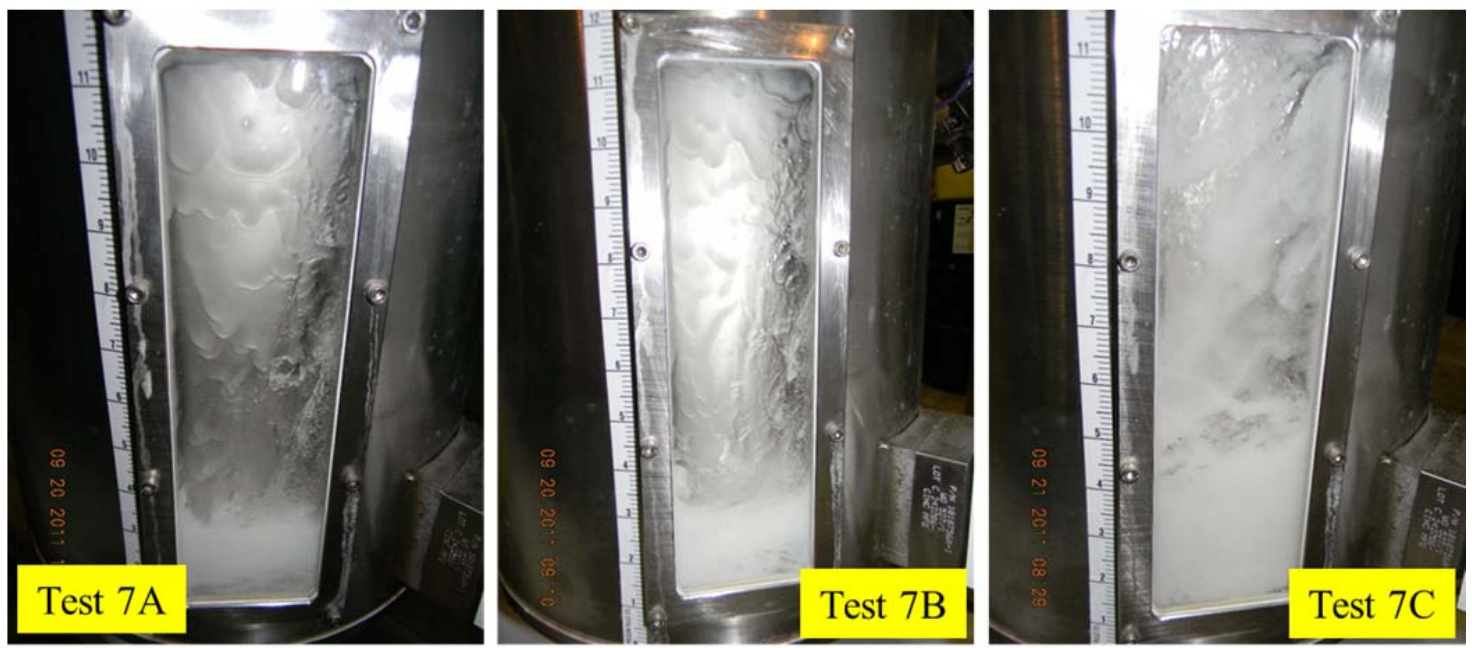

Figure 4-15. Pictures of V10 View Port during Extraction Testing 


\subsubsection{Feed and Discharge Clarity}

The process equipment was constructed with sight glasses on the inlet and outlet streams for both contactors. The sight glasses provided an opportunity to observe the clarity of the solvent entering and exiting the contactors during strip and extraction testing (Figure 4-16 for stripping and Figure 4-17 for extraction). Macro-scale observations offer potential insight into hydraulic performance of the system. For the solvent streams, the inlet streams were generally clear while the outlet streams exhibited foaming. The majority of the foaming dissipated quickly after being charged to the solvent reservoir but the solutions retained a fair amount of fine air and moisture droplet entrainment for extended periods. This behavior was not observed in the earlier testing with 2-cm contactors nor in standard dispersion and batch cesium mass transfer tests.
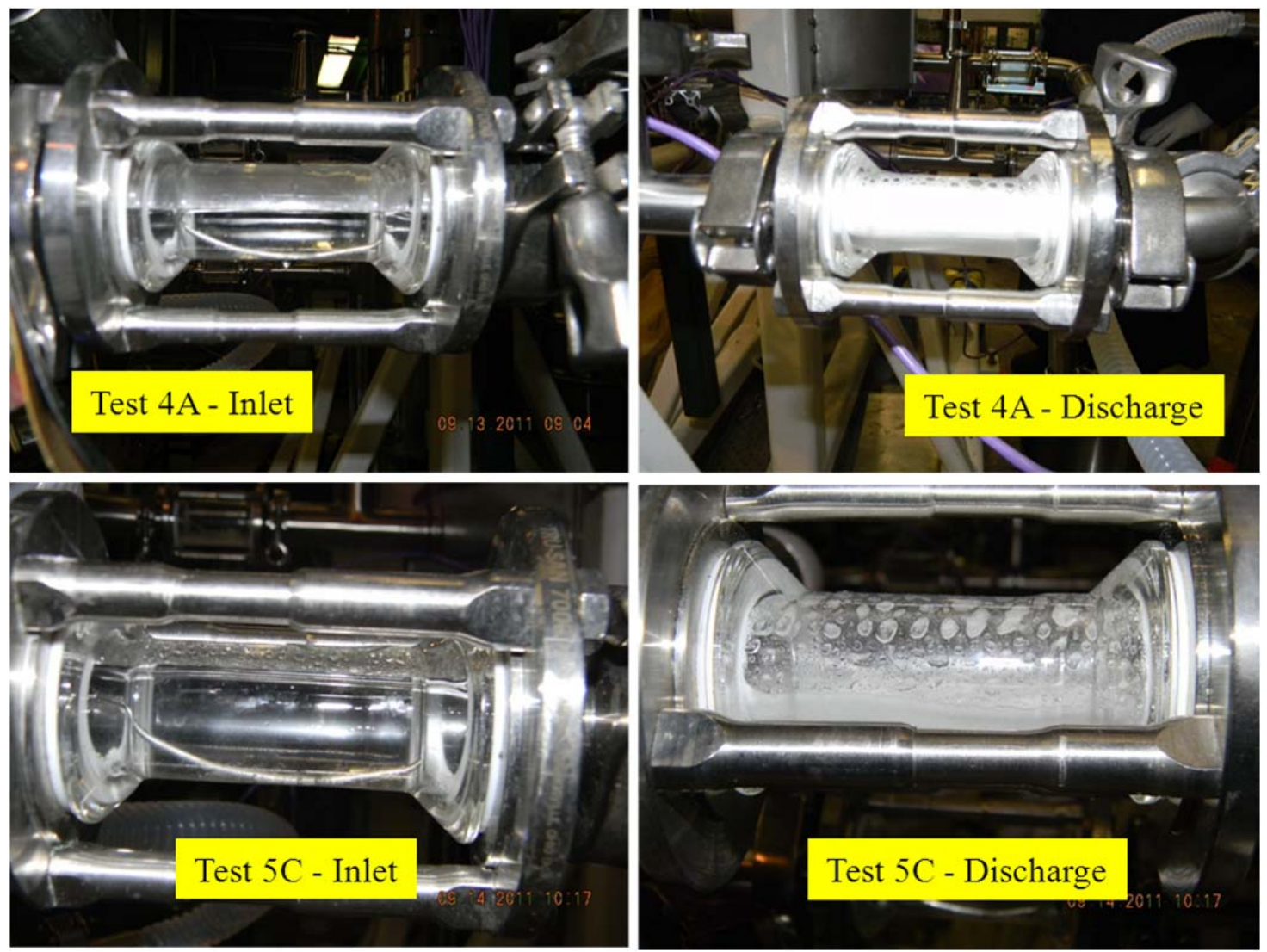

Figure 4-16. Pictures of Solvent Inlet and Outlet Lines during Strip Testing 

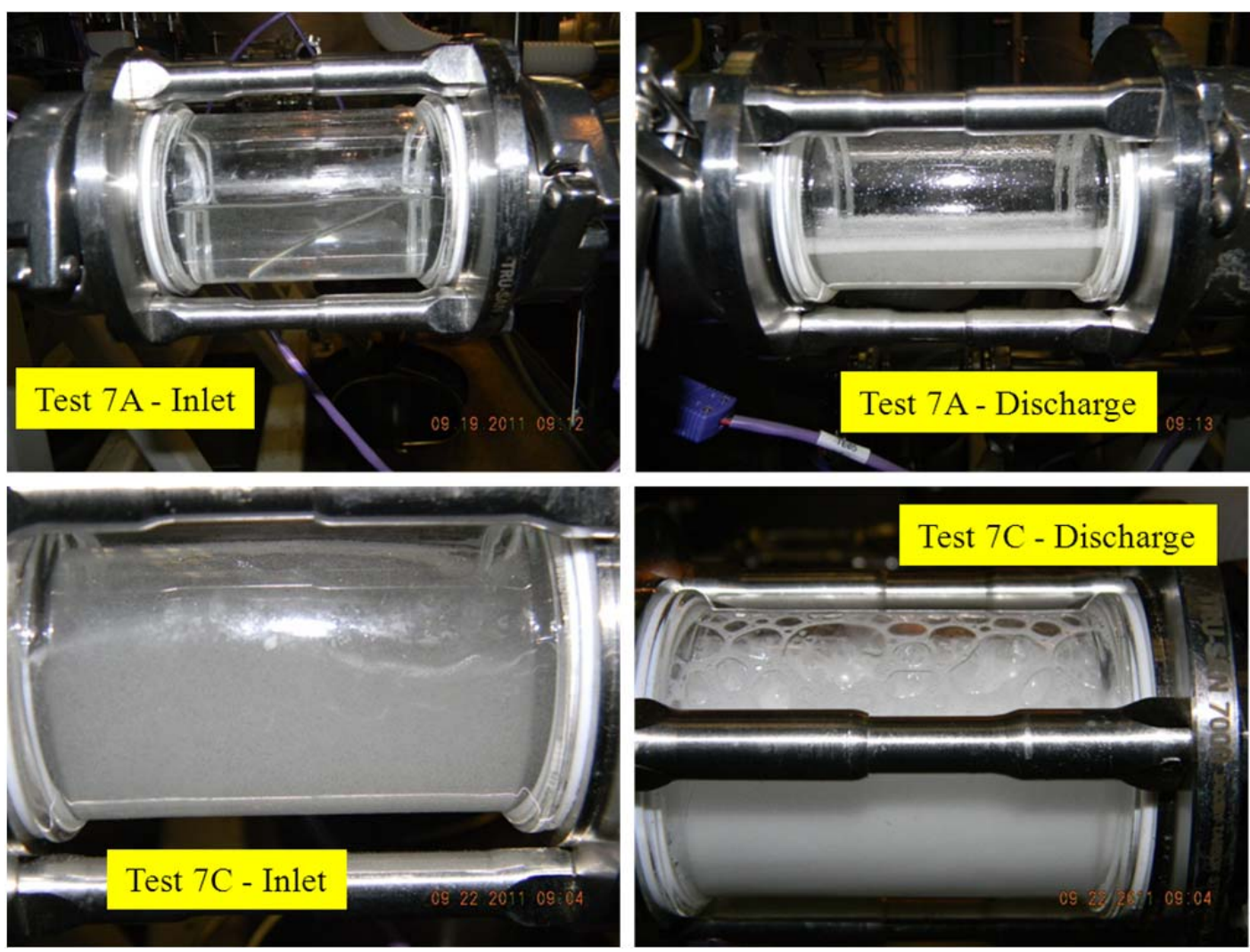

Figure 4-17. Pictures of Solvent Inlet and Outlet Lines during Extraction Testing

Similar observations were made for the aqueous streams into and out of the V5 and V10 contactors. Pictures of aqueous discharge samples for stripping (Figure 4-18), scrub (Figure 4-19), and extraction (Figure 4-20) are provided. Unlike the solvent, the aqueous streams were not clear and the cloudiness did not dissipate shortly after the aqueous entered the aqueous hold tank. The pictures indicate that a significant amount of the cloudiness can be attributed to air entrainment. For stripping, small bubbles were observed in the Test 4D graduated cylinder (Figure 4-18), which was a common occurrence for other stripping tests. The pictures from scrub testing show the dissipation of gas bubbles from the Test 2B beaker samples (Figure 4-19). The dissipation of gas from the aqueous streams, after a settling period, is shown vividly in the comparison of graduated cylinders for Tests 7A and 7B (Figure 4-20). For Tests 7A and 7B, the graduated cylinders on the right show the stream immediately after being collected while the cylinders on the left reflect solution clarity after over an hour of settling. 

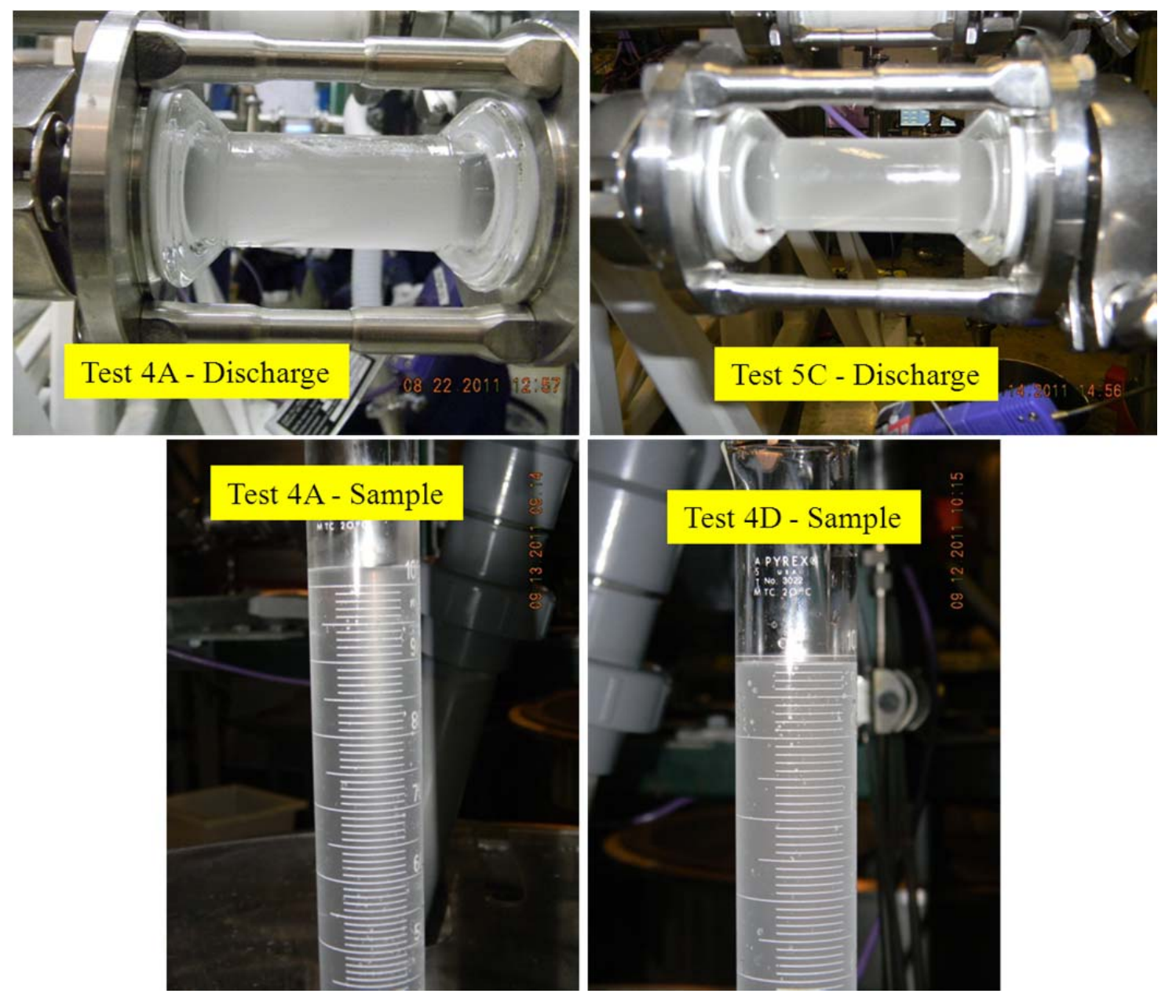

Figure 4-18. Pictures of Aqueous Discharge Samples during Strip Testing 

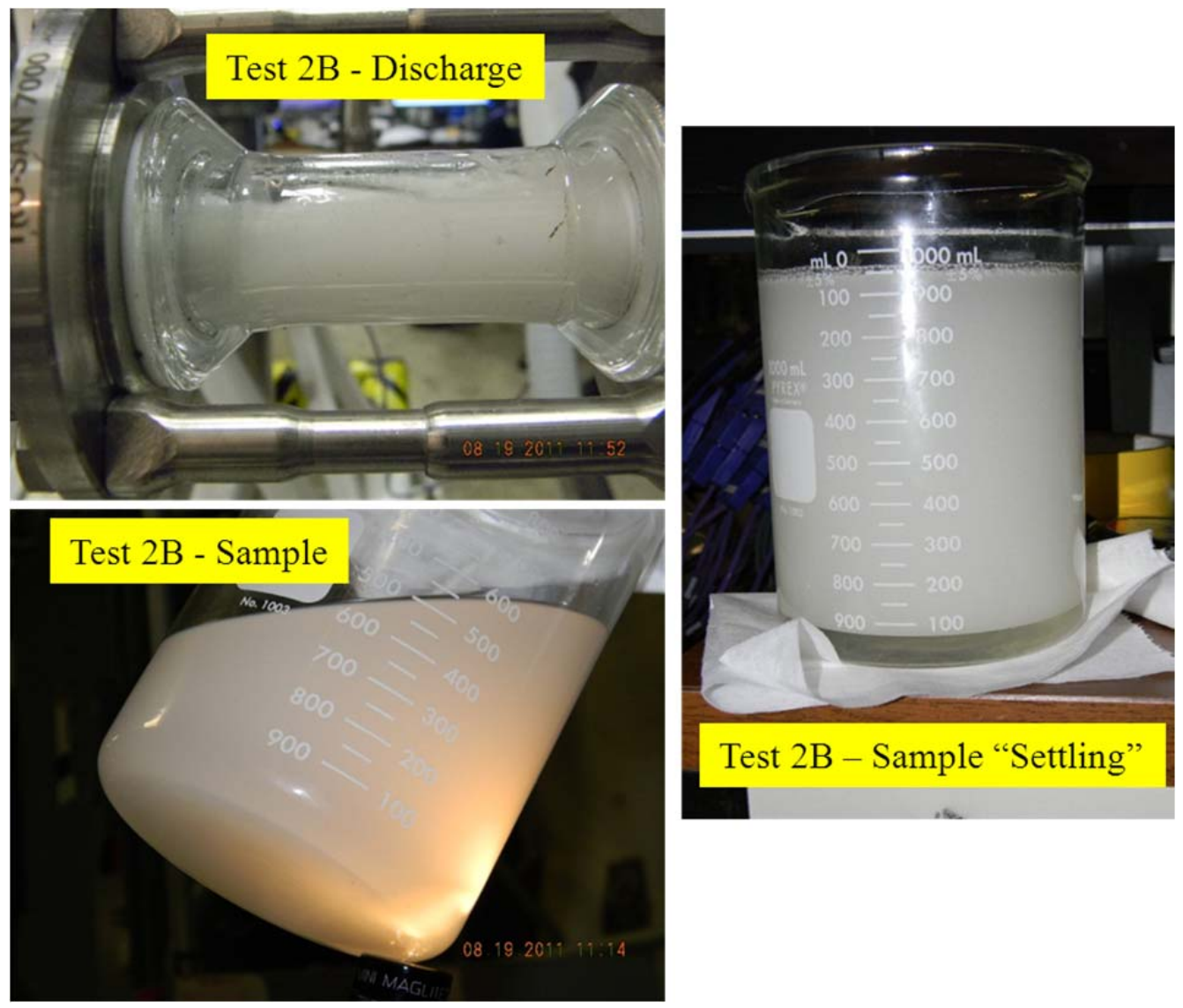

Figure 4-19. Pictures of Aqueous Discharge Samples during Scrub Testing 

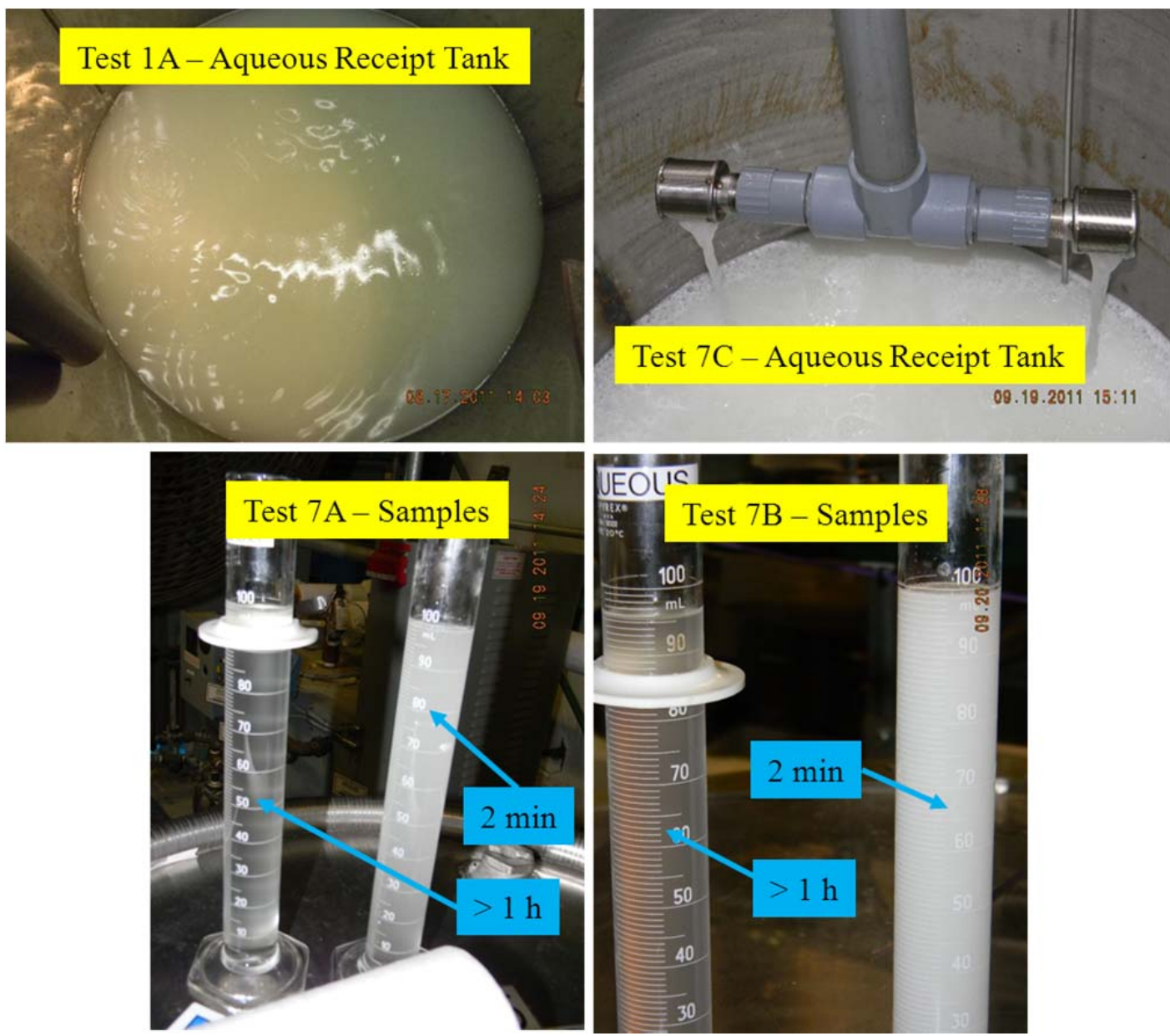

Figure 4-20. Pictures of Aqueous Discharge Samples during Extraction Testing

\subsubsection{Coalescer Behavior}

Pictures of the coalescer during stripping and extraction tests provide an indication of whether the coalescer is performing its function. The pictures do not allow any quantitative assessment, but the data are intended to complement the SVOA and FTIR data. The pictures for Tests 4D, 7A, and $7 \mathrm{~B}$ clearly show the formation of solvent bubble growth in the coalescers (Figure 4-21). The visual observations from Test $5 \mathrm{C}$ are not conclusive. For Tests $4 \mathrm{D}$ and $5 \mathrm{C}$ (stripping), the aqueous streams that are downstream from the coalescer exhibit cloudiness. The aqueous streams for extraction (Tests 7A and 7B) exhibit much less cloudiness.

The coalescence behavior differed appreciably for the extraction and the stripping operations. For extraction, the droplets that disengaged on the shell side of the coalescer formed very large globules and accumulated rapidly. For the stripping coalescers - with finer fiber dimensions the agglomerating droplets looked more like a "mesh" which observers likened to "fish eggs". A persistent two-phase structure clung to the coalescer element and disengagement seemed slower. 


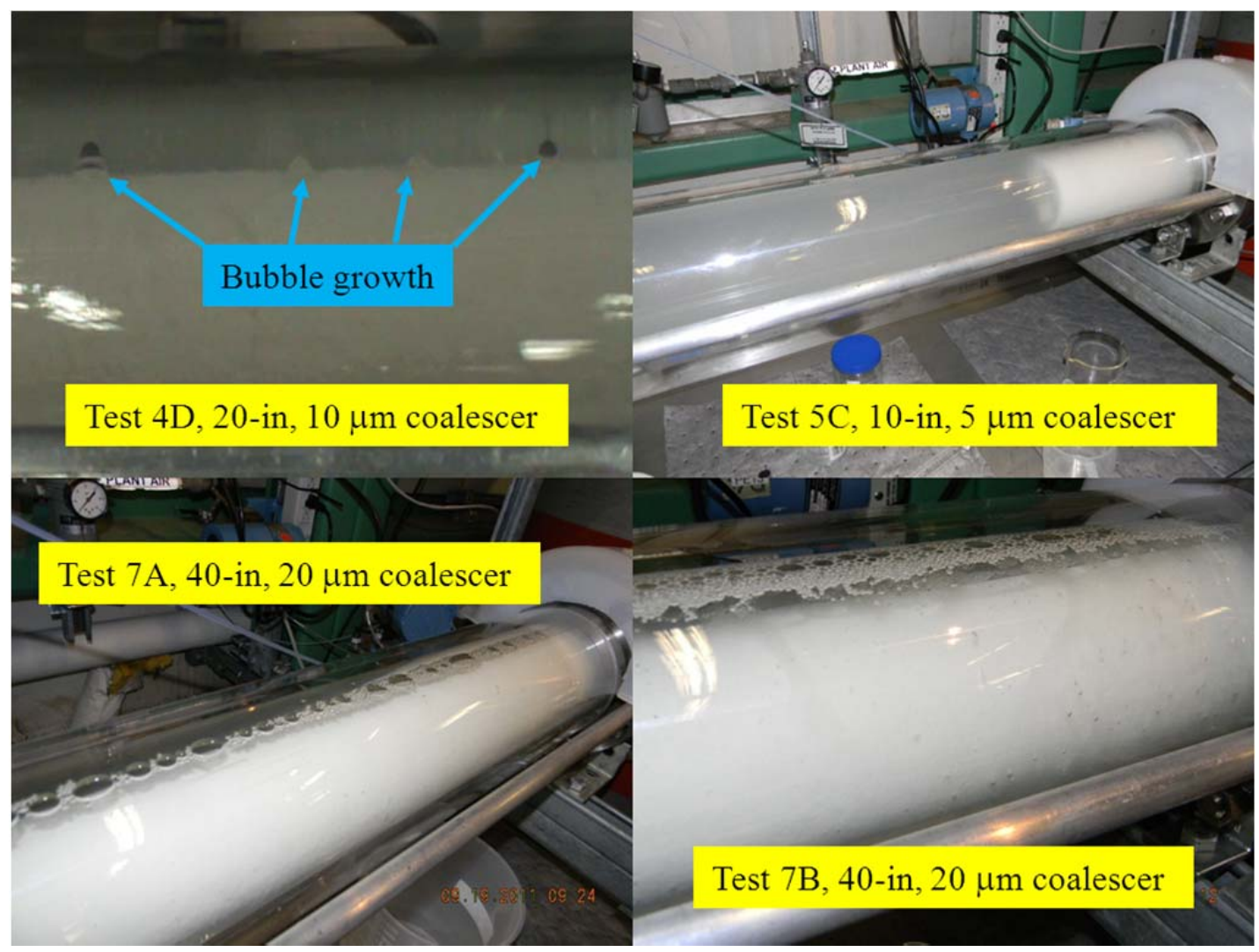

Figure 4-21. Pictures of Coalescer Performance during Testing

\subsection{Discussion}

\subsection{Contactor Hydraulic Performance}

Contactor hydraulic performance is based on two primary measures - stage efficiency and second-phase carryover. Stage efficiency is determined using Cs mass transfer measurements. Second-phase carryover was analyzed only for organic in the aqueous phase. Analyses included SVOA, FTIR, HPLC, MicroTrac ${ }^{\mathrm{TM}}$, and PLM measurements.

\subsubsection{Mass Transfer}

The aqueous and organic samples were analyzed by ICPMS for Cs (mass 133). In the case of the organic samples, they were digested first via Parr Bomb. By dividing the Cs concentration for the organic phase by the Cs concentration in the aqueous phase, a Cs distribution ratio $[\mathrm{D}(\mathrm{Cs})]$ was calculated. For the extraction tests, the results are displayed in Table 5-1. The results in parentheses are the standard deviations for the average results. 
Table 5-1. Extraction Mass-Transfer Test Results

\begin{tabular}{|c|c|c|c|c|c|}
\hline $\begin{array}{l}\text { Test } \\
\text { ID }\end{array}$ & $\begin{array}{l}\text { Rotor } \\
\text { Speed } \\
\text { (rpm) }\end{array}$ & $\begin{array}{c}\text { Aqueous } \\
\text { (gpm) }\end{array}$ & $\begin{array}{c}\text { Organic } \\
(\mathrm{gpm})\end{array}$ & $\begin{array}{l}\text { Contactor Volumes } \\
\text { When Sampled }\end{array}$ & $\mathrm{D}(\mathrm{Cs})$ \\
\hline \multirow[t]{4}{*}{$1 \mathrm{~A}$} & \multirow[t]{4}{*}{1200} & \multirow[t]{4}{*}{4.0} & \multirow[t]{4}{*}{1.0} & 6 & 17.8 \\
\hline & & & & 7 & 18.0 \\
\hline & & & & 8 & 16.7 \\
\hline & & & & average & $17.5(0.680)$ \\
\hline \multirow[t]{4}{*}{ 1B } & \multirow[t]{4}{*}{1700} & \multirow[t]{4}{*}{8.0} & \multirow[t]{4}{*}{2.0} & 6 & 15.9 \\
\hline & & & & 7 & 16.3 \\
\hline & & & & 8 & 15.7 \\
\hline & & & & average & $16.0(0.332)$ \\
\hline \multirow[t]{4}{*}{$1 \mathrm{C}$} & \multirow[t]{4}{*}{1700} & \multirow[t]{4}{*}{12.0} & \multirow[t]{4}{*}{3.0} & 6 & 13.2 \\
\hline & & & & 7 & 13.9 \\
\hline & & & & 8 & 13.8 \\
\hline & & & & average & $13.6(0.374)$ \\
\hline \multirow[t]{4}{*}{$1 \mathrm{D}$} & \multirow[t]{4}{*}{1700} & \multirow[t]{4}{*}{8.5} & \multirow[t]{4}{*}{2.1} & 6 & 11.9 \\
\hline & & & & 7 & 11.8 \\
\hline & & & & 8 & 11.3 \\
\hline & & & & average & $11.7(0.340)$ \\
\hline
\end{tabular}

For the extraction tests, high values are desired to indicate that the solvent successfully removed the cesium from the aqueous phase. ORNL tests with $20 \mathrm{mM}$ MaxCalix measured an extraction DF of 25.2. ${ }^{[11]}$ In each of the four tests, the $\mathrm{D}(\mathrm{Cs})$ results for the individual tests are virtually the same across all the contactor volume samples. This indicates that equilibrium is achieved rapidly and maintained throughout sampling. The differences between Tests 1A, 1B, 1C, and 1D (based on Table 4-2) are statistically insignificant. Although statistically insignificant, the gradual decline in $\mathrm{D}(\mathrm{Cs})$ from Test $1 \mathrm{~A}$ to Test $1 \mathrm{D}$ and the difference between Tests $1 \mathrm{~B}$ and 1D (essentially the same process conditions) raises concern regarding whether there is some developing mechanical problem across the test series.

The results of the two scrub tests are listed in Table 5-2. The nominal target scrub values are $\sim 1.0-2.5{ }^{[12]}$ The results in parentheses are the standard deviations for the average results. Direct comparisons between Tests 2A and 2B should be avoided because Test 2A was performed as the first scrub stage prior to strip tests while Test $2 \mathrm{~B}$ was performed as the second scrub stage prior to strip tests. However, the decrease in $\mathrm{D}(\mathrm{Cs})$ from Test $2 \mathrm{~A}$ to $2 \mathrm{~B}$ is a good result as this is the expected response between the first and second scrub stages.

Table 5-2. Scrub Mass-Transfer Test Results

\begin{tabular}{|c|c|c|c|c|c|}
\hline $\begin{array}{l}\text { Test } \\
\text { ID }\end{array}$ & $\begin{array}{l}\text { Rotor } \\
\text { Speed } \\
(\mathrm{rpm})\end{array}$ & $\begin{array}{l}\text { Aqueous } \\
\text { Flow } \\
\text { (gpm) }\end{array}$ & $\begin{array}{l}\text { Organic } \\
\text { Flow } \\
(\mathrm{gpm})\end{array}$ & $\begin{array}{l}\text { Contactor Volumes } \\
\text { When Sampled }\end{array}$ & $\mathrm{D}(\mathrm{Cs})$ \\
\hline \multirow[t]{5}{*}{$2 \mathrm{~A}$} & \multirow[t]{5}{*}{1800} & \multirow[t]{5}{*}{0.27} & \multirow[t]{5}{*}{1.0} & 6 & 1.39 \\
\hline & & & & 7 & 1.18 \\
\hline & & & & 8 & 1.19 \\
\hline & & & & 10 & 1.10 \\
\hline & & & & average & $1.21(0.121)$ \\
\hline \multirow[t]{5}{*}{$2 \mathrm{~B}$} & \multirow[t]{5}{*}{2100} & \multirow[t]{5}{*}{0.80} & \multirow[t]{5}{*}{3.0} & 6 & 1.31 \\
\hline & & & & 7 & 0.646 \\
\hline & & & & 8 & 0.646 \\
\hline & & & & 10 & 0.509 \\
\hline & & & & Average & $0.779(0.363)$ \\
\hline
\end{tabular}


It is possible that there is a slight declining trend in the $\mathrm{D}(\mathrm{Cs})$ values of Test $2 \mathrm{~A}$, although the differences in each test set are within the analytical uncertainty of the ICPMS method (20\%). For Test $2 \mathrm{~B}$, there is a distinct decline in values. This may indicate that the slightly lower rotor speed in Test $2 \mathrm{~B}$ requires a longer time to reach equilibrium. It may also be related to shift in $\mathrm{D}(\mathrm{Cs})$ as the $\mathrm{pH}$ of the solvent is gradually lowered by the scrub solution. In any case, the differences are not considered problematic.

The results of the six strip tests are listed in Table 5-3. The results in parentheses are the standard deviations for the average results. For stripping behavior, lower values are desired, indicating that the cesium in the solvent is being released into the strip aqueous stream. Each test was operated in a manner to represent the first strip stage. The nominal target value for the first strip stage is $\sim 1.0 \times 10^{-3} .^{[11]}$

Table 5-3. Strip Mass-Transfer Test Results

\begin{tabular}{|c|c|c|c|c|c|}
\hline Test ID & $\begin{array}{l}\text { Rotor } \\
\text { Speed } \\
\text { (rpm) }\end{array}$ & $\begin{array}{l}\text { Aqueous } \\
\text { Flow } \\
\text { (gpm) }\end{array}$ & $\begin{array}{l}\text { Organic } \\
\text { Flow } \\
\text { (gpm) }\end{array}$ & $\begin{array}{l}\text { Contactor Volumes } \\
\text { When Sampled }\end{array}$ & $\mathrm{D}(\mathrm{Cs})$ \\
\hline \multirow[t]{4}{*}{$3 \mathrm{~A}$} & \multirow[t]{4}{*}{1800} & \multirow[t]{4}{*}{0.27} & \multirow[t]{4}{*}{1.0} & 6 & 0.114 \\
\hline & & & & 8 & 0.0683 \\
\hline & & & & 10 & 0.0638 \\
\hline & & & & average & $0.0821(0.0278)$ \\
\hline \multirow[t]{4}{*}{$3 \mathrm{~B}$} & \multirow[t]{4}{*}{2100} & \multirow[t]{4}{*}{0.53} & \multirow[t]{4}{*}{2.0} & 6 & 0.0605 \\
\hline & & & & 8 & 0.0511 \\
\hline & & & & 10 & 0.0441 \\
\hline & & & & average & $0.0519(0.0082)$ \\
\hline \multirow[t]{4}{*}{$3 \mathrm{C}$} & \multirow[t]{4}{*}{2100} & \multirow[t]{4}{*}{0.80} & \multirow[t]{4}{*}{3.0} & 6 & 0.0605 \\
\hline & & & & 8 & 0.0434 \\
\hline & & & & 10 & 0.0535 \\
\hline & & & & average & $0.0525(0.00858)$ \\
\hline \multirow[t]{4}{*}{$3 \mathrm{D}$} & \multirow[t]{4}{*}{2100} & \multirow[t]{4}{*}{0.40} & \multirow[t]{4}{*}{2.0} & 6 & 0.0764 \\
\hline & & & & 8 & 0.0553 \\
\hline & & & & 10 & 0.0443 \\
\hline & & & & average & $0.0587(0.0163)$ \\
\hline \multirow[t]{4}{*}{$3 \mathrm{E}$} & \multirow[t]{4}{*}{2100} & \multirow[t]{4}{*}{0.28} & \multirow[t]{4}{*}{2.0} & 6 & 0.123 \\
\hline & & & & 8 & 0.0893 \\
\hline & & & & 10 & 0.0733 \\
\hline & & & & average & $0.0953(0.0255)$ \\
\hline \multirow[t]{4}{*}{$3 \mathrm{~F}$} & \multirow[t]{4}{*}{2100} & \multirow[t]{4}{*}{0.43} & \multirow[t]{4}{*}{3.0} & 6 & 0.113 \\
\hline & & & & 8 & 0.0852 \\
\hline & & & & 10 & 0.0697 \\
\hline & & & & average & $0.0894(0.0221)$ \\
\hline
\end{tabular}

Tests $3 \mathrm{~A}$ and $3 \mathrm{~B}$ provide for the lowest average $\mathrm{D}(\mathrm{Cs})$ values $(0.052$ for each), although the average result of Test $3 \mathrm{C}$ is statistically indeterminate from Tests $3 \mathrm{~A}$ and $3 \mathrm{~B}$. If the Test $3 \mathrm{~A}$ sample at 6 Contactor Volumes was omitted, the results for Tests $3 \mathrm{~A}, 3 \mathrm{~B}$, and $3 \mathrm{C}$ would all be similar. This is significant because all three tests use the same feed ratios but significantly different cumulative flow rates.

Similar behavior is observed for Tests $3 \mathrm{E}$ and $3 \mathrm{~F}$, which were performed at an O:A ratio of 7:1 instead of 3.75:1 (for Tests 3A, 3B, and 3C). The difference between Tests $3 \mathrm{E}$ and $3 \mathrm{~F}$ are 
statistically insignificant at every sampling volume. Test $3 \mathrm{~F}$ has a flow rate that is $50 \%$ greater than that of $3 \mathrm{E}$ but the same O:A ratio.

Tests 3A, 3D, 3E, and 3F show a statistically significant decline in $\mathrm{D}(\mathrm{Cs})$ values over time. This may be an indication that six contactor volumes was not enough time to reach steady-state operations under the conditions of those tests. Test $3 \mathrm{~A}$ takes longer to reach equilibrium because of the low flow rates and low liquid volume in the mixing section (similar to Test $4 \mathrm{~A}$ in Figure 4-14). Tests 3D, 3E, and 3F take longer to reach equilibrium because of much lower O:A ratios.

To determine the mass-transfer efficiency of the V5 and V10 contactors, the data in the three previous tables must be compared to the equilibrium distribution ratios based on the data of Table 4-5. The $\mathrm{D}(\mathrm{Cs})$ calculations and along with temperature correction are provided in Table 5-4. ${ }^{[12]}$ For the data in Table 5-4, the measured $D(C s)$ value was calculated from the analytical data and corrected for temperature. The temperature-corrected $\mathrm{D}(\mathrm{Cs})$ value was then used to calculate the Cs concentrations in the aqueous and organic streams, normalized to the total mass of Cs reported in Table 4-5 for a particular test. The normalized Cs concentrations after temperature correction - are used to calculated temperature-corrected stage efficiency values in Table 5-5.

Table 5-4. Mass Transfer Equilibrium Distribution Ratios

\begin{tabular}{|c|c|c|c|c|c|}
\hline $\begin{array}{l}\text { Test } \\
\text { ID }\end{array}$ & $\begin{array}{c}\text { Temperature } \\
\left({ }^{\circ} \mathrm{C}\right)\end{array}$ & $\begin{array}{l}\text { Process } \\
\text { Stream }\end{array}$ & $\begin{array}{c}\text { Measured } \\
\mathrm{D}(\mathrm{Cs})\end{array}$ & $\begin{array}{c}\text { Temperature- } \\
\text { Corrected } \\
\text { Equilibrium } \\
\mathrm{D}(\mathrm{Cs}) \\
\end{array}$ & $\begin{array}{c}\text { Normalized Cs } \\
\text { Aqu / Org } \\
(\mathrm{mg} / \mathrm{L})\end{array}$ \\
\hline $1 \mathrm{~A}$ & 23.7 & Extract & 20.4 & $21.1^{*}$ & $1.36 / 28.8^{*}$ \\
\hline $2 \mathrm{~A}$ & 23.7 & Scrub & 0.40 & $0.41^{*}$ & $4.71 / 1.95^{*}$ \\
\hline $3 \mathrm{~A}$ & 23.7 & Strip & 0.044 & $0.023^{\#}$ & $22.0 / 0.515^{\#}$ \\
\hline $3 \mathrm{~A}$ & 23.7 & Strip & 0.044 & $0.033^{\triangle}$ & $21.8 / 0.710^{\triangle}$ \\
\hline $\begin{array}{l}\text { Corr } \\
{ }^{*} \text { Corr } \\
{ }^{\text {Corr }}\end{array}$ & $\begin{array}{l}1 \text { to } 23{ }^{\circ} \mathrm{C} \\
\text { to } 33{ }^{\circ} \mathrm{C} \\
\text { to } 28^{\circ} \mathrm{C}\end{array}$ & & & & \\
\hline
\end{tabular}

Stage efficiency was calculated using the Murphree stage efficiency calculation. ${ }^{[13]}$ The Murphree stage efficiency is calculated by dividing the difference between the initial and test Cs concentrations for the test by the difference between the initial and temperature-corrected equilibrium Cs concentrations. Due to the nature of the process chemistry, because mass transfer during scrub is intentionally limited, only the efficiencies for strip and extraction at the baseline $\mathrm{O}: \mathrm{A}$ ratios are calculated (Table 5-5). Calculations are based on the stage being depleted of Cs, which is the aqueous stream for extraction and the organic stream for stripping. 
Table 5-5. Extraction and Strip Stage Efficiency

\begin{tabular}{|c|c|c|c|c|c|}
\hline Test ID & $\begin{array}{l}\text { Rotor } \\
\text { Speed } \\
(\mathrm{rpm})\end{array}$ & $\begin{array}{c}\text { Aqueous } \\
\text { Flow } \\
\text { (gpm) }\end{array}$ & $\begin{array}{c}\text { Organic } \\
\text { Flow } \\
\text { (gpm) }\end{array}$ & $\begin{array}{l}\text { Contactor Volumes } \\
\text { When Sampled }\end{array}$ & $\begin{array}{l}\text { Extraction Stage } \\
\text { Efficiency }(\%)\end{array}$ \\
\hline \multirow[t]{4}{*}{$1 \mathrm{~A}$} & \multirow[t]{4}{*}{1200} & \multirow[t]{4}{*}{4.0} & \multirow[t]{4}{*}{1.0} & 6 & 98.9 \\
\hline & & & & 7 & 97.9 \\
\hline & & & & 8 & 97.9 \\
\hline & & & & average & 98.2 \\
\hline \multirow[t]{4}{*}{$1 \mathrm{~B}$} & \multirow[t]{4}{*}{1700} & \multirow[t]{4}{*}{8.0} & \multirow[t]{4}{*}{2.0} & 6 & 96.8 \\
\hline & & & & 7 & 96.6 \\
\hline & & & & 8 & 96.6 \\
\hline & & & & average & 96.7 \\
\hline \multirow[t]{4}{*}{$1 \mathrm{C}$} & \multirow[t]{4}{*}{1700} & \multirow[t]{4}{*}{12.0} & \multirow[t]{4}{*}{3.0} & 6 & 94.7 \\
\hline & & & & 7 & 94.7 \\
\hline & & & & 8 & 94.7 \\
\hline & & & & average & 94.7 \\
\hline \multirow[t]{4}{*}{$1 \mathrm{D}$} & \multirow[t]{4}{*}{1700} & \multirow[t]{4}{*}{8.5} & \multirow[t]{4}{*}{2.1} & 6 & 91.0 \\
\hline & & & & 7 & 90.4 \\
\hline & & & & 8 & 90.0 \\
\hline & & & & average & 90.5 \\
\hline \multirow[t]{4}{*}{$3 \mathrm{~A}$} & \multirow[t]{4}{*}{1800} & \multirow[t]{4}{*}{0.27} & \multirow[t]{4}{*}{1.0} & 6 & 76.4 \\
\hline & & & & 8 & 84.6 \\
\hline & & & & 10 & 84.8 \\
\hline & & & & average & $82.0^{*} / 83.4^{\#}$ \\
\hline \multirow[t]{4}{*}{$3 \mathrm{~B}$} & \multirow[t]{4}{*}{2100} & \multirow[t]{4}{*}{0.53} & \multirow[t]{4}{*}{2.0} & 6 & 88.3 \\
\hline & & & & 8 & 88.8 \\
\hline & & & & 10 & 89.9 \\
\hline & & & & average & $89.0^{*} / 90.7^{\#}$ \\
\hline \multirow[t]{4}{*}{$3 \mathrm{C}$} & \multirow[t]{4}{*}{2100} & \multirow[t]{4}{*}{0.80} & \multirow[t]{4}{*}{3.0} & 6 & 90.5 \\
\hline & & & & 8 & 92.2 \\
\hline & & & & 10 & 88.1 \\
\hline & & & & average & $90.2^{*} / 91.7^{\#}$ \\
\hline
\end{tabular}

The data show good stage efficiency for extraction (Tests 1A-1D), ranging from $98.2 \%$ for Test $1 \mathrm{~A}$ to $90.5 \%$ for Test $1 \mathrm{D}$. There is a distinct decrease in the efficiency with each test, although the decrease in efficiency is within the analytical uncertainty of $20 \%$. The temperature data for Tests 1A to 1C suggests that the slight decrease in efficiency can be attributed to small temperature increases between the tests Figure 5-1). However, Test 1D does not follow this pattern. Therefore, it is possible that the decrease in efficiency is also related to a mechanical issue, but the specific nature of that issue is not known.

The data for strip (Tests 3A-3C) show acceptable stage efficiency, ranging from $82.0 \%$ for Test $3 \mathrm{~A}$ to $89-90 \%$ for Tests $3 \mathrm{~B}$ and $3 \mathrm{C}$. The difference in efficiency between Test $3 \mathrm{~A}$ and Tests $3 \mathrm{~B}$ and $3 \mathrm{C}$ may be attributable to the low volume in the contactor housing (Similar to Test 4A in Figure 4-14). If the volume in the mixing zone is low, then mixing will not be as effective and stage efficiency can be reduced. 
The stage efficiencies are as good as or better than those measured for similar conditions with the V5 contactor at Wright Industries for the CSSX solvent, simulant salt solution, and dilute $\mathrm{HNO}_{3}$ (Table 5-6). ${ }^{[14]}$ The stage efficiencies compare well with those measured for the 2-cm centrifugal contactor tests with NGS and both non-radioactive simulant and actual Tank 49H HLW. ${ }^{[3]}$ For non-radioactive simulant tests, the average extraction and strip stage efficiencies were $89-91 \%$. Stage efficiencies for the radioactive demonstration were $94-96 \%$.

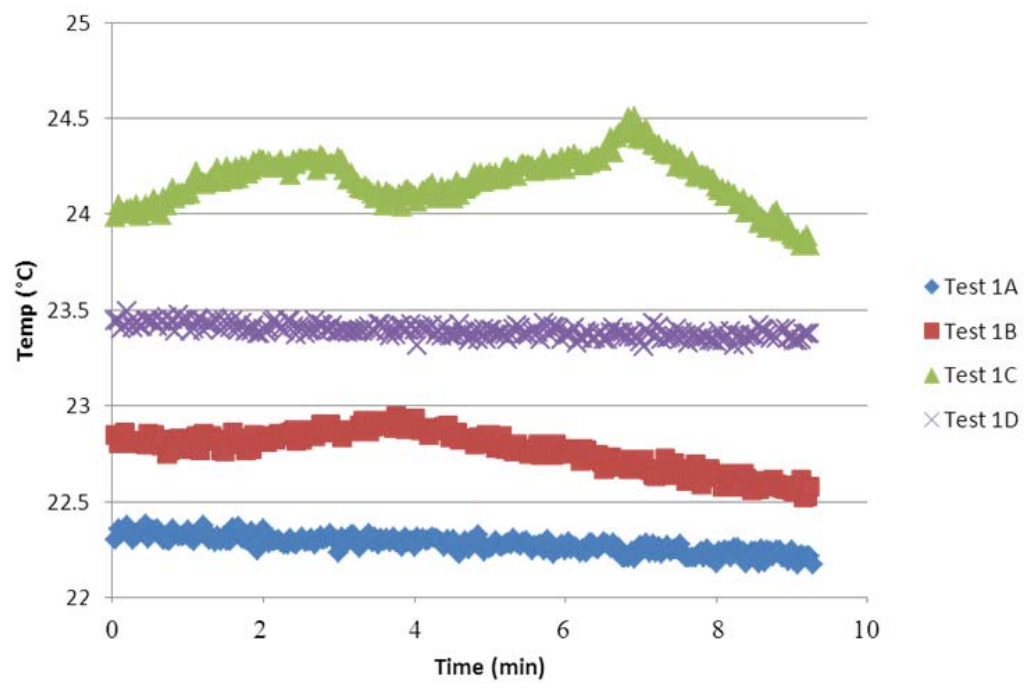

Figure 5-1. Aqueous Discharge Temperatures for Extraction Testing

Table 5-6. Stage Efficiency Comparison for V5 and V10 Testing

\begin{tabular}{|c|c|c|c|c|c|c|c|}
\hline \multirow{2}{*}{$\begin{array}{c}\text { Test } \\
\text { ID }\end{array}$} & Rotor & $\begin{array}{c}\text { NGS Testing at EDL } \\
\text { Flows } \\
(\mathrm{gpm})\end{array}$ & $\begin{array}{c}\text { Rotor } \\
\text { Speed } \\
(\mathrm{rpm})\end{array}$ & $\begin{array}{c}\text { Stage } \\
\text { Eff } \\
(\%)\end{array}$ & $\begin{array}{c}\text { CSSX } \\
\text { Org/Aqu } \\
\text { Flows } \\
(\mathrm{gpm})\end{array}$ & $\begin{array}{c}\text { Rotor } \\
\text { Speed } \\
(\mathrm{rpm})\end{array}$ & $\begin{array}{c}\text { Stage } \\
\text { Eff } \\
(\%)\end{array}$ \\
\hline 1A & V10 & $1 / 4$ & 1200 & 98.2 & $1.2 / 3.7$ & 1200 & $80-85$ \\
\hline 1B & V10 & $2 / 8$ & 1700 & 96.7 & $2.3 / 7.5$ & 1800 & 83 \\
\hline 1C & V10 & $3 / 12$ & 1700 & 94.7 & & & \\
\hline 1D & V10 & $2.1 / 8.5$ & 1700 & 90.5 & $2.3 / 7.5$ & 1800 & 83 \\
\hline 3A & V5 & $1 / 0.27$ & 1800 & 82.0 & $1.2 / 0.23$ & 1800 & $81-88$ \\
\hline 3B & V5 & $2 / 0.53$ & 2100 & 89.0 & $2.3 / 0.47$ & 2100 & $85-87$ \\
\hline 3C & V5 & $3 / 0.80$ & 2100 & 90.2 & $2.8 / 0.57$ & 2100 & $101-107$ \\
\hline
\end{tabular}

For the V5 and V10 tests, while minimal temperature correction was required for Tests 1A-1D, the data for Tests $3 \mathrm{~A}-3 \mathrm{C}$ were temperature corrected to $33{ }^{\circ} \mathrm{C}$. However, process data indicate that while the liquid feed temperatures for these tests were at $30-33{ }^{\circ} \mathrm{C}$, the outlet temperatures into the holding tanks were on the order of $23-25{ }^{\circ} \mathrm{C}$ (Figure 4-2). The inlet and discharge temperature data for Tests $3 \mathrm{~B}$ and $3 \mathrm{C}$ were comparable to the data for Test 3A (Figure 4-2).

The consequence of the temperature data is that there is no certain understanding of the temperatures in the strip contactor. If temperature corrections are made based on the average of the inlet and outlet temperatures $\left(\operatorname{avg}=28^{\circ} \mathrm{C}\right)$, the stage efficiency increases by about $1.5 \%$ for all three strip tests (Tests 3A-3C). These calculations are shown in Table 5-4 and Table 5-5. 
Although not shown, no temperature correction of the strip data would yield strip stage efficiency calculation at $\sim 3.2 \%$ greater than those corrected to $33{ }^{\circ} \mathrm{C}$.

\subsubsection{Second-Phase Carryover}

The extent of organic carryover into the strip effluent (SE) and decontaminated salt solution (DSS) streams is important. Both streams eventually end up at facilities that are subject to strict controls on the amount of entering combustibles and flammables. Therefore, both streams are constantly monitored for the major carryover component, Isopar $\mathrm{L}^{\circledR}$. If the other components of NGS remain soluble in Isopar $L^{\circledR}$ during operations downstream of the contactors (as typically expected), then the measurement of other solvent components, such as the CS-7B Modifier, can also provide an indirect indication of Isopar $\mathrm{L}^{\circledR}$ carryover into the aqueous streams.

The strip tests used the V5 contactor and the inlet solution temperatures were maintained at $33 \pm 3{ }^{\circ} \mathrm{C}$. The extraction tests used the V10 contactor and the inlet solution temperatures were held at $23{ }^{\circ} \mathrm{C}$. Samples were pulled from two different locations downstream of the contactors. For samples upstream the coalescer ("pre"), the samples were removed via valve V-22 from the bottom of a horizontal section of piping, while samples downstream from the coalescer ("post") were removed via valve V-25 from a vertical section of piping.

The pre-coalescer samples provide the best available measurement of solvent carryover from the contactors but are not from direct contactor outlet streams as in prior SRNL and Wright Industries test reports. In the current testing, sampling came after a stilling tank that allows some coalescence of the solvent to occur. Personnel visually observed the stilling tank for gross signs of organic accumulation during testing and did not observe accumulation of a large volume of separated organic although some droplets did form and accumulate within the tank.

The concentrations of Isopar $\mathrm{L}^{\circledR}$ and Modifier, as measured by SVOA and FTIR, are tabulated in Table 5-7. A discussion of the limitations associated with the SVOA data is provided in Section 5.2. A look at the Isopar $\mathrm{L}^{\circledR}$ data as measured by FTIR for Tests 4A-4D suggests an impact due to rotor speed and net flow rate (Table 5-8). As the rotor speed decreases, the liquid level in the contactor also decreases. This could result in more air entrainment which could also entrap solvent. A similar change in Isopar $\mathrm{L}^{\circledR}$ carryover is observed between Tests $7 \mathrm{~B}$ and $7 \mathrm{C}$. However, the results for Test $5 \mathrm{C}$ do not correlate at all with the parallel data of Test $4 \mathrm{C}$, and thereby suggest that other factors are impacting carryover. It should also be noted that the data set is too sparse to allow definitive conclusions. 
Table 5-7. SVOA/FTIR Pre-Coalescer Data

\begin{tabular}{|c|c|c|c|c|c|c|c|}
\hline $\begin{array}{c}\text { Test } \\
\text { ID }\end{array}$ & $\begin{array}{c}\text { Sample Time } \\
\text { and Date }\end{array}$ & $\begin{array}{c}\text { Contactor } \\
\text { Type }\end{array}$ & $\begin{array}{c}\text { Rotor } \\
\text { Speed } \\
(\mathrm{rpm})\end{array}$ & $\begin{array}{c}\text { SVOA } \\
\text { Isopar } \\
(\mathrm{mg} / \mathrm{L})\end{array}$ & $\begin{array}{c}\text { SVOA } \\
\text { Modifier } \\
(\mathrm{mg} / \mathrm{L})\end{array}$ & $\begin{array}{c}\text { FTIR } \\
\text { Isopar } \\
(\mathrm{mg} / \mathrm{L})\end{array}$ & $\begin{array}{c}\text { FTIR } \\
\text { Modifier } \\
(\mathrm{mg} / \mathrm{L})\end{array}$ \\
\hline 4B & $09: 00,9 / 7 / 11$ & V5 & 2100 & 16 & 86 & 606 & 230 \\
\hline 4B & $10: 00,9 / 7 / 11$ & V5 & 2100 & 10 & 63 & 550 & 214 \\
\hline 4C & $09: 30,9 / 8 / 11$ & V5 & 2100 & 1733 & 151 & 400 & 106 \\
\hline 4C & $10: 30,9 / 8 / 11$ & V5 & 2100 & 1336 & 135 & 387 & 103 \\
\hline 4C & $11: 30,9 / 8 / 11$ & V5 & 2100 & 1426 & 154 & 364 & 94 \\
\hline 4D & $13: 06,9 / 12 / 11$ & V5 & 2100 & 1891 & 189 & 487 & 137 \\
\hline 4D & $14: 06,9 / 12 / 11$ & V5 & 2100 & 1885 & 204 & 533 & 144 \\
\hline 4D & $15: 06,9 / 12 / 11$ & V5 & 2100 & 1878 & 197 & 518 & 139 \\
\hline 4A & $10: 00,9 / 13 / 11$ & V5 & 1800 & 225 & 110 & 1298 & 342 \\
\hline 4A & $11: 00,9 / 13 / 11$ & V5 & 1800 & 508 & 119 & 1289 & 370 \\
\hline 4A & $12: 00,9 / 13 / 11$ & V5 & 1800 & 318 & 113 & 1305 & 463 \\
\hline 5C & $10: 00,9 / 14 / 11$ & V5 & 2100 & 788 & 166 & 1323 & 346 \\
\hline 5C & $11: 00,9 / 14 / 11$ & V5 & 2100 & 802 & 182 & 1304 & 328 \\
\hline 5C & $12: 00,9 / 14 / 11$ & V5 & 2100 & 793 & 165 & 1323 & 346 \\
\hline 5C & $13: 00,9 / 14 / 11$ & V5 & 2100 & 689 & 160 & 1322 & 442 \\
\hline 5C & $14: 00,9 / 14 / 11$ & V5 & 2100 & 787 & 170 & & \\
\hline 7A & $9: 30,9 / 19 / 11$ & V10 & 1200 & 93 & 73 & & \\
\hline 7A & $11: 15,9 / 19 / 11$ & V10 & 1200 & 161 & 50 & & \\
\hline 7A & $12: 30,9 / 19 / 11$ & V10 & 1200 & 113 & 53 & & 11 \\
\hline 7B & $9: 45,9 / 20 / 11$ & V10 & 1700 & 261 & 75 & 247 & 63 \\
\hline 7B & $11: 30,9 / 20 / 11$ & V10 & 1700 & 361 & 98 & 357 & 51 \\
\hline 7B & $12: 45,9 / 20 / 11$ & V10 & 1700 & 220 & 123 & 353 & \\
\hline 7C & $10: 15,9 / 22 / 11$ & V10 & 1700 & 388 & 155 & 60 & \\
\hline 7C & $11: 45,9 / 22 / 11$ & V10 & 1700 & 225 & 150 & 71 & \\
\hline 7C & $13: 15,9 / 22 / 11$ & V10 & 1700 & 375 & 140 & 88 & \\
\hline & & & & & & & \\
\hline
\end{tabular}

Table 5-8. Average Carryover Concentrations Measured by FTIR

\begin{tabular}{|c|c|c|c|c|c|}
\hline $\begin{array}{c}\text { Test } \\
\text { ID }\end{array}$ & $\begin{array}{c}\text { Contactor } \\
\text { Type }\end{array}$ & $\begin{array}{c}\text { Rotor } \\
\text { Speed } \\
(\mathrm{rpm})\end{array}$ & $\begin{array}{c}\text { Aqueous/organic } \\
\text { Flow Rates } \\
(\mathrm{gpm})\end{array}$ & $\begin{array}{c}\text { FTIR } \\
\text { Isopar } \\
(\mathrm{mg} / \mathrm{L})\end{array}$ & $\begin{array}{c}\text { FTIR } \\
\text { Modifier } \\
(\mathrm{mg} / \mathrm{L})\end{array}$ \\
\hline 4A & V5 & 1800 & $0.27 / 1$ & 1297 & 392 \\
\hline 4B & V5 & 2100 & $0.53 / 2$ & 578 & 222 \\
\hline 4C & V5 & 2100 & $0.80 / 3$ & 384 & 111 \\
\hline 4D & V5 & 2100 & $0.40 / 2$ & 513 & 140 \\
\hline 5C & V5 & 2100 & $0.80 / 3$ & 1318 & 366 \\
\hline 7A & V10 & 1200 & $4 / 1$ & & \\
\hline 7B & V10 & 1700 & $8 / 2$ & 319 & 42 \\
\hline 7C & V10 & 1700 & $12 / 3$ & 73 & \\
\hline
\end{tabular}

The presence of about 500-1700 mg/L (0.05-0.17\%) of Isopar $\mathrm{L}^{\circledR}$ and Modifier may provide some explanation for the lack of clarity of aqueous streams exiting the contactors (Figure 4-18, Figure 4-19, and Figure 4-20). However, as shown in the comparison of graduated cylinders for Tests 7A and 7B (Figure 4-20), which were taken from the same location but at different times, there is a significant amount of air entrainment that dissipates in time. Similar behavior, although 
less explicit, can be seen in the pictures for Test 2B (Figure 4-19) and in the presence of gas bubbles along the side wall of the graduated cylinder for the sample from Test 4D (Figure 4-18).

The presence of air in the post-contactor solutions is a cause for concern, at least as a point of comparison with the $2-\mathrm{cm}$ contactor testing of NGS. ${ }^{[3]}$ In the small-scale NGS tests, no visible entrainment of air was noted for either the non-radioactive simulant or actual Tank $49 \mathrm{H}$ waste tests. Extraction, stripping, and solvent outlet streams were clear instead of cloudy. Concurrent with the lack of cloudiness, the amount of solvent in the DSS and SE streams for the nonradioactive test was $<50 \mathrm{mg} / \mathrm{L}$; for the radioactive test, the concentration of solvent in the DSS was no more than $140 \mathrm{mg} / \mathrm{L}$ and in the SE it was $\sim 24 \mathrm{mg} / \mathrm{L}$. It should be noted that the solvent carry over measurements for the $2-\mathrm{cm}$ contactor tests were collected without a coalescer and using a 5-min decanter residence time for the DSS and a 20-min residence time for the SE.

When the current test data compared to previous V5 and V10 contactors tests with BOB CalixC6 solvent, the measured Isopar $\mathrm{L}^{\circledR}$ carry over values are of the same order of magnitude for extraction, but not for stripping. ${ }^{[14]}$ While carryover for stripping operations were comparable in some cases, in other cases the carryover was appreciably (e.g., 2-3X) higher. It should be noted, however, that the data for stripping are for dilute nitric acid, not $\mathrm{H}_{3} \mathrm{BO}_{3}$. A list of comparable data is provided in Table 5-9. A similar data set from the MCU equipment integrated tests is shown in Table 5-10. ${ }^{[15]}$ In the integrated tests, the carry over numbers are of the same order as those for the current tests. It is worth noting that photographs of process steams from the integrated tests do not show the visible presence of gross air entrainment.

Table 5-9. Solvent Carry Over from Individual Contactor Tests with BOB CalixC6 ${ }^{[14]}$

\begin{tabular}{|c|c|c|c|c|c|}
\hline $\begin{array}{c}\text { Test ID } \\
\text { for } \\
\text { Comparison }\end{array}$ & $\begin{array}{c}\text { Contactor } \\
\text { Type }\end{array}$ & $\begin{array}{c}\text { Rotor } \\
\text { Speed } \\
(\mathrm{rpm})\end{array}$ & $\begin{array}{c}\text { Aqeuous } \\
\text { Feed } \\
(\mathrm{gpm})\end{array}$ & $\begin{array}{c}\text { Organic } \\
\text { Feed } \\
(\mathrm{gpm})\end{array}$ & $\begin{array}{c}\text { Average Isopar in } \\
\text { Aqeuous } \\
(\mathrm{mg} / \mathrm{L})\end{array}$ \\
\hline 4A & V5 & 1800 & 0.23 & 1.17 & 83 \\
\hline 4A & V5 & 1800 & 0.31 & 1.67 & 83 \\
\hline 4B & V5 & 2100 & 0.31 & 1.67 & 56 \\
\hline 4B & V5 & 2100 & 0.52 & 2.83 & 1950 \\
\hline 7A & V10 & 1200 & 3.73 & 1.17 & 675 \\
\hline 7A & V10 & 1800 & 5.33 & 1.67 & 1120 \\
\hline 7B & V10 & 1800 & 9.07 & 2.83 & 1550 \\
\hline
\end{tabular}

Table 5-10. Solvent Carry Over from MCU Integrated Tests with BOB CalixC6 ${ }^{[15]}$

\begin{tabular}{|c|c|c|c|c|c|}
\hline $\begin{array}{c}\text { Test ID } \\
\text { for } \\
\text { Comparison }\end{array}$ & $\begin{array}{c}\text { Contactor } \\
\text { Type }\end{array}$ & $\begin{array}{c}\text { Rotor } \\
\text { Speed } \\
(\mathrm{rpm})\end{array}$ & $\begin{array}{c}\text { Aqeuous } \\
\text { Feed } \\
(\mathrm{gpm})\end{array}$ & $\begin{array}{c}\text { Organic } \\
\text { Feed } \\
(\mathrm{gpm})\end{array}$ & $\begin{array}{c}\text { Average Isopar in } \\
\text { Aqeuous } \\
(\mathrm{mg} / \mathrm{L})\end{array}$ \\
\hline 4A & V5 & 1800 & 0.23 & 1.17 & 170 \\
\hline 4B & V5 & 2100 & 0.47 & 2.33 & 370 \\
\hline 4B & V5 & 2100 & 0.57 & 2.83 & 330 \\
\hline 4B & V5 & 2100 & 0.40 & 2.00 & 370 \\
\hline 7A & V10 & 1200 & 3.5 & 1.17 & 85 \\
\hline 7B & V10 & 1800 & 7.0 & 2.33 & 300 \\
\hline 7B & V10 & 1800 & 8.5 & 2.83 & 1000 \\
\hline 7B & V10 & 1800 & 6.0 & 2.00 & 130 \\
\hline
\end{tabular}




\subsection{Coalescer Performance}

Pre-coalescer and post-coalescer samples were measured for Isopar $L^{\circledR}$ and Modifier concentrations by SVOA, HPLC, and FTIR; droplet sizes in the aqueous phase were analyzed by MicroTrac ${ }^{\mathrm{TM}}$. Post-decanter samples were analyzed for Isopar $\mathrm{L}^{\circledR}$ and Modifier concentrations by FTIR. Although pre-coalescer and post-coalescer samples were collected $30 \mathrm{~min}$ (for stripping) to $45 \mathrm{~min}$ (for extraction) apart, it was expected that steady-state operations would have been established and the time difference would be of little significance.

Assuming steady-state operations and correct functioning of the coalescer and decanter, expectations were that the coalescer would contain large droplets of coalesced solvent that was removed from the aqueous stream. As a result of coalescence, the droplet-size data for postcoalescer samples would be expected show larger droplets than the pre-coalescer samples.

\subsubsection{SVOA and FTIR Data}

The important characteristics of the hydraulic tests are displayed in Table 5-11. While this information is also reported in Table 3-1, it is summarized here for clarity. The samples from the strip tests (Tests 4A, 4B, 4C, 4D, and 5C) were analyzed using SVOA and FTIR. Due to a delay in the time between sampling and analyses for the extraction tests (Tests $7 \mathrm{~A}, 7 \mathrm{~B}$, and $7 \mathrm{C}$ ), samples from those tests were also analyzed using HPLC.

Table 5-11. Hydraulic Test Parameters

\begin{tabular}{|c|c|c|c|c|c|}
\hline Test ID & $\begin{array}{c}\text { Contactor } \\
\text { Type }\end{array}$ & $\begin{array}{c}\text { Rotor } \\
\text { Speed } \\
\text { (rpm) }\end{array}$ & $\begin{array}{c}\text { Coalescer } \\
\text { Length (in) }\end{array}$ & $\begin{array}{c}\text { Coalescer } \\
\text { Rated Size } \\
\text { (microns) }\end{array}$ & $\begin{array}{c}\text { Aqueous/organic } \\
\text { Flow Rates (gpm) }\end{array}$ \\
\hline 4A & V5 & 1800 & 20 & 10 & $0.27 / 1$ \\
\hline 4B & V5 & 2100 & 20 & 10 & $0.53 / 2$ \\
\hline 4C & V5 & 2100 & 20 & 10 & $0.80 / 3$ \\
\hline 4D & V5 & 2100 & 20 & 10 & $0.40 / 2$ \\
\hline 5C & V5 & 2100 & 10 & 5 & $0.80 / 3$ \\
\hline 7A & V10 & 1200 & 40 & 20 & $4 / 1$ \\
\hline 7B & V10 & 1700 & 40 & 20 & $8 / 2$ \\
\hline 7C & V10 & 1700 & 40 & 20 & $12 / 3$ \\
\hline
\end{tabular}

The Isopar $\mathrm{L}^{\circledR}$ and Modifier data for strip testing measured by SVOA are listed in Table 4-6. Because of the scatter associated with the data, an analysis of the data was required to determine which data were technically admissible for comparison with FTIR data. The total organic concentration in the SVOA samples sometimes exceeded the upper calibration range for the analytical method. Since the respective calibration lines for Isopar $\mathrm{L}^{\circledR}$ and Modifier show increasing non-linearity at higher concentrations, the data becomes less reliable and eventually invalid at high concentrations. To assess this limitation, the data were plotted based on the expected Isopar-to-Modifier ratio, which was 3.65 in the NGS blend. Based on the SVOA uncertainty of $20 \%$, the Isopar-to-Modifier ratio data were analyzed at $+/-40 \%$ of the expected value. The analysis is shown in Figure 5-2.

Table 5-12 shows data with the expected Isopar-to-Modifier ratio in green highlights. Yellow highlights show instances with Modifier concentration concentrations fall within the analytical calibration range but with Isopar-to-Modifier ratio outside the expected range. The red highlighted data show instance in which the Modifier concentration exceeded the calibration range and for which the Isopar-to-Modifier data does not agree with expected values. Those data highlighted in either green or yellow in Table 5-12 are the primary basis for comparison with FTIR. 
Further examination of the green highlighted values in Table 5-12 show a Modifier concentration ranging between 110 and $180 \mathrm{mg} / \mathrm{L}$. Within the method uncertainty of $20 \%$ for the upper and lower bounds of the range for the Modifier, many of the other samples in Table 5-12 (highlighted in yellow) offer potential data points for Modifier comparison with FTIR. On a related note, the Isopar-to-Modifier ratio of the FTIR data (Table 4-8) for Tests 4A, 4C, 4D, and 5C are all (except one) $\pm 30 \%$ of the expected ratio. Test $4 \mathrm{~B}$ data had ratios of 2.26-2.64.

For the extraction test data (Table 5-13), sufficient data have acceptable Isopar-to-Modifier ratios (highlighted in green) to not require additional assumptions about the Modifier concentration (highlighted in yellow in Table 5-12). The SVOA and HPLC data always show statisticallysignificant greater concentrations of solvent (30-1500\%) in the post-coalescer samples when compared with the previous pre-coalescer sample. The same increase in solvent concentration does not appear in the FTIR data.

Table 5-13 shows the measured ratio of Isopar $\mathrm{L}^{\circledR}$ to Modifier by FTIR was higher than expected in the extraction tests, especially in Test 7B. Inspection of the FTIR spectra shows that the presence of nitrate provides peaks in the same wavelength range as the dominant peak for the Modifier. Quantification of the Modifier concentration by FTIR is based on a reference sample of caustic solution without any organic history. When this reference was subtracted from the spectra measurements, the nitrate peaks "inverted" indicating a higher nitrate concentration in the reference solution than in the solution being processing in the contactor. Hence, the area of the Modifier peaks in the FTIR difference spectra are biased appreciably low for all the extraction tests. Use of FTIR for on-line monitoring in the process facility may require a concurrent reference sample analysis of the feed salt solution to mitigate this data analysis limitation if measurement of Modifier is desired. For this study, the measurement of Modifier was added after discovering discrepancies with the SVOA data.

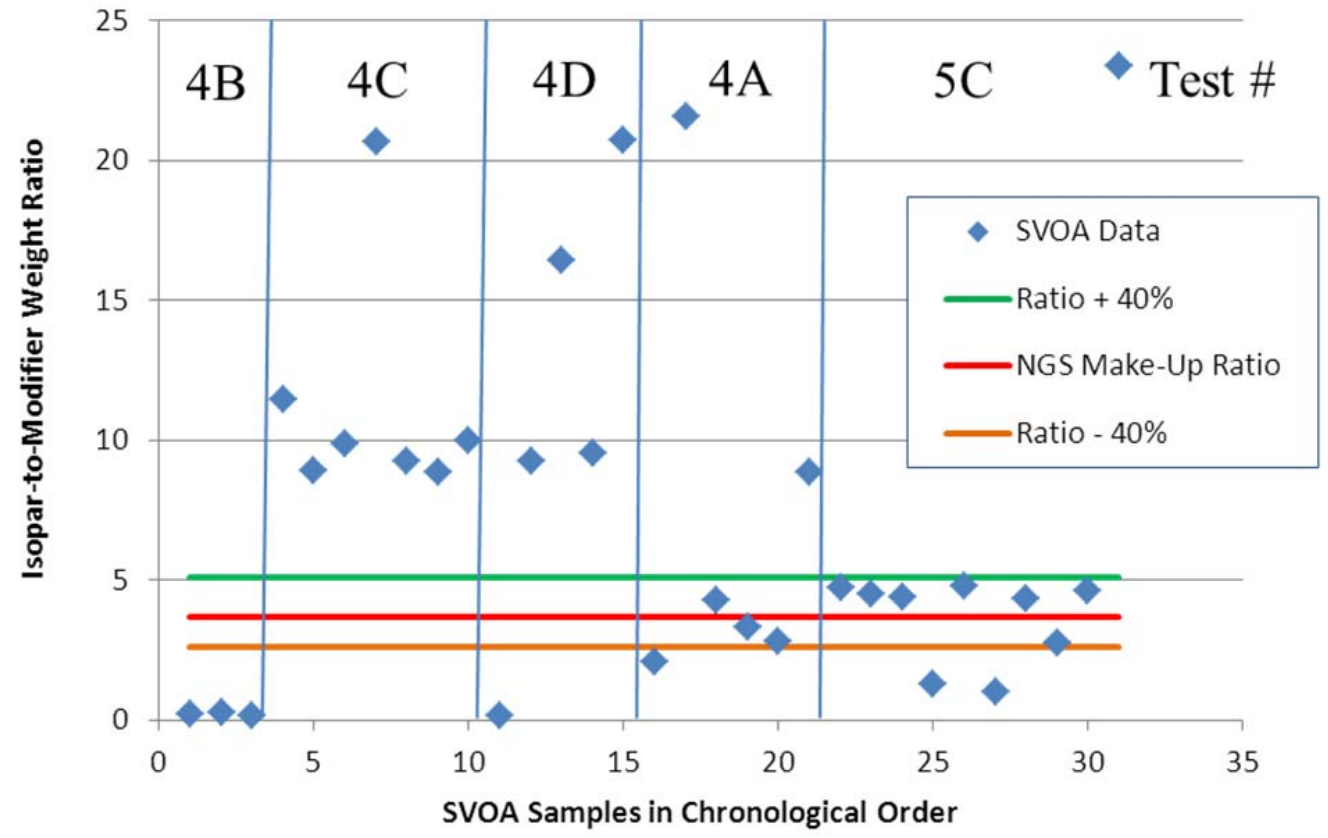

Figure 5-2. Analysis of SVOA Strip Data for Admissibility 
Table 5-12. SVOA/FTIR Data Comparison - Strip Tests

\begin{tabular}{|c|c|c|c|c|c|}
\hline Test ID & $\begin{array}{l}\text { Pre or Post } \\
\text { Coalescer? }\end{array}$ & $\begin{array}{l}\text { SVOA } \\
\text { Isopar } \\
(\mathrm{mg} / \mathrm{L})\end{array}$ & $\begin{array}{l}\text { SVOA } \\
\text { Modifier } \\
(\mathrm{mg} / \mathrm{L})\end{array}$ & $\begin{array}{l}\text { FTIR } \\
\text { Isopar } \\
\text { (mg/L) } \\
\end{array}$ & $\begin{array}{c}\text { FTIR } \\
\text { Modifier } \\
(\mathrm{mg} / \mathrm{L})\end{array}$ \\
\hline $4 \mathrm{~B}$ & pre & 16 & 86 & & \\
\hline $4 B$ & post & 23 & 100 & & \\
\hline $4 B$ & pre & 10 & 63 & & \\
\hline $4 \mathrm{C}$ & pre & 1733 & 151 & 606 & 230 \\
\hline $4 \mathrm{C}$ & post & 1161 & 130 & 516 & 220 \\
\hline $4 C$ & pre & 1336 & 135 & 550 & 214 \\
\hline $4 \mathrm{C}$ & post & 6786 & 328 & 621 & 270 \\
\hline $4 \mathrm{C}$ & pre & 1426 & 154 & & \\
\hline $4 \mathrm{C}$ & post & 1477 & 167 & 514 & 227 \\
\hline $4 \mathrm{D}$ & pre & 1891 & 189 & & \\
\hline $4 \mathrm{D}$ & post & 13 & 103 & & \\
\hline 4D & pre & 1885 & 204 & 487 & 137 \\
\hline $4 \mathrm{D}$ & post & 6013 & 366 & 522 & 108 \\
\hline 4D & pre & 1878 & 197 & 533 & 144 \\
\hline $4 \mathrm{D}$ & post & 12725 & 614 & 506 & 130 \\
\hline $4 \mathrm{~A}$ & pre & 225 & 110 & 1298 & 342 \\
\hline $4 \mathrm{~A}$ & post & 14125 & 654 & 1359 & 347 \\
\hline $4 \mathrm{~A}$ & pre & 508 & 119 & 1289 & 370 \\
\hline $4 \mathrm{~A}$ & post & 431 & 130 & 1269 & 358 \\
\hline $4 \mathrm{~A}$ & pre & 318 & 113 & 1305 & 463 \\
\hline $4 \mathrm{~A}$ & post & 1818 & 206 & 1287 & 442 \\
\hline $5 \mathrm{C}$ & pre & 788 & 166 & 1323 & 346 \\
\hline $5 \mathrm{C}$ & post & 725 & 161 & 1369 & 323 \\
\hline $5 \mathrm{C}$ & pre & 802 & 182 & 1304 & 328 \\
\hline $5 \mathrm{C}$ & post & 146 & 115 & 1327 & 395 \\
\hline $5 \mathrm{C}$ & pre & 793 & 165 & 1323 & 346 \\
\hline $5 \mathrm{C}$ & post & 96 & 98 & 1325 & 466 \\
\hline $5 \mathrm{C}$ & pre & 689 & 160 & 1322 & 442 \\
\hline $5 \mathrm{C}$ & post & 344 & 126 & 1387 & 446 \\
\hline $5 \mathrm{C}$ & pre & 787 & 170 & & \\
\hline $5 \mathrm{C}$ & post & 36871 & 1575 & & \\
\hline \multicolumn{6}{|c|}{$\begin{array}{l}\text { - Green indicates acceptable Isopar-to-Modifier ratio } \\
\text { - Yellow indicates unacceptable Isopar-to-Modifier ratio but the } \\
\text { Modifier concentration is in the calibration range } \\
\text { - Red indicates unacceptable Isopar-to-Modifier ratio and Modifier } \\
\text { concentration outside of the calibration range }\end{array}$} \\
\hline
\end{tabular}


Table 5-13. SVOA/HPLC/FTIR Data Comparison - Extraction Tests

\begin{tabular}{|c|c|c|c|c|c|c|}
\hline $\begin{array}{c}\text { Test } \\
\text { ID }\end{array}$ & $\begin{array}{l}\text { Pre or Post } \\
\text { Coalescer? }\end{array}$ & $\begin{array}{l}\text { SVOA } \\
\text { Isopar } \\
(\mathrm{mg} / \mathrm{L})\end{array}$ & $\begin{array}{l}\text { SVOA } \\
\text { Modifier } \\
(\mathrm{mg} / \mathrm{L})\end{array}$ & $\begin{array}{c}\text { FTIR } \\
\text { Isopar } \\
(\mathrm{mg} / \mathrm{L}) \\
\end{array}$ & $\begin{array}{c}\text { FTIR } \\
\text { Modifier } \\
(\mathrm{mg} / \mathrm{L})\end{array}$ & $\begin{array}{c}\text { HPLC } \\
\text { Modifier } \\
(\mathrm{mg} / \mathrm{L})\end{array}$ \\
\hline $7 \mathrm{~A}$ & Pre & 93 & 73 & & & \\
\hline $7 \mathrm{~A}$ & Post & 1085 & 294 & & & \\
\hline $7 \mathrm{~A}$ & Pre & 161 & 50 & & & 43 \\
\hline $7 \mathrm{~A}$ & Post & 597 & 217 & & & 161 \\
\hline $7 \mathrm{~A}$ & Pre & 113 & 53 & & & \\
\hline $7 \mathrm{~A}$ & Post & 1744 & 628 & & & \\
\hline $7 B$ & Pre & 261 & 75 & 247 & 11 & \\
\hline $7 B$ & Post & 474 & 134 & 211 & 6 & \\
\hline $7 B$ & Pre & 361 & 98 & 357 & 63 & 77 \\
\hline $7 B$ & Post & 1820 & 449 & 325 & 54 & 345 \\
\hline $7 \mathrm{~B}$ & Pre & 220 & 123 & 353 & 51 & \\
\hline $7 B$ & Post & 2130 & 675 & 359 & 39 & \\
\hline $7 \mathrm{C}$ & Pre & 388 & 155 & 60 & & \\
\hline $7 C$ & Post & 1145 & 360 & 70 & & \\
\hline $7 \mathrm{C}$ & Pre & 225 & 150 & 71 & & 99 \\
\hline $7 \mathrm{C}$ & Post & 1208 & 375 & 72 & & 246 \\
\hline $7 \mathrm{C}$ & Pre & 375 & 140 & 88 & & \\
\hline $7 \mathrm{C}$ & Post & 492 & 232 & 72 & & \\
\hline \multicolumn{7}{|c|}{$\begin{array}{l}\text { - Green indicates acceptable Isopar-to-Modifier ratio } \\
\text { - Yellow indicates unacceptable Isopar-to-Modifier ratio but the Modifier concentration is } \\
\text { in the calibration range } \\
\text { - Red indicates unacceptable Isopar-to-Modifier ratio and Modifier concentration outside } \\
\text { of the calibration range }\end{array}$} \\
\hline
\end{tabular}

The flow rate and pressure drop in the sampling loop differed appreciably for the FTIR analyzer and the grab samples. The flow rate for the grab samples was appreciably faster. Grab samples were collected in $60-80 \mathrm{~mL}$ over about four seconds; the sampling valve provided little pressure restriction and the velocity was relatively high (e.g., $\sim 1 \mathrm{~L} / \mathrm{min}$ ). For the FTIR analyzer, the design restricted flow through the sampling loop to $\sim 10 \mathrm{~mL} / \mathrm{min}$ to mimic the range used in earlier development of the analyzer. The added pressure drop from the longer length of tubing and the presence of a flow control valve reduced the flow rate to the FTIR probe. Hence the motive force to move larger droplets or globules toward the FTIR analyzer was less than for the grab samples. As a result, the FTIR data will under-report total organic concentration. A full mathematical reduction of the impact of pressure drop on two phase flow is beyond the scope of this analysis. However, the reader can consult the literature for a methodology that will facilitate such calculations. ${ }^{[17]}$

The FTIR analyzer also will only detect droplets within a limited penetration length of the probe. The penetration distance is a function of the laser energy and the specific material absorbance. Using standard analysis, we roughly estimate the penetration depth for this configuration as on the order of 15 microns. $^{[18]}$ As the effective diameter of globules exceed roughly $2 \mathrm{X}$ the penetration depth, the FTIR loses the ability to discriminate the contribution of these droplets to the overall concentration in the time averaging that occurs. As with the discussion in the preceding paragraph, larger globules will be less likely to contact the probe tip due to the pressure 
gradient boundary. Further development of the on-line analyzer will need to assess the impact of sampling rate and droplet size discrimination prior to final deployment of the equipment.

Interpretation and comparison of the SVOA and FTIR data requires an understanding of the sampling configuration for the system, without which the apparent differences in the data will not make sense. Labeled pictures of the piping and sample flows are provided in Figure 5-3 and Figure 5-4. As liquid flows from the Aqueous Receipt Tank (Line 1 of Figure 5-3) along the horizontal section of piping, it flows past the pre-coalescer sampling point (Line 2). For SVOA, a relatively large sample is taken (via downward flow) in a relatively short time $(\sim 4 \mathrm{~s})$. For FTIR, a small sample (Line 3 ) is continuously drawn off from below the pipe and sent to the FTIR. The post decanter sample (Line 5) to the FTIR shares a section of piping (Line 6) with the precoalescer FTIR sample. It should also be noted that the SVOA (and HPLC) samples are collected over a relatively short time (seconds) while the FTIR data is averaged over a substantially longer period (minutes). Consequently, variations in sample content due to slugs of coalesced solvent may be more apparent in the SVOA and HPLC data.

The pre-coalescer sampling point for both the FTIR and the bulk sample (for SVOA) share a common piping tee at the same elevation. The liquid comes from the exact same line at the same elevation. The only substantive difference between the two samples is the added pressure drop on the tubing to the FTIR sampling line and hence a different (longer) time to flush the line. Sampling is controlled by separate valves to either instrument from a common tee. The valves are normally in the off position except when sampling. One other minor difference is that the FTIR sample was always obtained after the SVOA grab sample, being taken a few seconds later.

For post-coalescer sampling (Figure 5-4), the upward vertical flow from the coalescer (Line 9) contains both aqueous and coalesced solvent. As the combined flow passes the post-coalescer sampling point for SVOA (Line 7), nothing prevents the sampling of either aqueous or coalesced solvent or both. For sampling of the post-coalescer stream for FTIR, the horizontal sampling line (Line 8) does not extend into the post-coalescer pipe (Line 9). Due to natural upward flow of the less-dense solvent traveling in the vertical pipe and the smaller diameter of Line 8 (compared to Line 9), the FTIR sampling configuration may preclude capture of bulk coalesced solvent as readily as a sample collected as a grab sample over a relatively short time. Conversely, the collection of a grab sample over a short time $(\sim 4 \mathrm{~s})$ for SVOA could result in large globules of coalesced solvent being collected with the sample, thereby introducing bias into the SVOA data.

The sampling configuration has several ramifications for the data in Table 5-12 and Table 5-13. The first is that the pre-coalescer sample for FTIR, because it is a small flow drawn from the bottom of a larger horizontal flow, may not be representative of pre-coalescer flow. In this piping configuration, any large globules of solvent have the potential to rise in the large diameter pipe and not be drawn into the FTIR sample. If that occurred, the sample would be similar a postcoalescence sample due to the time that passes from the time of sampling (already nonrepresentative) to the time of analysis. In a similar manner, the post-coalescer FTIR sample (Line 8) does not have large globules in the solution being analyzed. Consequently, the pre- and post-coalescer samples measured by FTIR would both appear as post-coalescence samples with the coalesced material not part of the analyses. Therefore, the data of Table 5-12 and Table 5-13, which show no consistent difference between pre- and post-coalescer samples, can be seen as the expected response.

The comparable results for pre- and post-coalescer samples also helps explain why the postdecanter data are comparable to those of the pre- and post-coalescer samples (Table 4-8). The pre-coalescer and post-decanter samples to FTIR share a common line. Although calculations were conducted to determine the amount of time required to flush the pre-coalescer sample from the line so that a representative post-decanter reading could be obtained, apparently there was 
some other effect at work. In particular, the volume of the decanter is nominally 400 gal while the total aqueous flow for stripping tests were $\sim 200$ gal (Test 4B), 300 gal (Test 4C), 160 gal (Test 4D), $\sim 100$ gal (Test 4A), and $\sim 300$ gal (Test $5 \mathrm{C}$ ). No single test, or in some cases two successive tests, was able to completely replace the volume in the decanter. As a result, the postdecanter measurement should reflect to some degree the organic concentration in the aqueous from the previous test or two tests prior. However, the post-decanter data (Table 4-8) always show solvent concentrations comparable for the pre- and post-coalescer data for the current test.

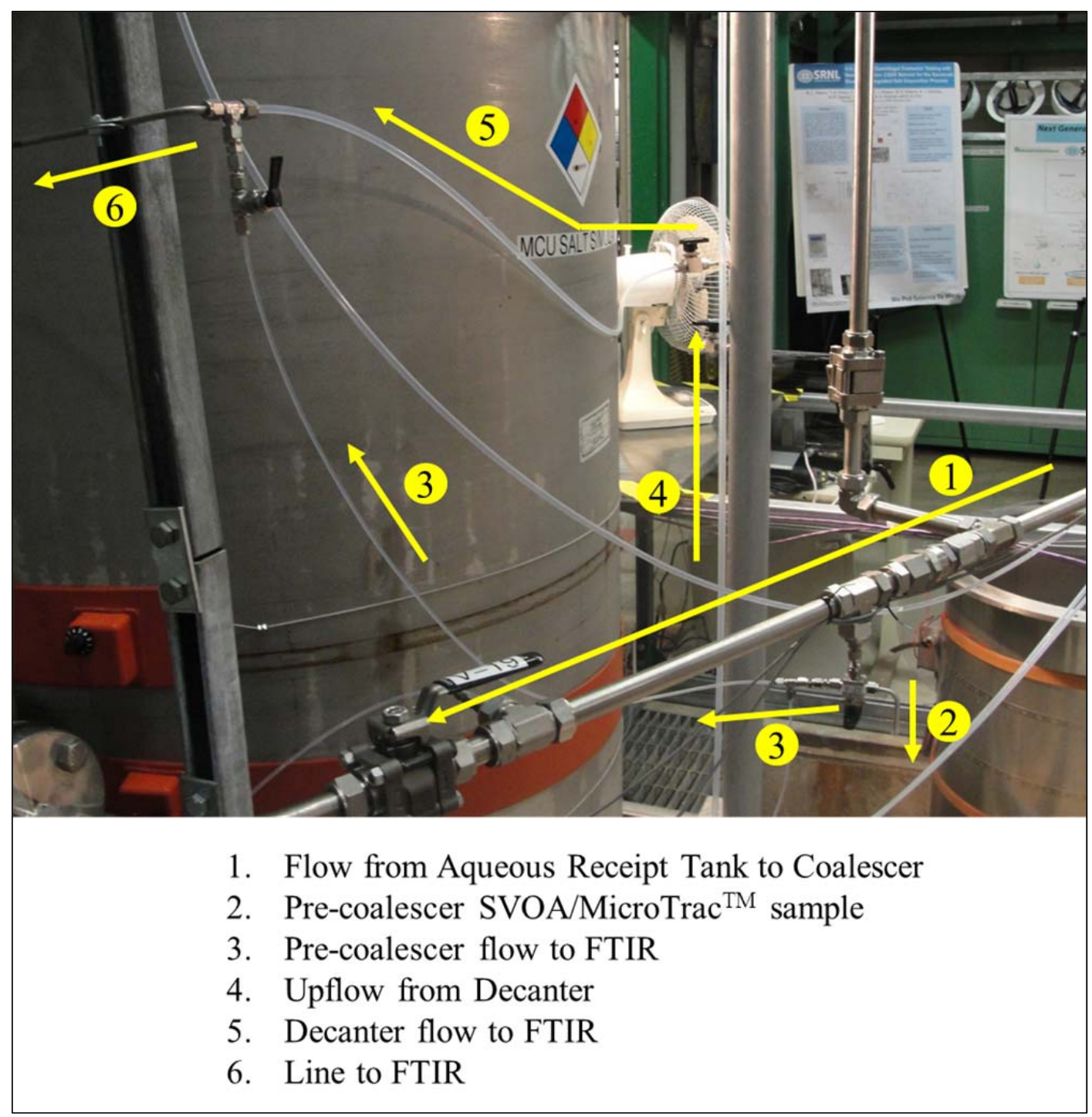

Figure 5-3. Pre-Coalescer and Decanter Sampling 


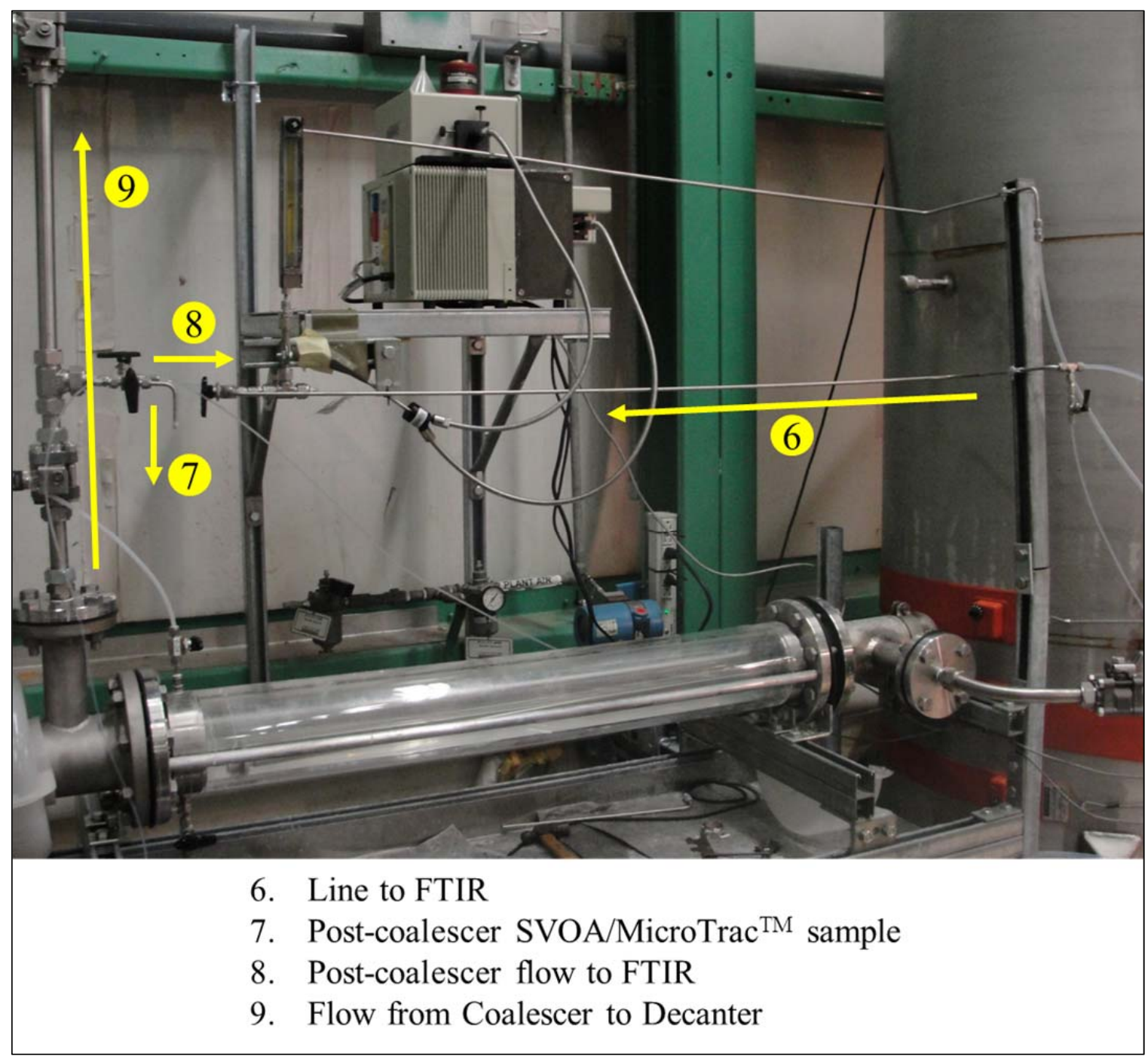

Figure 5-4. Post-Coalescer Sampling

A second consequence of the sampling is that it prevents any meaningful comparison of the FTIR and SVOA data. There are many places where the Isopar $\mathrm{L}^{\circledR}$ or Modifier or both concentrations agree between SVOA and FTIR. However, there are even more samples that show little or no correlation. To only pick the instances of data matching and conduct an analysis based on those would not be founded on good science. Nonetheless, both sets of analyses (SVOA and FTIR) contain internal consistencies that preclude eliminating either data set.

A third ramification of sampling strategy is reflected in the SVOA data of Table 5-13. In every sample, the post-coalescer concentration exceeds the concentration of the prior pre-coalescer sample. It should be noted that the general agreement of HPLC data for Modifier with SVOA Modifier measurements provides some level of validation for the SVOA data. However, both methods share a common sample preparation, so the methods are not independent. Using the SVOA Modifier data as a basis, the lowest Modifier concentration increase between pre- and post-coalescer samples was $70 \%$, with a maximum of $1180 \%$ and an average of $430 \%$. The mostlikely explanation is that volumes of coalesced solvent are being collected as part of the postcoalescer SVOA samples. This effect can even be seen in retrospect in some of the data in Table 5-12 (red highlighted data from Tests 4C, 4D, 4A, and 5C). What appears to be an 
aberration may now be viewed in light of the sample port configuration. However, the explanation still does not explain why the Isopar-to-Modifier ratios for those samples do not match the expected ratio.

It should be noted, that the pre-coalescer data in Table 5-13 seem to represent good measurements of carryover during extraction testing. The quantity of Isopar $\mathrm{L}^{\circledR}$ was $\sim 160 \mathrm{mg} / \mathrm{L}$ at low flow, $\sim 250-350 \mathrm{mg} / \mathrm{L}$ at moderate flow, and $\sim 220-390 \mathrm{mg} / \mathrm{L}$ at high flow. For the above Isopar $\mathrm{L}^{\circledR}$ concentrations, Modifier was also present at the nominal Isopar-to- Modifier ratio of 3.65.

Although issues with the post-coalescer SVOA sampling do present a problem, the elimination of non-representative samples from the data set for stripping still leaves enough data to observe the effect of the coalescer and the concentration of carryover from the contactor. Table 5-14 offers a subset of the SVOA data based on the above discussions. The first trend that becomes apparent is that the pre-coalescer data (highlighted) for each test are consistent within the test. For low-flow conditions, Isopar $\mathrm{L}^{\circledR}$ was $\sim 300-500 \mathrm{mg} / \mathrm{L}$. For moderate-flow conditions, Isopar $\mathrm{L}^{\circledR}$ was $\sim 1800$ $1900 \mathrm{mg} / \mathrm{L}$. For high-flow conditions, Isopar $\mathrm{L}^{\circledR}$ was $\sim 1350-1750 \mathrm{mg} / \mathrm{L}$ for one test and $\sim 700$ $800 \mathrm{mg} / \mathrm{L}$ for a second test. For the above Isopar $\mathrm{L}^{\circledR}$ concentrations, Modifier was also present at the nominal Isopar-to-Modifier ratio of 3.65.

The second observation is that the post-coalescer data (highlighted) tend to represent a reduction in solvent concentration from the pre-coalescer concentration, although with much more scatter in the data. Three of six post-coalescer analyses are lower than the pre-coalescer analyses (outside of measurement uncertainty) and three of six post-coalescer analyses show no change (within measurement uncertainty) when compared to the corresponding pre-coalescer concentration. A reduction in concentration may also indicate the coalescer had not reached steady-state operation in these tests. In light of the issues associated with post-coalescer SVOA sampling, this increased scatter for the post-coalescer samples is not surprising.

Table 5-14. Subset of SVOA Data - Strip Tests

\begin{tabular}{|c|c|c|c|}
\hline Test ID & $\begin{array}{c}\text { Pre or Post } \\
\text { Coalescer } ?\end{array}$ & $\begin{array}{c}\text { SVOA } \\
\text { Isopar } \\
(\mathrm{mg} / \mathrm{L})\end{array}$ & $\begin{array}{c}\text { SVOA } \\
\text { Modifier } \\
\text { (mg/L) }\end{array}$ \\
\hline 4C & pre & 1733 & 151 \\
\hline 4C & post & 1161 & 130 \\
\hline 4C & pre & 1336 & 135 \\
\hline 4C & pre & 1426 & 154 \\
\hline 4C & post & 1477 & 167 \\
\hline 4D & pre & 1891 & 189 \\
\hline 4D & pre & 1885 & 204 \\
\hline 4D & pre & 1878 & 197 \\
\hline 4A & pre & 508 & 119 \\
\hline 4A & post & 431 & 130 \\
\hline 4A & pre & 318 & 113 \\
\hline 5C & pre & 788 & 166 \\
\hline 5C & post & 725 & 161 \\
\hline 5C & pre & 802 & 182 \\
\hline 5C & post & 146 & 115 \\
\hline 5C & pre & 793 & 165 \\
\hline 5C & pre & 689 & 160 \\
\hline 5C & post & 344 & 126 \\
\hline 5C & pre & 787 & 170 \\
\hline
\end{tabular}




\subsubsection{MicroTrac ${ }^{\mathrm{TM}}$ and Microscopy}

The droplet-size data obtained by MicroTrac ${ }^{\mathrm{TM}}$ consistently show that the particle sizes measured post-coalescer exceed those measured pre-coalescer. The conclusion is based on calculations of the particle size for the $50^{\text {th }}$ percentile, but the same general observation can be made for the $25^{\text {th }}$, $75^{\text {th }}$, and $90^{\text {th }}$ percentiles. The occurrence of particle-size increase does not apply for all pre- and post-coalescer sequences, but does represent the majority of the data. Although the data contains a significant amount of scatter, typical particle-size increases are between 25 and $180 \%$.

Notable exceptions to the general trend are the first four samples for Tests $4 \mathrm{~B}$ and $4 \mathrm{C}$ (Table 4-9). The occurrence of negative particle size growth for these first few samples of the lower-flow rate tests suggests that perhaps there is an incubation period before the coalescer functions correctly. A similar incubation period for Test $5 \mathrm{C}$ (when the coalescer was changed prior to Test $5 \mathrm{C}$ ) can also be noted (Table 4-10).

The increase in droplet size appears to be greater, in general, for stripping tests than for the extraction tests (following the incubation period in the stripping tests). This behavior may be attributable to the smaller coalescer pore sizes used for the stripping tests (Table 3-1). For the extraction tests, the post-coalescer droplet sizes are always greater than the pre-coalescer measurement (Table 4-11), with modest particle-size increases ranging from $5-25 \%$. It is worth noting that the extraction data are much more consistent with little scatter.

The growth of particle sizes measured using MicroTrac ${ }^{\mathrm{TM}}$, and hence coalescence of solvent, is consistent with macro-scale observations of the coalescers. Still pictures of the coalescers (Figure 4-21) clearly show the removal of solvent from the aqueous stream through coalescence.

Since the 2005 testing at SRNL and Wright Industries used different configurations than this study, direct comparison of droplet size data with the current study requires caution. The SRNL testing examined only the performance of the V-5 contactor for stripping operation. ${ }^{[16]}$ The configuration included a 55 gal stilling tank, similar to the size of tank used in this study. The strip acid passed through a coalescer media prior to entering the tank. Personnel collected samples from the tank over a 50 minute period and analyzed for droplet size using the same protocols as in the study - and using an earlier model of MicroTrac ${ }^{\mathrm{TM}}$ instrument.

Figure 5-5, which is comparable to Figure 19 of Reference 16, shows a comparison of the data sets. The droplet distributions for the baseline solvent all show a higher fraction of lower diameter droplets than any of the sample points from this study, even though the 2005 data all is after passing through a coalescer media. Even after 50 minutes of operation, which would result in coalescence of droplets, the 2005 droplet size distributions still contain a higher fraction of smaller diameter droplets than any of the samples after collected after 30 minutes in this study. Although far from a rigorous comparison, this data suggests that the droplet sizes produced with the NGS may be larger than those produced with the baseline solvent under similar operating conditions. 


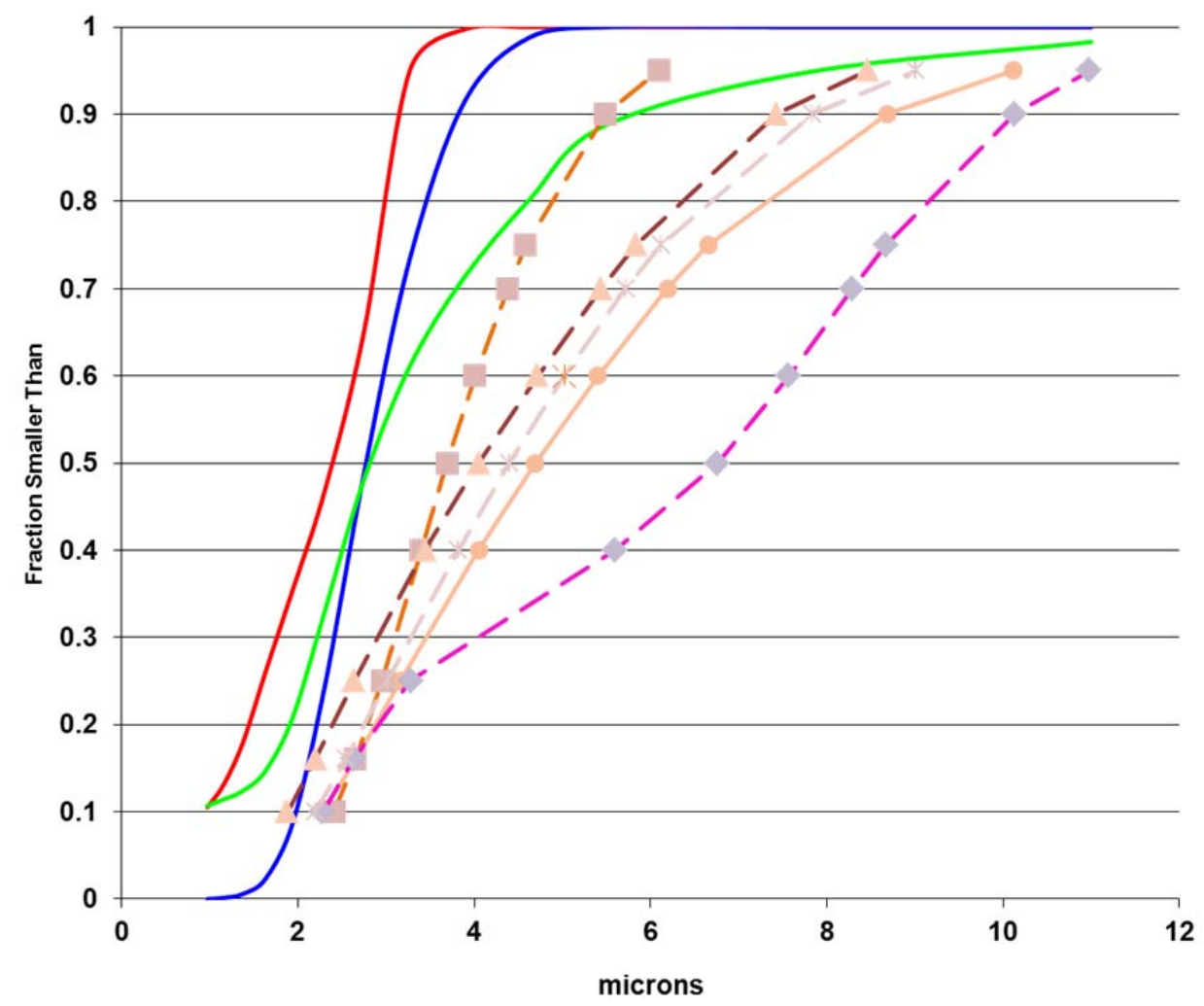

Figure 5-5. Droplet-Size Data from 2005 and 2011 Strip Effluent Streams

(The solid lines in Figure 5-5 show the 2005 data: red, initial sample; blue, after 27 minutes; and green, after 50 minutes. The dashed lines show the data for samples collected after 30 minutes for the test series of this study).

Due to operability issues, too few useful PLM pictures exist to make conclusions about coalescer performance. The best that can be obtained from the PLM data is a qualitative assessment of whether the PLM data correlates with the MicroTrac ${ }^{\mathrm{TM}}$ data. If the PLM and MicroTrac ${ }^{\mathrm{TM}}$ data correlate, it may offer a reason for considering whether to use PLM for future testing. For Test 4C, the droplet sizes in Figure 4-11 appear to be consistently greater than indicated for the data in Table 4-9; a similar behavior was observed for Test 5C between the droplets in Figure 4-12 and the data in Table 4-10. The data for Test 7A (Figure 4-13 and Table 4-11) show reasonable correlation between the PLM and MicroTrac ${ }^{\mathrm{TM}}$ data.

\subsubsection{Turbidity Measurements}

SRNL attempted to correlate the turbidity with bulk organic carryover during testing (Figure 4-9 and Figure 4-10). However, the increase in turbidity during almost every test is probably a function of increased air entrainment from the contactor operations and no correlation could be developed. The presence of air in the samples is depicted in Figure 4-18, Figure 4-19, and Figure 4-20. Even after a period of settling, cloudiness in the aqueous solutions persisted. Pictures taken with PLM (Figure 4-11 and Figure 4-13) also show the presence of air bubbles in the aqueous stream for both stripping and extraction. 


\subsubsection{Extended Coalescer Operation}

MCU typically measures pressure drop across the coalescer as psid per total volume pumped. To provide some comparison of the behavior of the different coalescers tested, the same data were collected during hydraulic testing. The results of all tests were plotted and a best-fit line drawn through data where the slope of the line represents the fouling rate of the coalescer. The fouling rate data are summarized in Figure 5-6. The data suggest that the "fouling" associated with lower flow rates is greater than that of the higher flow rates. The data also shows, as expected, that the pressure drop growth across the 40-in, 20-micron coalescer is much less than that of the shorter, less-porous coalescers. The 10-in, 5-micron coalescer at high flow may have a lower $\mathrm{dP}$ growth rate than its 20-in, 10-micron counterpart because the test with the 10-in, 5-micron coalescer represented operations with a new coalescer while the high flow rate in the 20-in, 10-micron coalescer reflects a coalescer that had already been used for at least two previous tests. It should be noted, however, that with all of the data in Figure 5-6 the time frame for the data collection is small in comparison with the operational life time of a coalescer in MCU.

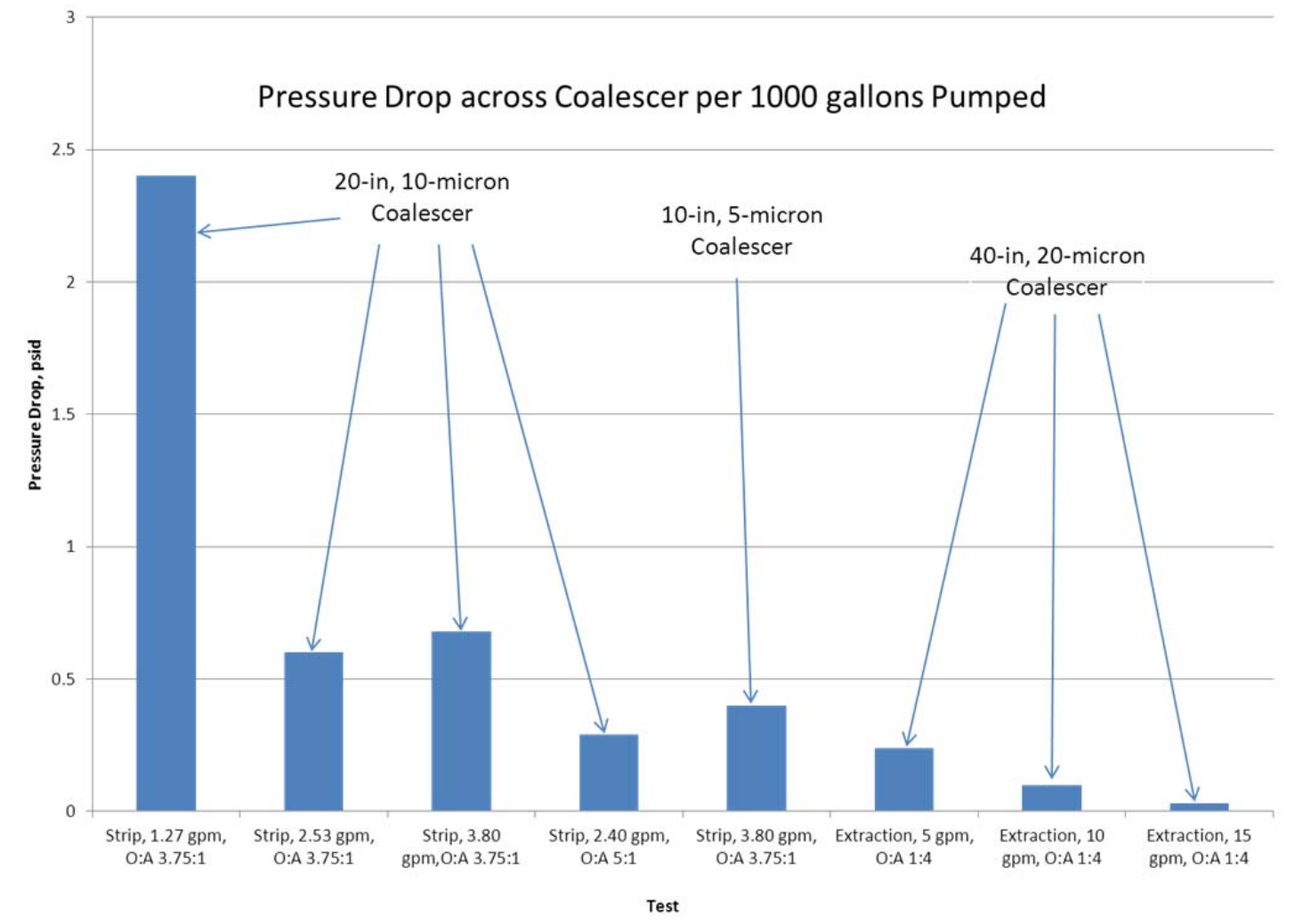

Figure 5-6. Coalescer Pressure Drop per 1000 gallons pumped.

\subsection{Decanter Performance}

The only method available for measuring the effect of the decanter on solvent concentration in the aqueous stream was FTIR. It should be noted that the decanter design was not prototypic of the MCU (or SWPF) design. Also, the working volume of the decanter was on the order of 400 gal while the flow of aqueous to the decanter ranged from 0.27-0.80 gal for stripping tests and 412 gal for extraction tests. Consequently, the residence time in the decanter during stripping tests was on the order of 500-1500 min, which means the decanter readings for stripping tests actually correspond better to the test conducted three days prior. Conversely, for extraction testing, the residence times were 33-100 $\mathrm{min}$. 
The data from Table 4-8 have been consolidated in Table 5-15. For clarity, the data that were labeled "post" (for post-coalescer) and "decanter" in Table 4-8 have be re-named "pre" (for predecanter) and "post" (for post-decanter), respectively, in Table 5-15. Within method uncertainty, there was no change in Isopar $\mathrm{L}^{\mathbb{B}}$ or Modifier concentrations due to the operation of the decanter. However, as described in Section 5.2.1, the result may be due to issues associated with sample port configuration.

Table 5-15. FTIR Data Pre- and Post-Decanter

\begin{tabular}{|c|c|c|c|c|c|c|}
\hline Test 4B & pre-decant & pre-decant & pre-decant & post-decant & & \\
\hline MicroTrac Sample & 6 & 8 & 10 & & & \\
\hline Isopar L (mg/L) & 516 & 621 & 514 & 610 & & \\
\hline Modifier (mg/L) & 220 & 270 & 227 & 244 & & \\
\hline Test 4C & pre-decant & pre-decant & pre-decant & post-decant & post-decant & \\
\hline MicroTrac Sample & 2 & 4 & 6 & & & \\
\hline Isopar L (mg/L) & 211 & 371 & 349 & 375 & 396 & \\
\hline Modifier (mg/L) & 110 & 95 & 93 & 103 & 95 & \\
\hline Test 4D & pre-decant & pre-decant & post-decant & & & \\
\hline Sample & 6 & 8 & & & & \\
\hline Isopar L (mg/L) & 522 & 506 & 573 & & & \\
\hline Modifier (mg/L) & 108 & 130 & 148 & & & \\
\hline Test 4A & pre-decant & pre-decant & pre-decant & post-decant & post-decant & post-decant \\
\hline MicroTrac Sample & 2 & 4 & 6 & & & \\
\hline Isopar L (mg/L) & 1359 & 1269 & 1287 & 1331 & 1321 & 1301 \\
\hline Modifier $(\mathrm{mg} / \mathrm{L})$ & 347 & 358 & 442 & 370 & 420 & 359 \\
\hline
\end{tabular}

\begin{tabular}{|l|c|c|c|c|c|c|}
\hline Test 5C & pre-decant & pre-decant & pre-decant & pre-decant & post-decant & post-decant \\
\hline MicroTrac Sample & 2 & 4 & 6 & 8 & & \\
\hline Isopar L (mg/L) & 1369 & 1327 & 1325 & 1387 & 1370 & 1297 \\
\hline Modifier (mg/L) & 323 & 395 & 466 & 446 & 362 & 454 \\
\hline
\end{tabular}

\begin{tabular}{|l|c|c|c|c|}
\hline Test 7B & pre-decant & pre-decant & pre-decant & post-decant \\
\hline MicroTrac Sample & 2 & 4 & 6 & \\
\hline Isopar L (mg/L) & 211 & 325 & 359 & 313 \\
\hline Modifier (mg/L) & 6 & 54 & 39 & 17 \\
\hline
\end{tabular}




\subsection{Conclusions}

SRNL designed a pilot-scale experimental program to test the full size strip (V5) and extraction (V10) contactors and the associated strip and extraction effluent coalescers to determine the hydraulic and mass transfer characteristics with the NGS. In the course of the program, SRNL determined the Cs mass transfer distribution ratios for a single stage of strip, scrub, and extraction centrifugal contactors. The test program evaluated the amount of organic carryover and the droplet size of the carryover phases using SVOA, FTIR, PLM, and MicroTrac ${ }^{\mathrm{TM}}$ analyses. Data were collected related to coalescer performance and visual observations of coalescence were made. The test program also assessed the impact of high flow rate conditions for both extraction and strip operations.

\subsection{Mass Transfer Testing}

Stage efficiency and mass distribution ratios were determined using Cs mass transfer measurements. For the extraction tests, in each of the four tests, the $\mathrm{D}(\mathrm{Cs})$ results for the individual tests were virtually the same throughout each test. This indicates that equilibrium is achieved rapidly and maintained throughout sampling. For $20 \mathrm{mM}$ extractant (instead of $50 \mathrm{mM}$ for recommended solvent), the nominal $\mathrm{D}(\mathrm{Cs})$ value was 16.0-17.5. The data showed good stage efficiency for extraction, ranging from $98.2 \%$ for the first test to $90.5 \%$ for the fourth test. Although the decrease in stage efficiency was within analytical uncertainty, there is a remaining uncertainty whether a mechanical issue was developing during testing; some of the variance is likely associated with a temperature effect. No statistically-significant differences were noted for operations at $12 \mathrm{gpm}$ aqueous flow when compared with either $4 \mathrm{gpm}$ or $8 \mathrm{gpm}$ of aqueous flow. The stage efficiencies are as good as or better than those previously measured using the baseline CSSX solvent system. The measured stage efficiencies agree with those measured during $2-\mathrm{cm}$ contactor tests with NGS.

The nominal target for distribution ratios for Cs during scrubbing are $\sim 1.0-2.5$. The first scrub test yielded an average scrub value of 1.21 and the second scrub test produced an average value of 0.78 . For the second test, there was a distinct decline in $\mathrm{D}(\mathrm{Cs})$ throughout the test. This may indicate that the slightly lower rotor speed required a longer time to reach equilibrium. The decline may also be related to a shift in $\mathrm{D}(\mathrm{Cs})$ as the $\mathrm{pH}$ is gradually lowered by the scrub solution. Regardless, neither value is considered problematic. Stage efficiency was not calculated for the scrub tests.

For stripping behavior, low Cs distribution values are desired, indicating that the cesium in the solvent is being released into the strip aqueous stream. Six tests were completed in a manner to represent the first strip stage. For three tests at the baseline flow ratios (O:A of 3.75:1) but at different total flow rates, the $\mathrm{D}(\mathrm{Cs})$ values were all similar at $\sim 0.052$. Similar $\mathrm{D}(\mathrm{Cs})$ behavior was observed for two tests performed at an O:A ratio of 7:1 instead of 3.75:1.

The data for the baseline strip tests exhibited acceptable stage efficiency, ranging from $82.0 \%$ for the low-flow test to $89-90 \%$ for medium-flow and high-flow tests. The difference in efficiency may be attributable to the low volume in the contactor housing. The data were temperature corrected to $33{ }^{\circ} \mathrm{C}$. However, process data indicate that while the liquid feed temperatures for these tests were at $33 \pm 3{ }^{\circ} \mathrm{C}$, the outlet temperatures into the holding tanks were on the order of 23-24 ${ }^{\circ} \mathrm{C}$. If temperature corrections are made based on the average of the inlet and outlet temperatures $\left(\operatorname{avg}=28{ }^{\circ} \mathrm{C}\right)$, the stage efficiency increases by about $1.5 \%$ for all three strip tests.

\subsection{Second-Phase Carryover}

The concentrations of Isopar $\mathrm{L}^{\circledR}$ and Modifier were measured using SVOA and FTIR. However, due to issues associated with sample point configuration, the two methods cannot be correlated. 
Isopar $\mathrm{L}^{\circledR}$ data as measured by FTIR for stripping suggests an impact due to rotor speed and net flow rate where carryover is reduced with increasing flow rates and contactor speed. A similar change in Isopar $\mathrm{L}^{\circledR}$ carryover was observed between the second and third extraction tests. However, coalescence of solvent in the process lines prior to the pre-coalescer FTIR sample point may result in FTIR underestimating the amount of solvent carryover in this configuration.

SVOA measurements also provided a measure of Isopar $\mathrm{L}^{\circledR}$ and Modifier for both stripping and extraction. Data for stripping tests offered no clear correlation between carryover and process conditions. For low-flow conditions, Isopar $\mathrm{L}^{\circledR}$ was $\sim 300-500 \mathrm{mg} / \mathrm{L}$. For moderate-flow conditions, Isopar $\mathrm{L}^{\circledR}$ was $\sim 1800-1900 \mathrm{mg} / \mathrm{L}$. For high-flow conditions, Isopar $\mathrm{L}^{\circledR}$ was $\sim 1350$ $1750 \mathrm{mg} / \mathrm{L}$ for one test and $\sim 700-800 \mathrm{mg} / \mathrm{L}$ for a second test. In extraction, the quantity of Isopar $\mathrm{L}^{\circledR}$ was $\sim 160 \mathrm{mg} / \mathrm{L}$ at low flow, $\sim 250-350 \mathrm{mg} / \mathrm{L}$ at moderate flow, and $\sim 220-390 \mathrm{mg} / \mathrm{L}$ at high flow. For the above Isopar $\mathrm{L}^{\circledR}$ concentrations, Modifier was also present at the nominal Isoparto-Modifier ratio of 3.65. The measured Isopar $\mathrm{L}^{\mathbb{B}}$ concentrations in extraction are consistent with the level of carry over observed for prior V5 and V10 contactor tests with BOB CalixC6 solvent.

\subsection{Coalescer Performance}

Droplet-size data obtained by MicroTrac ${ }^{\mathrm{TM}}$ consistently show that the particle sizes measured post-coalescer exceed those measured pre-coalescer. The conclusion is based on calculations of the particle size for the $50^{\text {th }}$ percentile, but the same general observation can be made for the $25^{\text {th }}$, $75^{\text {th }}$, and $90^{\text {th }}$ percentiles. Although the data contains a significant amount of scatter, typical particle-size increases are between 25 and 180\%. Notable exceptions to the general trend during the lower flow rate stripping tests suggest that perhaps there is an incubation period before the coalescer functions optimally.

The increase in droplet size appears greater, in general, for stripping tests than for the extraction tests. This behavior may be attributable to the smaller coalescer pore sizes used for the stripping tests. For the extraction tests, the post-coalescer droplet sizes are always greater than the precoalescer measurement, with modest particle-size increases ranging from 5-25\%. The growth of particle sizes measured using MicroTrac ${ }^{\mathrm{TM}}$, and hence coalescence of solvent, is consistent with macro-scale observations of the coalescers. For stripping and extraction tests, the size of the droplets exiting the coalescer was comparable even though stripping employed a 10-micron coalescer and extraction a 20 -micron coalescer.

SRNL attempted to correlate the turbidity with bulk organic carryover during testing. However, the increase in turbidity during almost every test was probably a function of increased air entrainment from the contactor operations, thus no correlation could be developed. The entrainment of air was noted by both macro-scale photography and microscopy. 


\subsection{Recommendations, Path Forward and Future Work}

The test program demonstrated high stage efficiencies and good coalescence behavior for the NGS when contrasted with prior baseline solvent testing. SRNL recommends proceeding with integrated flowsheet testing using full-scale contactors. Testing at the Parsons Technology Center is ideal for such an evaluation

When compared to the baseline CSSX solvent, NGS solvent carryover into the aqueous phases appeared lower than comparable data for the extraction operations. Carryover was similar or (as much as 2-3X) higher for strip operations, possibly reflecting an artifact of the boric acid but perhaps also reflective of the higher air entrainment observed in this testing. Exploration of the interfacial tensions and three phase behavior for the NGS / boric acid / air system may be beneficial if elevated carryover is observed in the planned integrated system testing.

The online FTIR analyses proved stable with no observed instrument maintenance issues. However, limitations of the sample port configurations did not allow reliable assessment of comparative performance with the baseline, remote analytical methods. Consideration is warranted in testing the FTIR equipment in the planned integrated tests on samples from the coalescer / decanter outlet.

Additional effort may be warranted in digitization and image analysis of the videotapes and the microscopy images for the coalescers. Converting the images to digital form, applying digital image analysis, and statistically assessing the data will provide additional insight into coalescer performance.

This report did not fully regress the droplet size data analysis and interpret relative to the available models for the MCU decanter operations. Additional value would be gained by that effort.

Coalescer testing indicated for newly-installed coalescers that there may be an incubation period for correct coalescence of the NGS. Additional studies of this phenomenon would be of value to the MCU operations.

The sample port configuration proved less effective than desired for this testing. Experimental design, analytical tools, and data regression tools were marginally effective in improving the understanding of coalescer performance. Additional investment in basic understanding and tools for testing two phase (stochastic) -- or three phase -- is warranted. 


\subsection{References}

1. P. V. Bonnesen, L. H. Delmau, T. J. Haverlock, and B. A. Moyer, Alkaline-Side Extraction of Cesium from Savannah River Tank Waste Using a Calixarene-Crown Ether Extractant, ORNL/TM-13704 (1998).

2. L. H. Delmau, G. J. Van Berkel, P. V. Bonnesen, and B. A. Moyer, Improved Performance of the Alkaline-Side CSEX Process for Cesium Extraction from Alkaline High-Level Waste Obtained by Characterization of the Effect of Surfactant Impurities, ORNL/TM-1999/209 (1999).

3. R. A. Pierce, T. B. Peters, M. L. Crowder, T. D. Caldwell, D. J. Pak, S. D. Fink, R. W. Blessing, and A. L. Washington, Demonstration of the Next-Generation Caustic-Side Solvent Extraction Solvent with 2-cm Centrifugal Contactors using Tank 49H Waste and Waste Simulant, Rev. 0 (2011)

4. B. A. Oard, NGS/mMST Studies at ARP/MCU, TTR-WPT-2010-00004, Rev. 3 (May 26, 2011)

5. M. L. Restivo, T. J. Steeper, and S. D. Fink, Task Technical and Quality Assurance Plan for ARP/MCU Life Extension Coalescer and Contactor Testing-Life Extension Program Needs, SRNL-RP-2011-00899, Rev. 1 (2011).

6. M. L. Restivo, Next Generation Solvent Strip and Extraction Demonstration in 786-A Contactor Tests, ITS-WI-0046, Rev. 1, (2011)

7. K. A. Holloway, Coalescer Decanter Test Report, N2794-26.1-024, Rev. 0 (2006) (SRS Document ID 00773515)

8. M. R. Poirier, Alternative Approaches for Recovering Entrained Solvent in Modular CausticSide Solvent Extraction Unit (MCU), SRNL-STI-2010-00595, Rev. 0, (2010).

9. CSSX Solvent Preparation, ITS-155, Rev. 0, SRNL Manual L29 (December 1, 2009).

10. Next Generation Solvent Preparation, ITS-173, Rev. 0, SRNL Manual L29 (July 22, 2011).

11. L. H. Delmau, J. F. Birdwell, P. V. Bonnesen, N. B. Ladd, B. A. Moyer, E. L. Stoner, D. L. Lee, and F. V. Sloop, Next Generation Caustic Side Solvent Extraction Process, ORNL-LTRNGCSSX-016 (2011).

12. N. J. Williams and B. A. Moyer, Temperature Dependence of the Next Generation Caustic Side Solvent Extraction (NG-CSSX) Process Solvent), ORNL-LTR-NGCSSX-012 (2011).

13. E. V. Murphree, Graphical Rectifying Column Calculations, Ind. Eng. Chem., 17, 960-964 (1925).

14. S. Campbell, J. Carter, E. Brass, S. Brown, and B. Narrows, MCU Individual Contactor Test \#4 and Individual Contactor Mass Transfer Test Report, LWO-SPT-2006-00033 (August 2006).

15. K. A. Holloway, Integrated Test Report, N2794-26.1-028, Rev 1, Wright Industries, August 2006.

16. S. D. Fink, M. L. Restivo, T. B. Peters, M. D. Fowley, D. B. Burns, W. M. Smith, Jr., F. F. Fondeur, S. L. Crump, M. A. Norato, D. T. Herman, and C. A. Nash, Entrainment of Solvent in Aqueous Stream from CINC V-5 Contactor, WSRC-TR-2005-00187 (April 2005).

17. S. T. Hwang and R. T. Lahey, Jr., A Study on Single and Two-Phase Pressure Drop in Branching Conduits, Experimental Thermal and Fluid Science, 1, 111-125 (1988).

18. Application Brief AB-046: Multireflection ATR Infrared Spectroscopy, Smiths Detection Technical Information (www.smithsdetection.com). 


\subsection{Appendices}

9.1 Appendix A - Design Details of Coalescer Housing

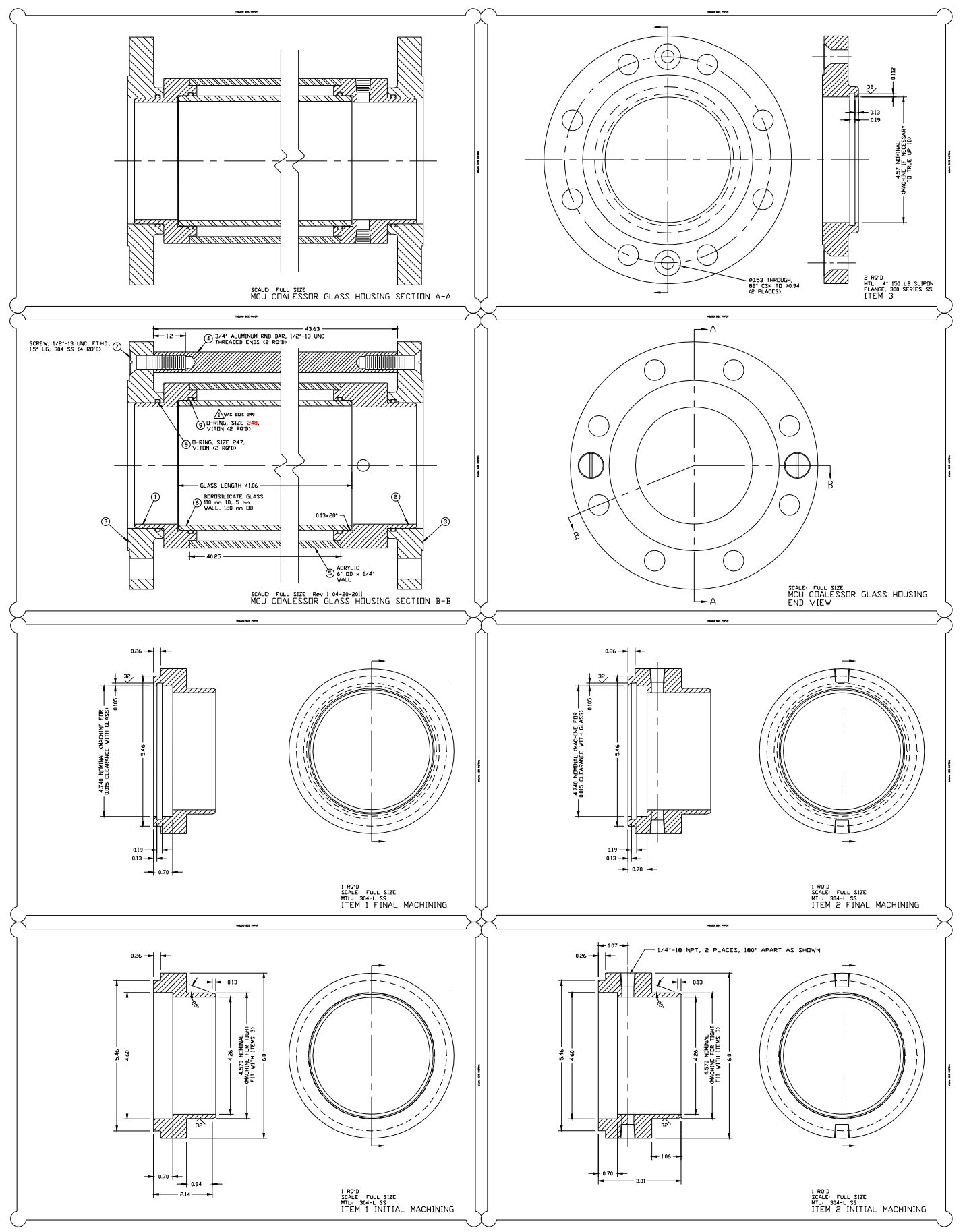




\subsection{Appendix B - Instrument List}

\begin{tabular}{|c|c|c|c|c|c|c|c|c|}
\hline \multirow{3}{*}{ DAS Chan. } & \multirow[b]{2}{*}{ Loop ID\# } & \multicolumn{3}{|c|}{ MCU/ARP Contactor Test Rig } & \multirow[b]{2}{*}{ Make } & \multirow[b]{2}{*}{ Model/Serial } & \multirow[b]{2}{*}{ Raw } & \multirow[b]{2}{*}{ Calibrated Range } \\
\hline & & Description & Instrument & M\&TE\# & & & & \\
\hline & & & & & & & Signal & \\
\hline 0 & TE01 & Organic Feed Temp & Thermocouple & TR-40086 & Omega & 1/16", 48"L, Type E, Omega \# GEQSS-116(G)-48 & Type E TC & $0-100 \mathrm{C}$ \\
\hline 1 & TE02 & Aqueous Feed Temp & Thermocouple & TR-40087 & Omega & 1/16", 48"L, Type E, Omega \# GEQSS-116(G)-48 & Type E TC & $0-100 \mathrm{C}$ \\
\hline 2 & TE03 & V-10 Contactor Organic Feed Temp & Thermocouple & TR-40102 & Omega & 1/16", 24"L, Type E, Omega \# GEQSS-116(G)-24 & Type E TC & $0-100 \mathrm{C}$ \\
\hline 3 & TE04 & V-10 Contactor Aqueous Feed Temp & Thermocouple & TR-40097 & Omega & 1/16", 24"L, Type E, Omega \# GEQSS-116(G)-12 & Type E TC & $0-100 \mathrm{C}$ \\
\hline 4 & TE05 & V-10 Contactor Organic Discharge Temp & Thermocouple & TR-40098 & Omega & 1/16", 12"L, Type E, Omega \# GEQSS-116(G)-12 & Type E TC & $0-100 \mathrm{C}$ \\
\hline 5 & TE06 & V-10 Contactor Aqueous Discharge Temp & Thermocouple & TR-40099 & Omega & 1/16", 12"L, Type E, Omega \# GEQSS-116(G)-12 & Type E TC & $0-100 \mathrm{C}$ \\
\hline 6 & TE07 & Aqueous Tank Independent Temp & Thermocouple & TR-40100 & Omega & 1/16", 12"L, Type E, Omega \# GEQSS-116(G)-12 & Type ETC & $0-100 \mathrm{C}$ \\
\hline 7 & TE08 & Aqueous Tank Temp & Thermocouple & TR-40101 & Omega & 1/16", 12"L, Type E, Omega \# GEQSS-116(G)-12 & Type E TC & $0-100 \mathrm{C}$ \\
\hline 8 & TE09 & V-5 Contactor Organic Feed Temp & Thermocouple & TR-40103 & Omega & 1/16", 12"L, Type E, Omega \# GEQSS-116(G)-12 & Type E TC & $0-100 \mathrm{C}$ \\
\hline 9 & TE10 & V-5 Contactor Aqueous Feed Temp & Thermocouple & TR-40104 & Omega & 1/16", 12"L, Type E, Omega \# GEQSS-116(G)-12 & Type E TC & $0-100 \mathrm{C}$ \\
\hline 10 & TE11 & V-5 Contactor Organic Discharge Temp & Thermocouple & TR-40114 & Omega & 1/16", 12"L, Type E, Omega \# GEQSS-116(G)-12 & Type E TC & $0-100 \mathrm{C}$ \\
\hline 11 & TE12 & V-5 Contactor Aqueous Discharge Temp & Thermocouple & TR-40115 & Omega & 1/16", 12"L, Type E, Omega \# GEQSS-116(G)-12 & Type E TC & $0-100 \mathrm{C}$ \\
\hline 12 & TE13 & spare & Thermocouple & spare & Omega & 1/16", 12"L, Type E, Omega \# GEQSS-116(G)-12 & Type E TC & $0-100 \mathrm{C}$ \\
\hline 13 & TE14 & spare & Thermocouple & spare & Omega & 1/16", 12"L, Type E, Omega \# GEQSS-116(G)-12 & Type E TC & $0-100 \mathrm{C}$ \\
\hline 14 & FE01 & Organic Feed Flow & Turbine Meter & TR-40111 & Omega & FTB-1422/032111309 & 4-20 mADC & $0-7.5$ gpm solvent \\
\hline 15 & $\mathrm{FE} 02$ & Aqueous Feed Flow & Mag Flowmeter & TR-40122 & $\mathrm{ABB}$ & 10D1475JN09PD29KC51C1112Cl & 4-20 mADC & $0-15$ gpm aqueous \\
\hline & & & & & & 3К620000076989 & & \\
\hline 16 & FE03 & Organic Supply Air Inleakage & Hot Wire Anemometer & TR-40091 & Kurz & $505-8-02$ & $0-5 \mathrm{VDC}$ & $0-10$ SCFM \\
\hline 17 & FE04 & Aqueous Discharge Air Vent & Hot Wire Anemometer & TR-40092 & Kurz & $505-8-02$ & $0-5 \mathrm{VDC}$ & $0-10$ SCFM \\
\hline 18 & FE05 & Organic Discharge Air Vent & Hot Wire Anemometer & TR-40093 & Kurz & $505-9-00$ & $0-5 \mathrm{VDC}$ & $0-15$ SCFM \\
\hline 19 & FE06 & Aqueous Supply Air InLeakage & Hot Wire Anemometer & TR-40094 & Kurz & $505-9 \mathrm{~A}-0$ & $0-5 \mathrm{VDC}$ & $0-25$ SCFM \\
\hline 20 & dPE12 & Coalescer Pressure Drop & diff. Press. Transducer & TR-40108 & Rosemount & 1151DP6E22/1368962 & 4-20 mADC & $0-100 \mathrm{psid}$ \\
\hline 21 & PE13 & Coalescer Feed Pressure & Pressure Transducer & TR-40107 & Rosemount & 1144G-0600A22M1/445192 & 4-20 mADC & $0-150$ psig \\
\hline 22 & V5RPM & V-5 RPM & VFD & $\mathrm{N} / \mathrm{A}$ & Leeson & 5 HP Leeson VFD, PN 174919 & $0-10 \mathrm{VDC}$ & $0-3450$ RPM \\
\hline 23 & V10RPM & V-10 RPM & VFD & $\mathrm{N} / \mathrm{A}$ & Leeson & 10 HP Leeson VFD, PN & $0-10 \mathrm{VDC}$ & $0-1780 \mathrm{RPM}$ \\
\hline 24 & TURB1 & Turbidity & Turbidity Meter & $\mathrm{N} / \mathrm{A}$ & Thermo & Readout/Controller-AV38 & 4-20 mADC & $0.1-4000 \mathrm{NTU}$ \\
\hline & & & & & Scientific & Transducer-AquaSensor DataStick & & $0.1-4000 \mathrm{NTU}$ \\
\hline
\end{tabular}


9.3 Appendix C - High Mix Bottom Plate for the V-10 as supplied by CINC MFG

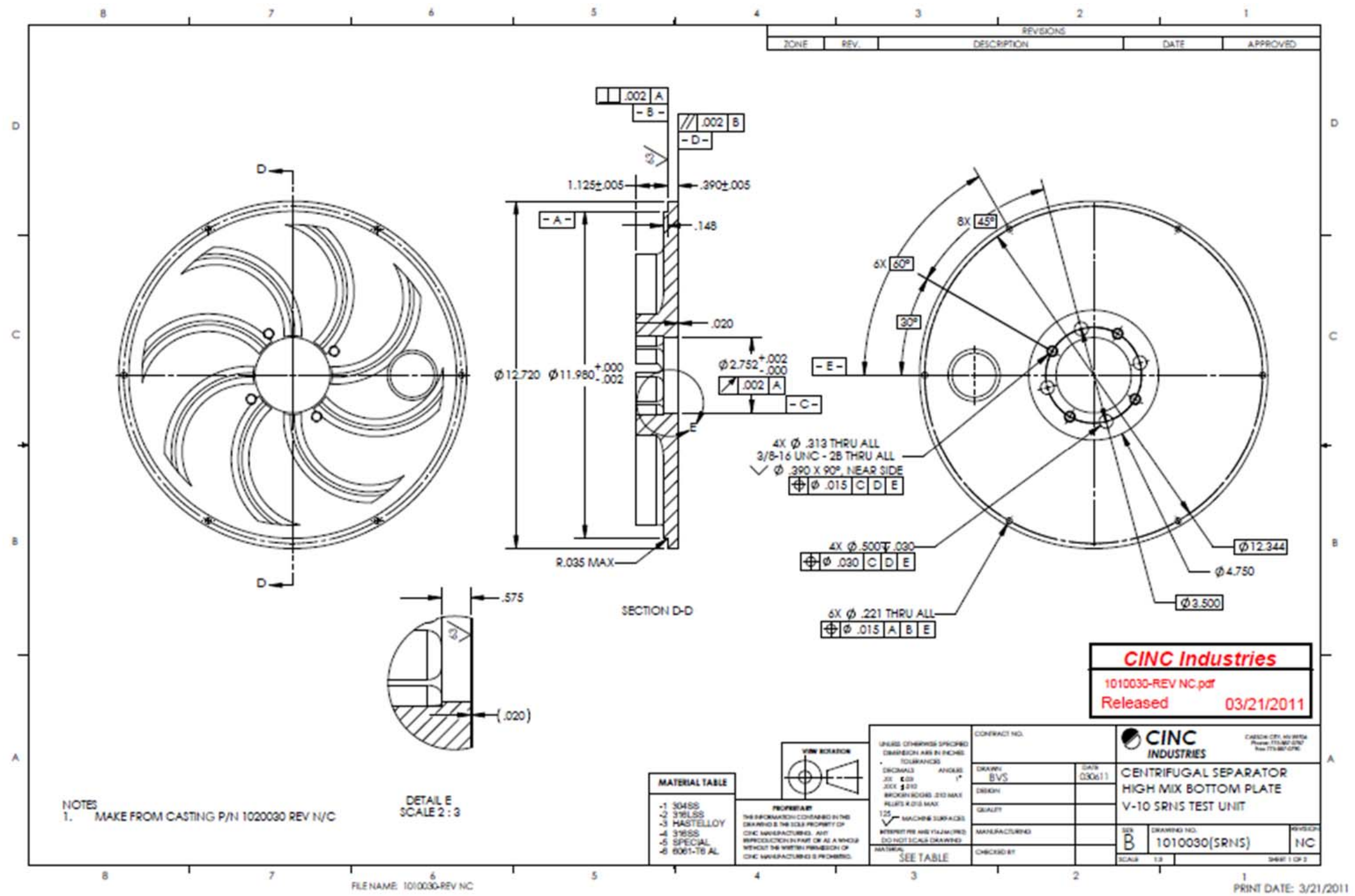




\section{Distribution:}
A. B. Barnes, 999-W
S. D. Fink, 773-A
B. J. Giddings, 786-5A
C. C. Herman, 999-W
S. L. Marra, 773-A
F. M. Pennebaker, 773-42A
W. R. Wilmarth, 773-A
J. C. Griffin, 773-A
T. B. Peters, 773-42A
R. A. Pierce, 773-A
A. L. Washington, 773-42A
F. F. Fondeur, 773-A
R. E. Edwards, 773-67A
M. W. Geeting, 241-152H
B. A. Gifford, 704-56H
B. A. Oard, 241-197H
A. Samadi, 241-197H
S. McLeskey, 241-152H
D. J. Martin, 241-152H
E. J. Freed, 704-56H
W. B. Brasel, 992-2W
C. Conner, Parsons
R. D. Lentsch, Parsons
M. S. Brugh, Parsons
T. D. Burns, Parsons
A. N. Singer, Parsons
M. J. Thomas, Parsons
R. J. Schepens, Parsons
R. K. Leugemors, 992-5W
P. G. Suggs, 704-S
P. Jackson, 703-46A
B. A. Moyer, ORNL
L. H. Delmau, ORNL
J. F. Birdwell, ORNL 